\title{
العلاقة بين التوافق الأسري وسوء استخدام الإنترنت
}

\author{
إعلداد

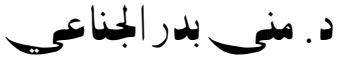 \\ كلية التربية الأساسية \\ الهيئة العامة للتعليم التطبيقي - دولة الكويت
}

مجلة بحوث التربية النوعية - جامعة المنصورة

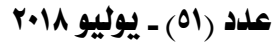




\section{العلاقة بين التوافق الأسري وسوء استخدام الإنترنت}

إعداد

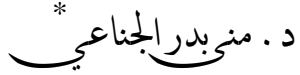

ul|l|

استهدفت هذه الدراسة تقصي وتفسير العلاقة بين سوء استخدام الإنترنت من جهة

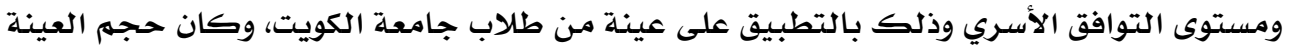

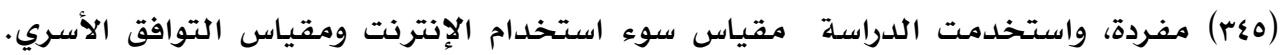

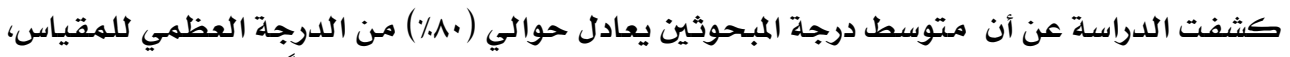

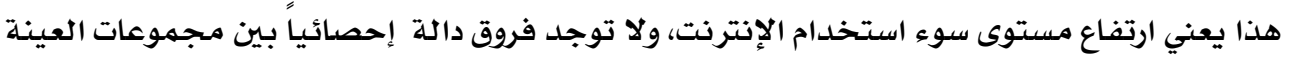

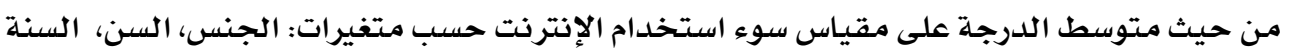

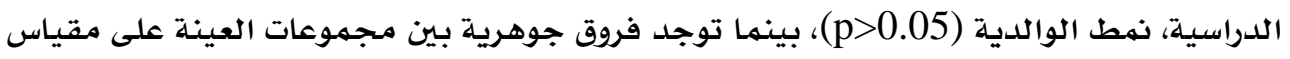

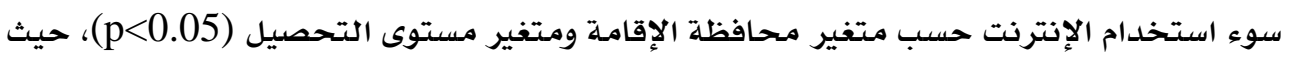

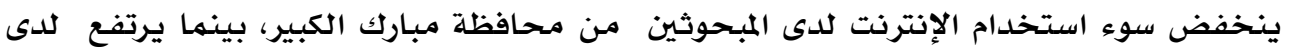

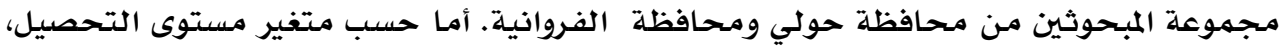

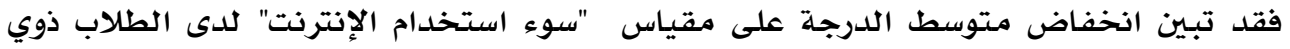

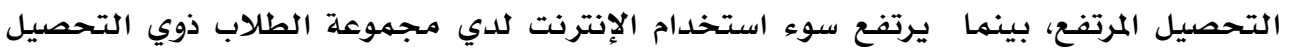

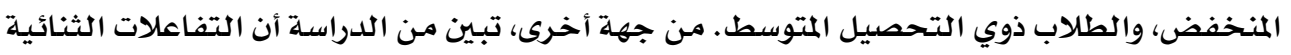

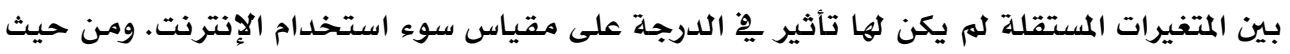

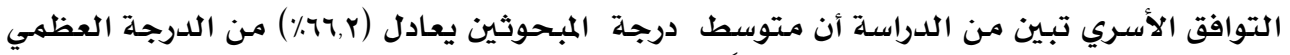

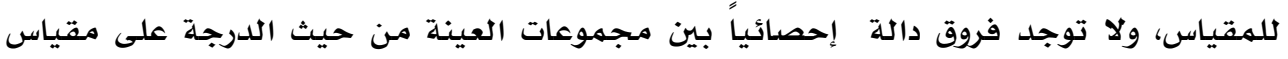

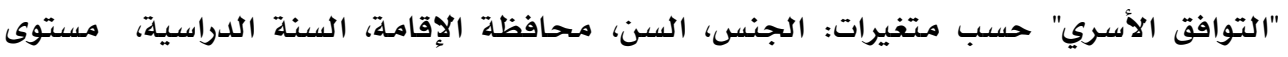

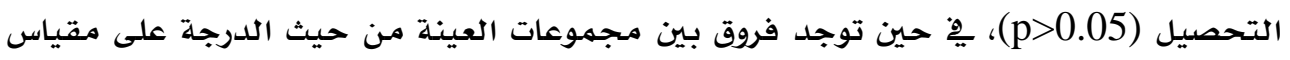

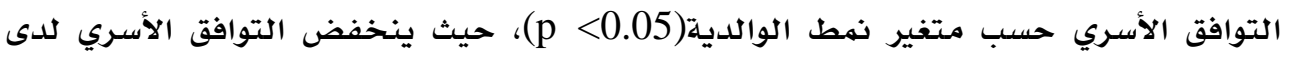

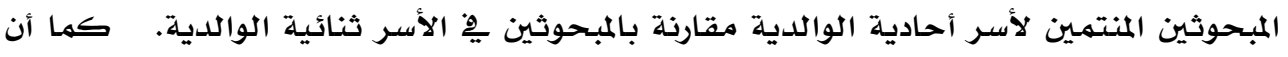

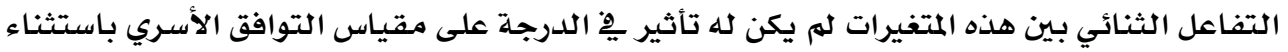

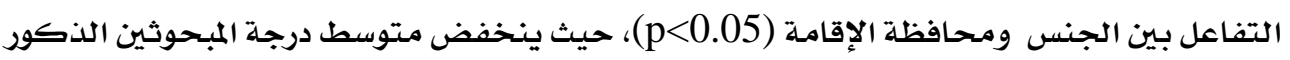

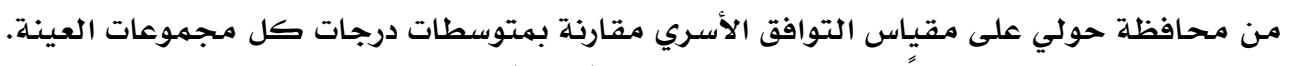

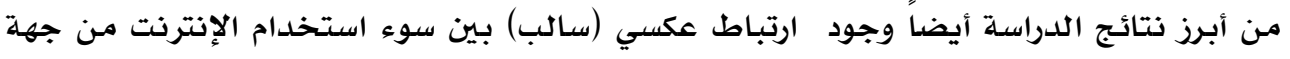


والتوافق الأسري من جهة ثانية،أي أنه كلما زاد سوء استخدام الإنترنت انخفض التوافق الأسري،

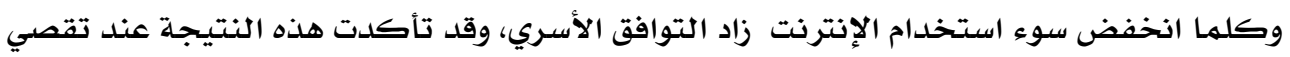

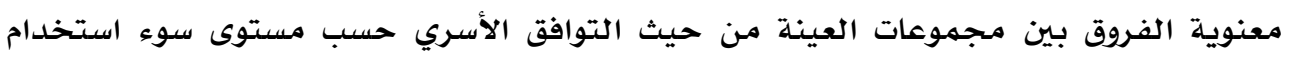

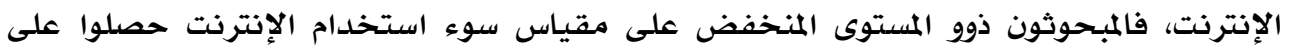

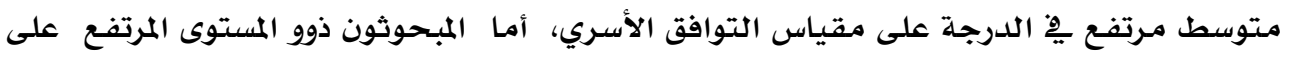

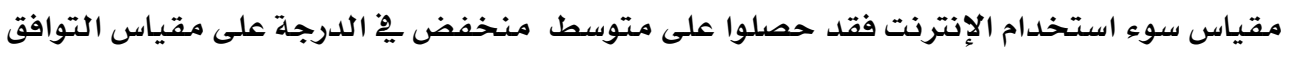

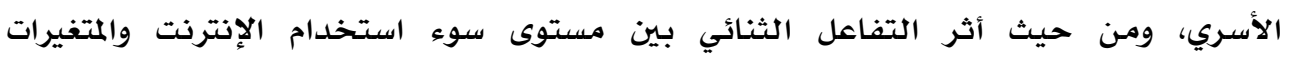

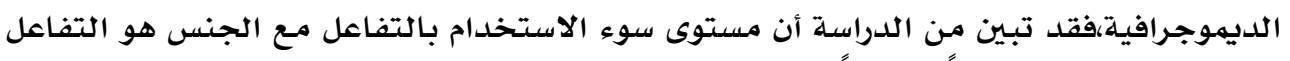

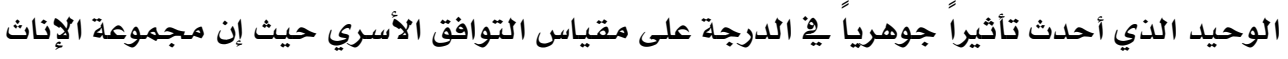

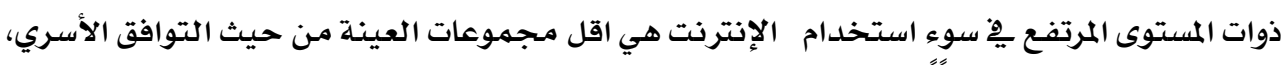

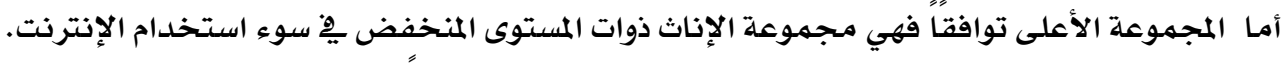

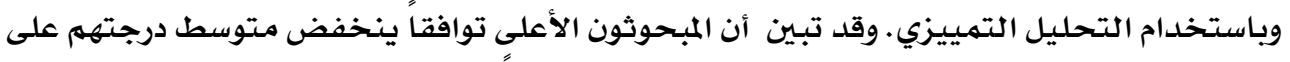

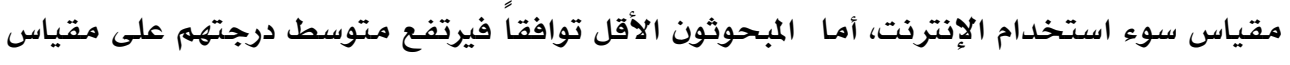

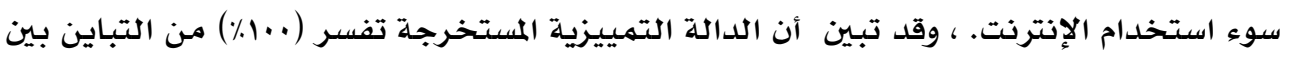

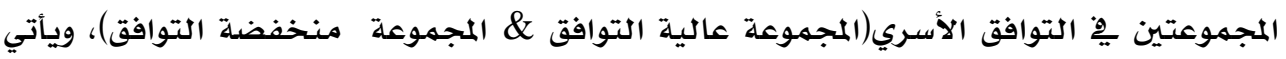

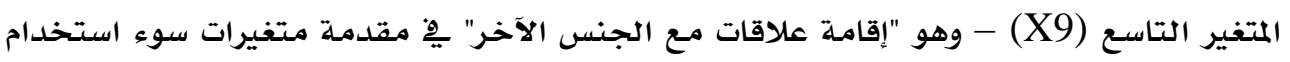

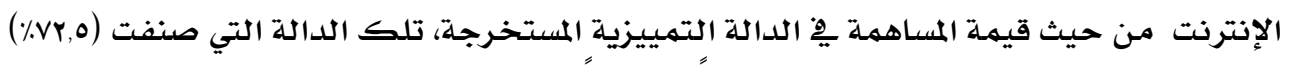

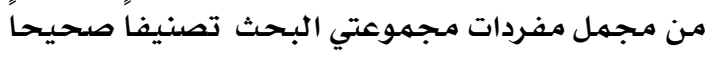

مقدمهة

يأتي تأثير وسائط الإنترنت على الأسرة باعتباره من أهم مجالات البحوث المعنية بالأسرة ـيخ

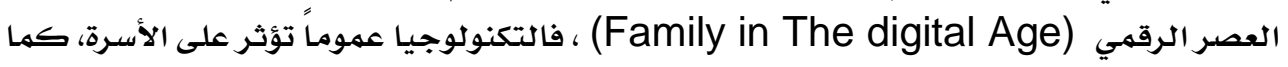

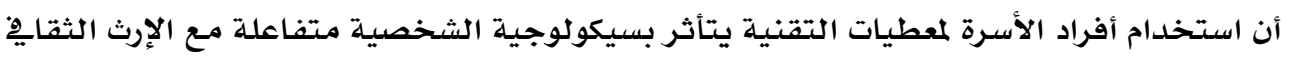

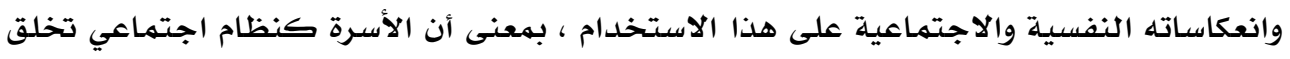

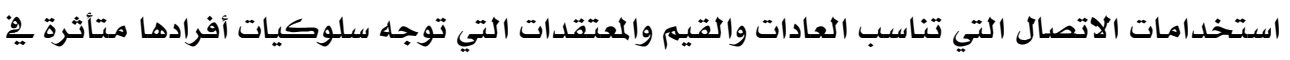
ذلك بتكنولوجيا الاتصال الحديثة التي أصبحت لا تنفصل عن حدود الأسرة (Family)

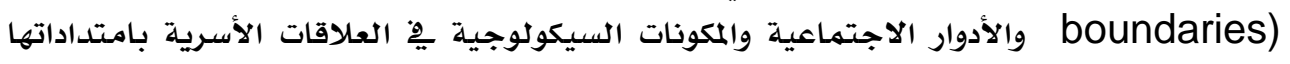

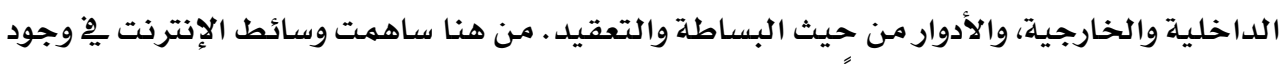

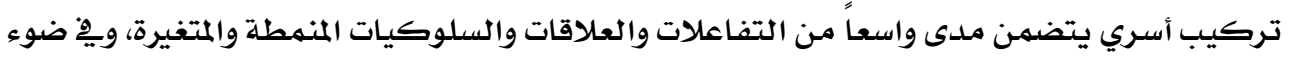

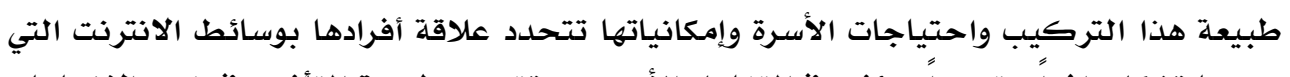

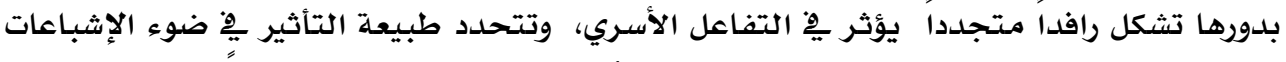

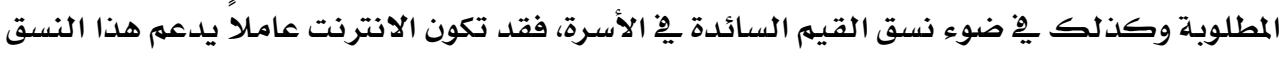

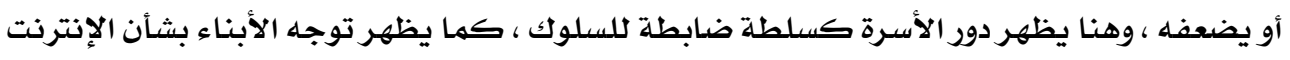




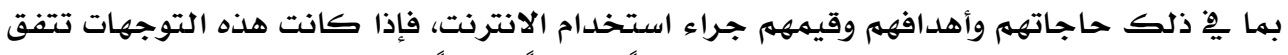

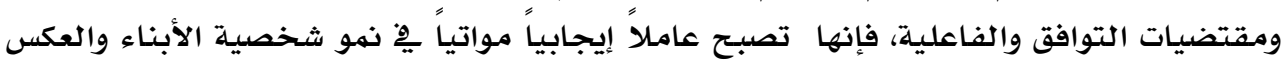

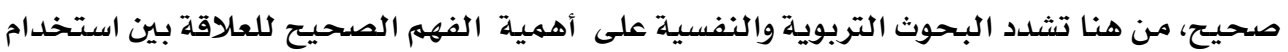

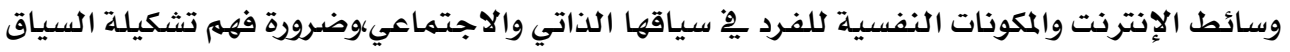

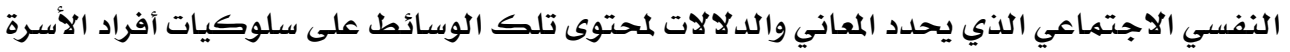

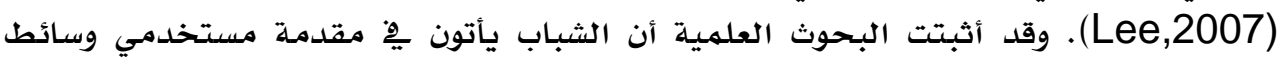

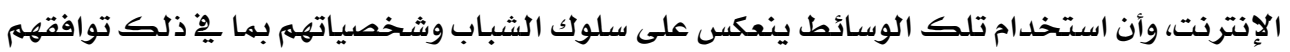

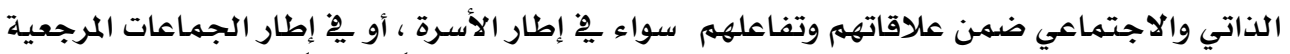

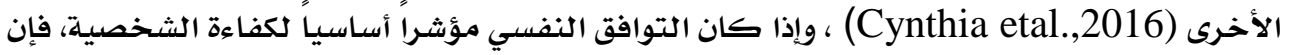

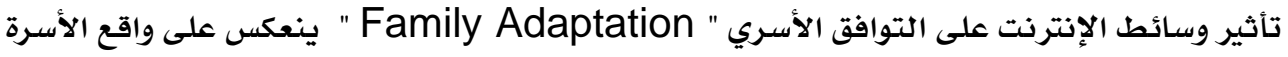

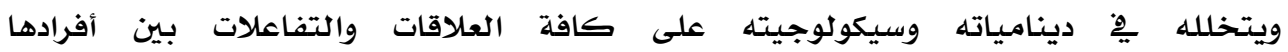

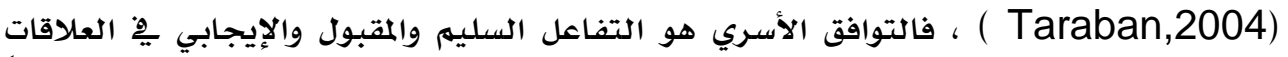

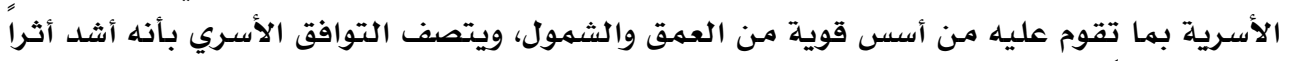

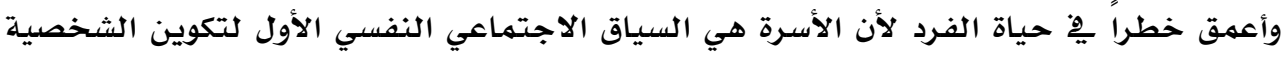

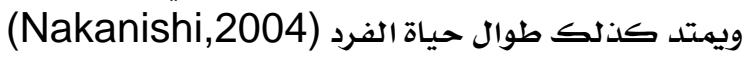

\section{مشكلة الدراسة:}

نظراً لكثافة استخدام الشباب لوسائط الإنترنت، وبالتالي احتمالات تأثير هذا الاستخدام

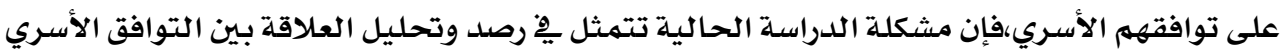

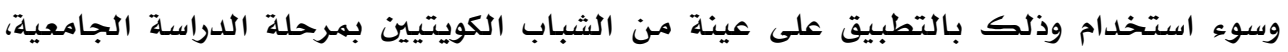

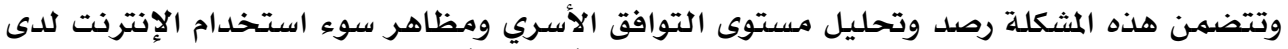

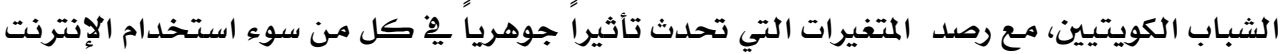

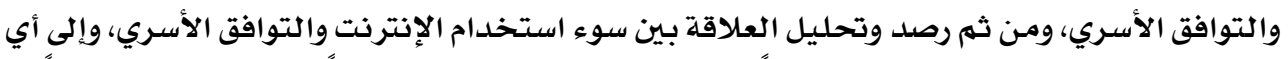

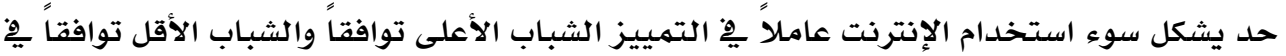
المحيط الأسري.

\section{الدراسات السابقة:}

تعتبر الأسرة واحدة من أهم الجماعات التي حظيت بـاهتمام مكثف من الدراسات العلمية

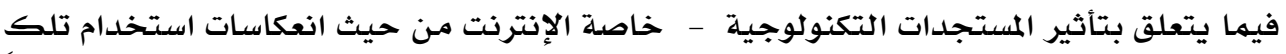

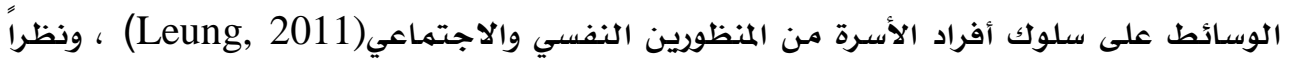

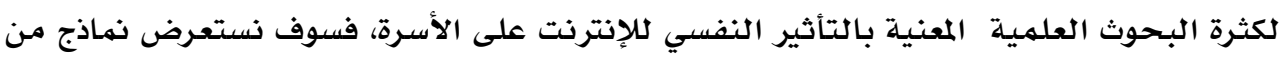

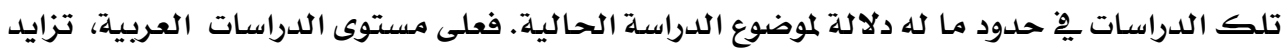

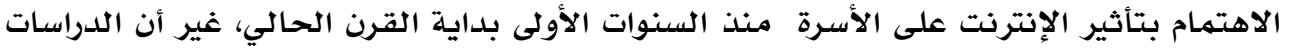

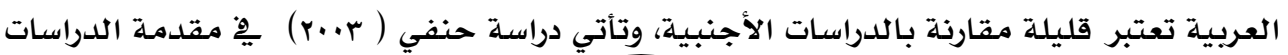


التي اهتمت بتحليل أثر استخدام وسائط الإنترنت (الحاسوب الشخصي) على التفاعل الاجتماعي

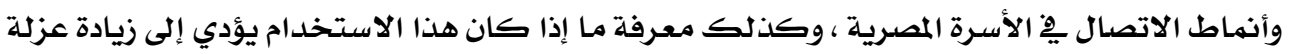

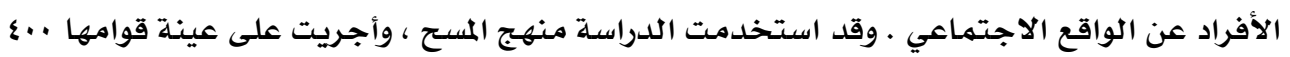

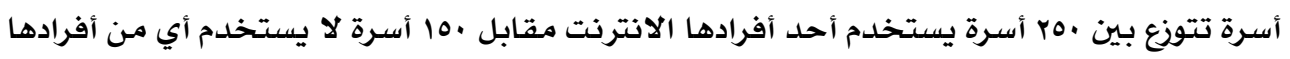

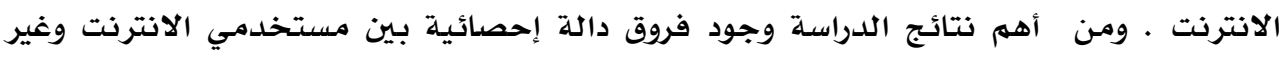

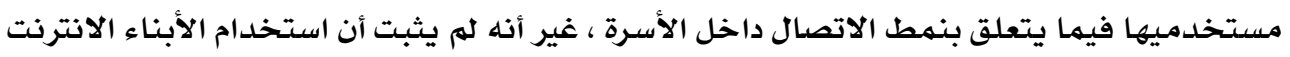

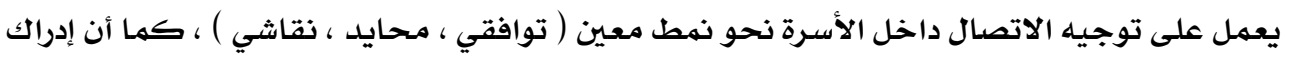

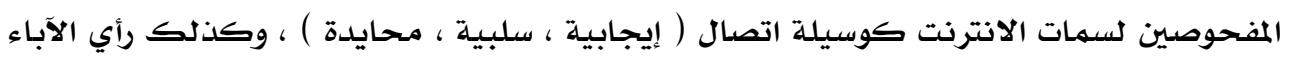

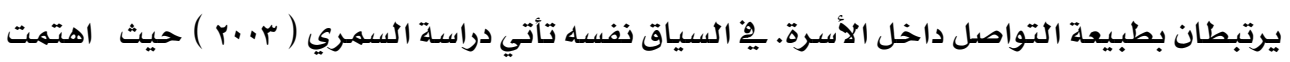

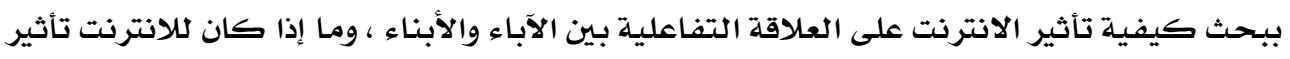

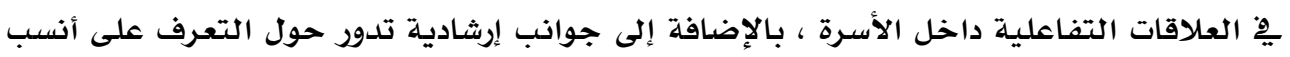

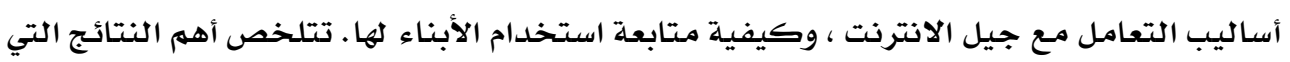

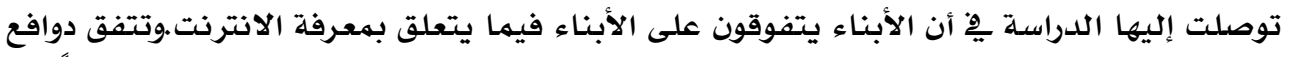

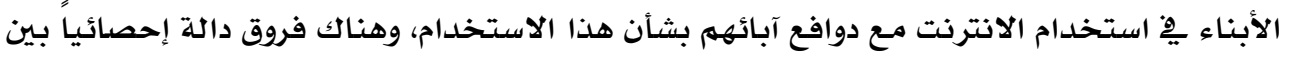

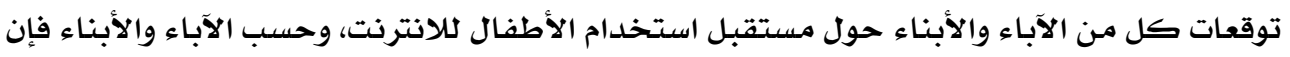

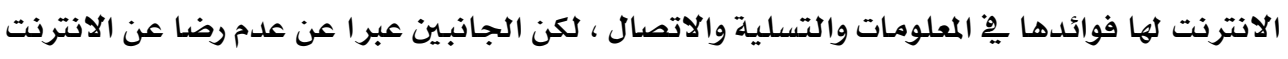

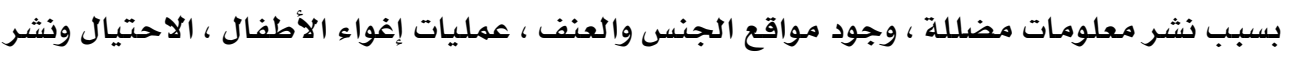

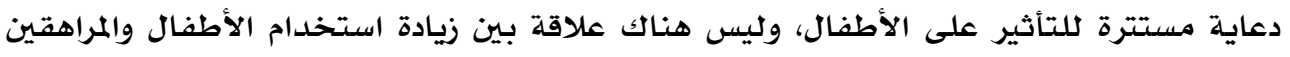

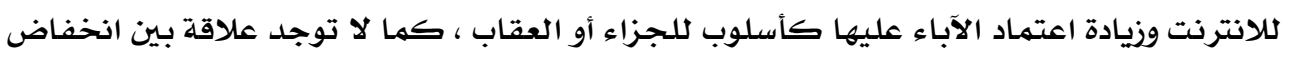

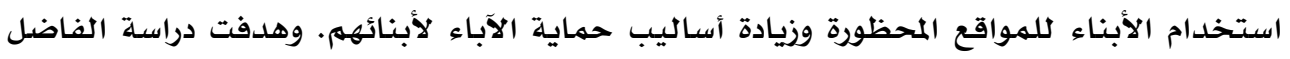

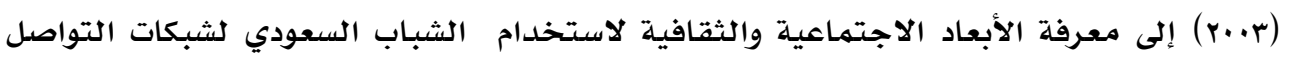

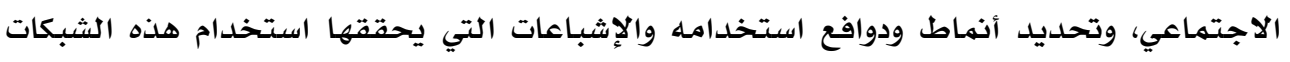

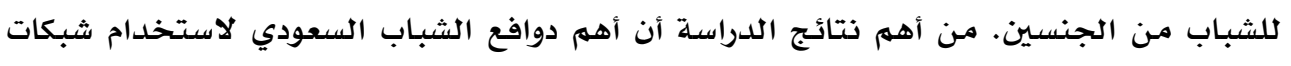

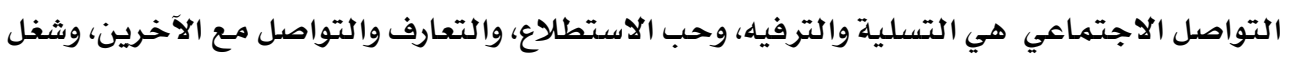

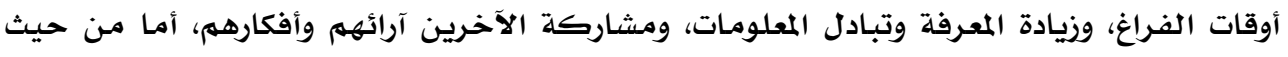

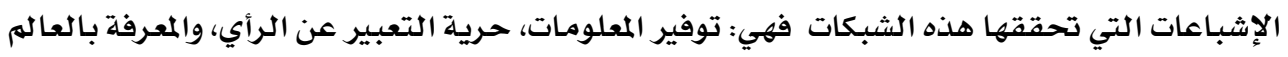

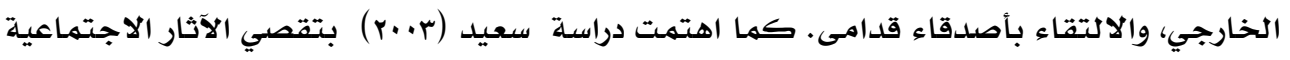

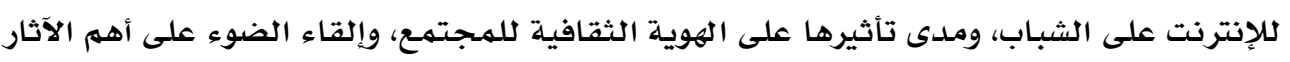

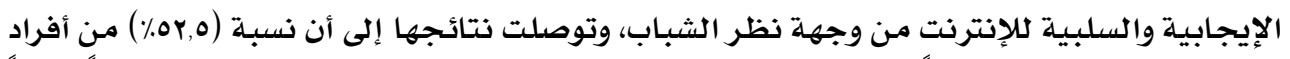

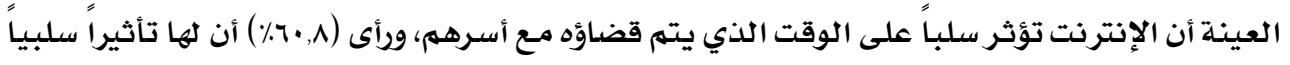

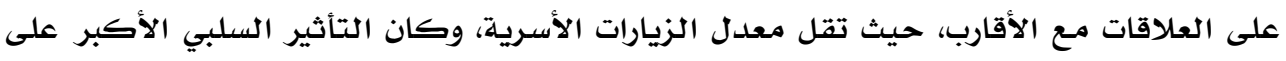

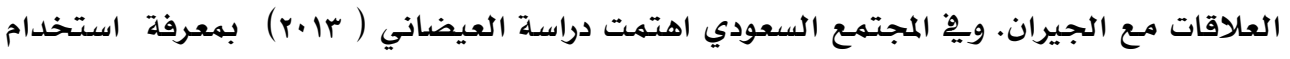

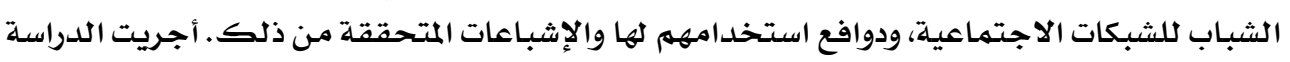


على عينة من طلاب وطالبات المرحلة الثانوية بمدينة الرياض بالمملكة العربية السعودية. وقد تبين

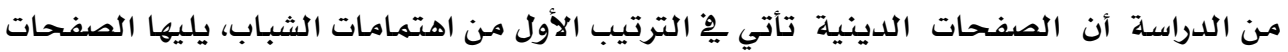

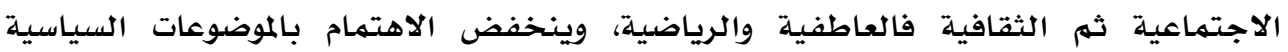

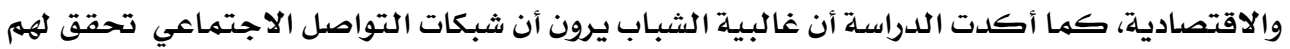

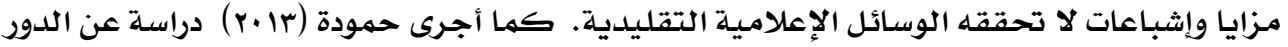

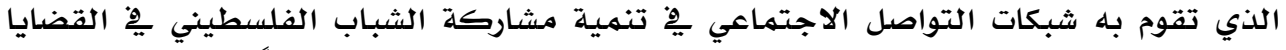

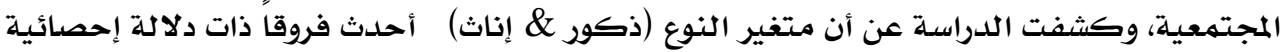

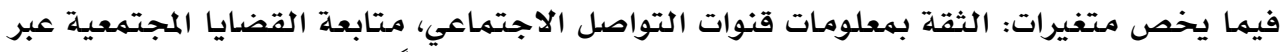

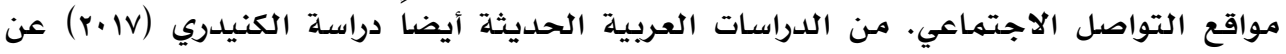

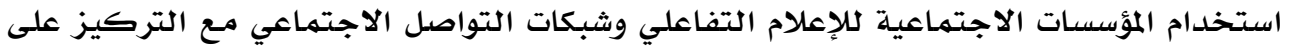

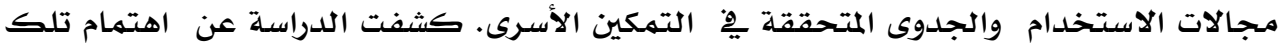

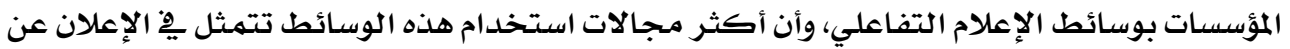

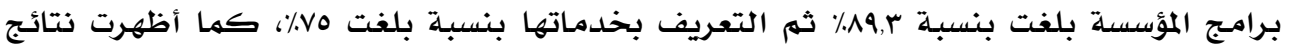

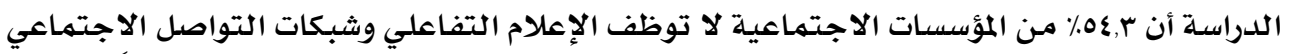

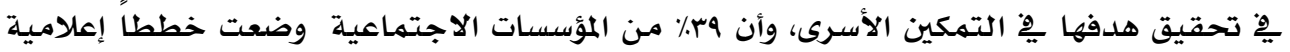
لاستخدام الإعلام التفاعلي يِّ الوصول إلى الجماهير المستهدفة والتهي والتعريف بأنشطتها.

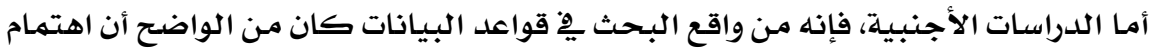

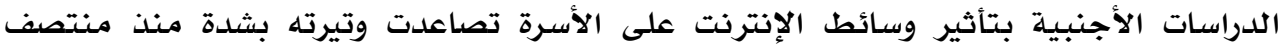

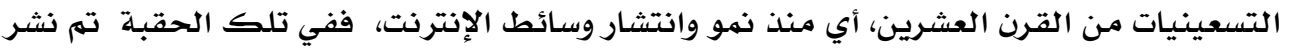

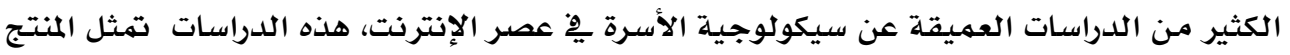

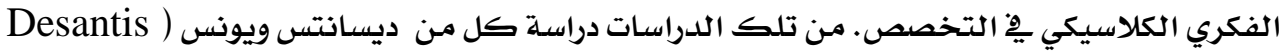

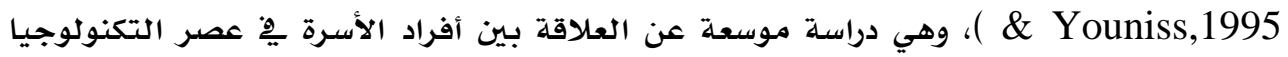

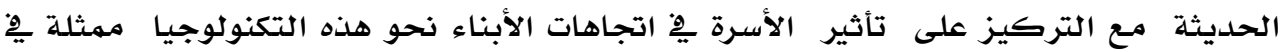

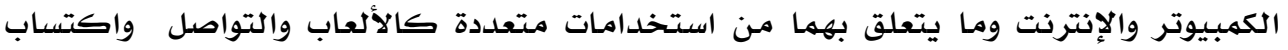

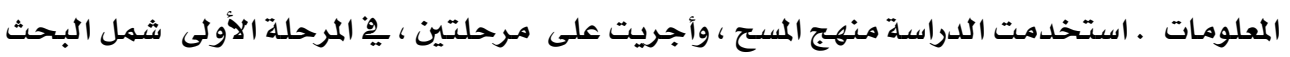

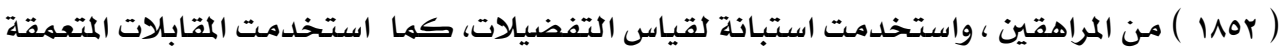

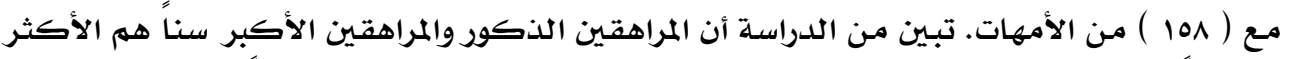

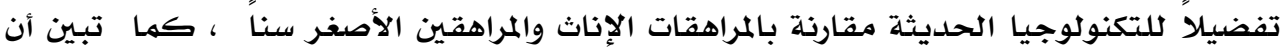

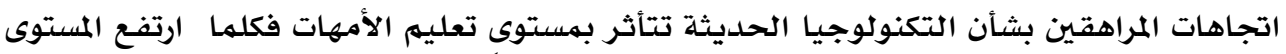

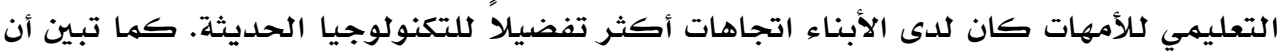

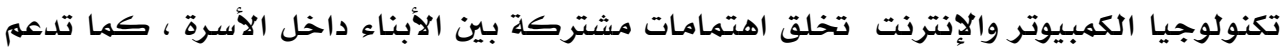

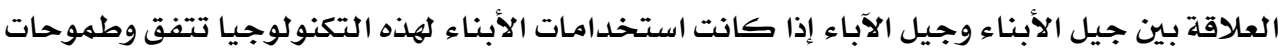


الأسرة ، لكن هذه العلاقة قد تتحول من التوافق إلى الصراع إذا لجأت الأمهات إلى أسلوب العقاب ـِيْ

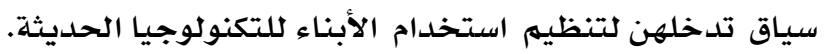

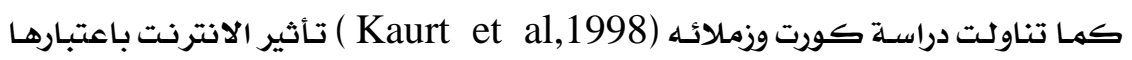

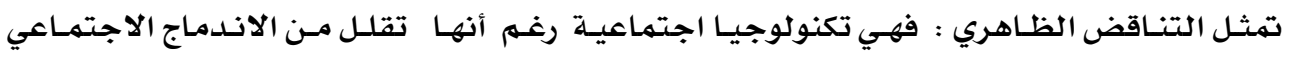

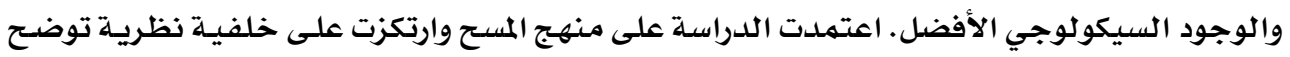

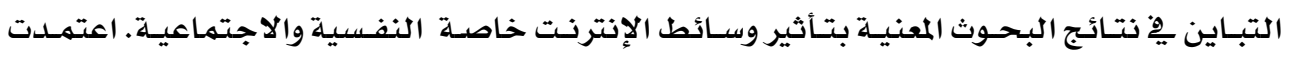

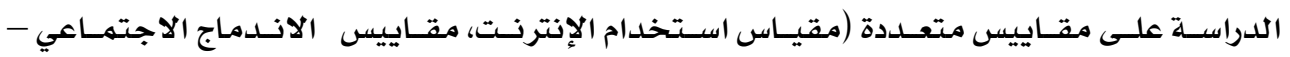

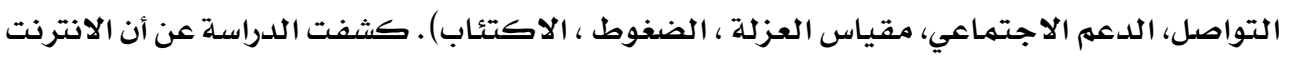

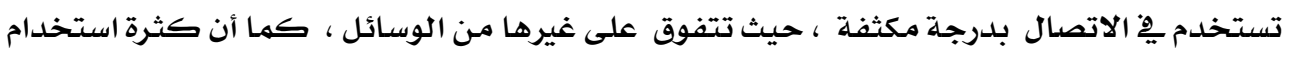

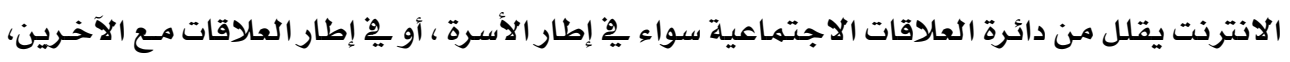

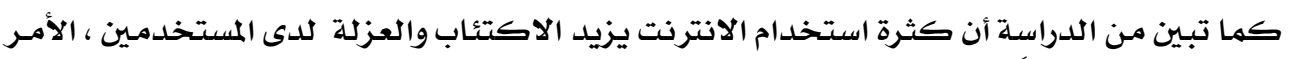

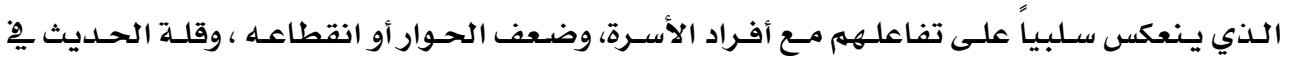

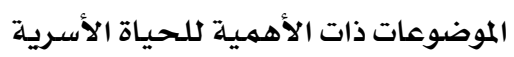

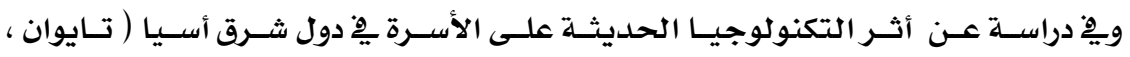

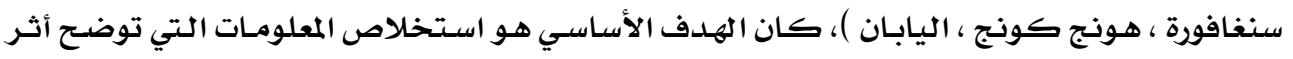

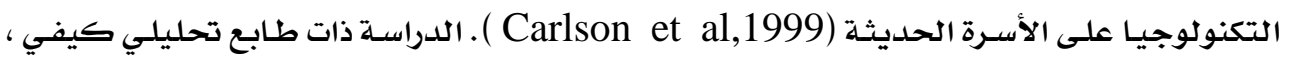

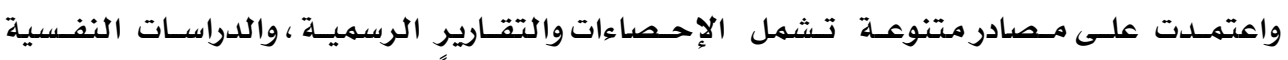

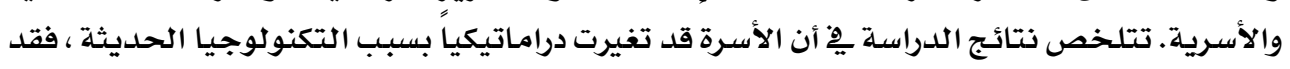

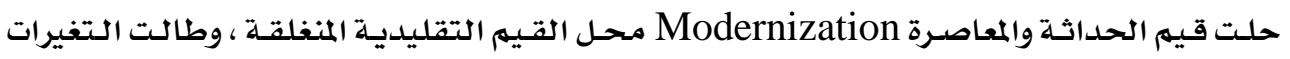

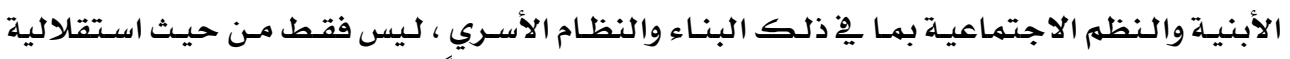

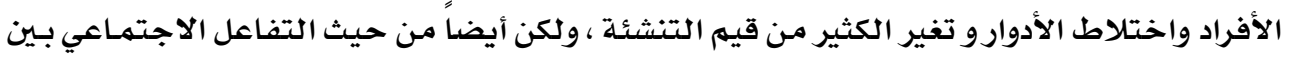

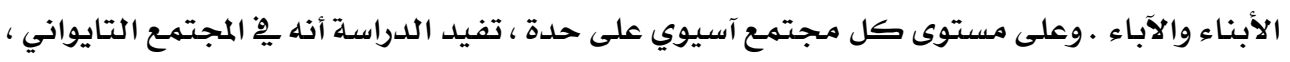

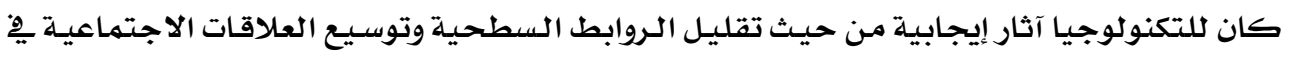

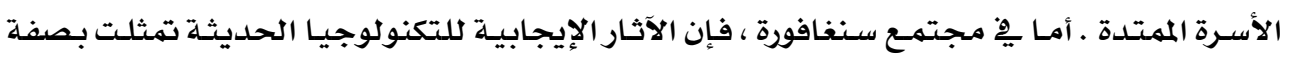

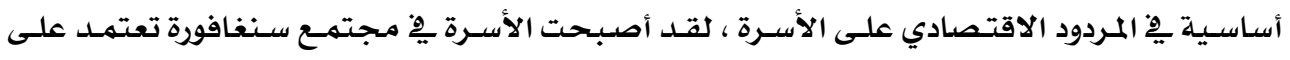

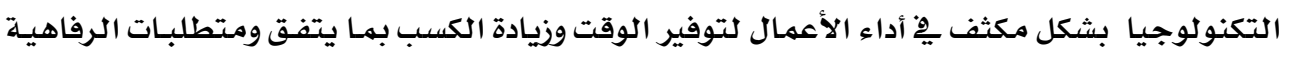

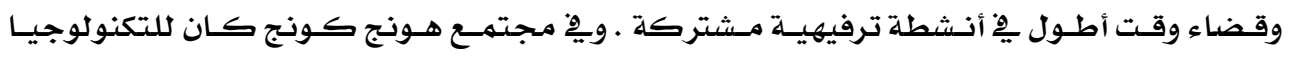

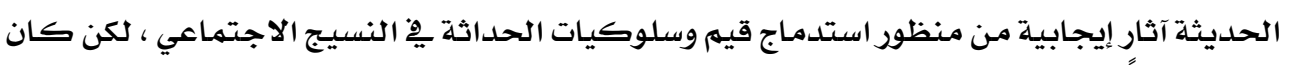

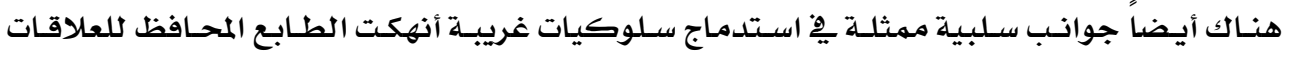

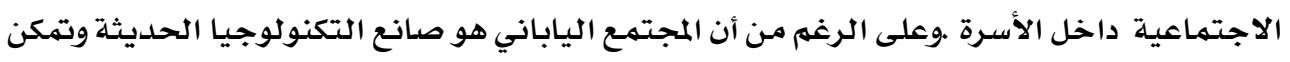

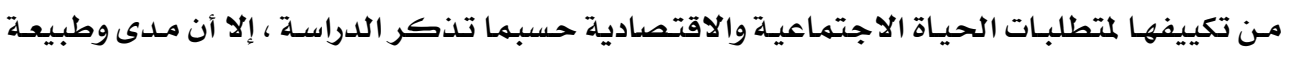

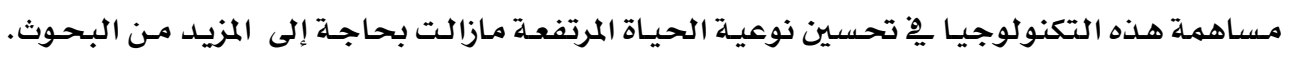


صحيح أن الأسـرة اليابانيـة تعيث حيـاة حديثة بكل المعايير ( مـن المنظور الاقتصادي والتقني ) لكن التقاليد المحافظة هي الغالبـة على الحياة الأسرية. كمـا تناولـت دراسـة أورافيـك ( Oravec,2000 ) أثر الانترنت علسى التفاعل داخل

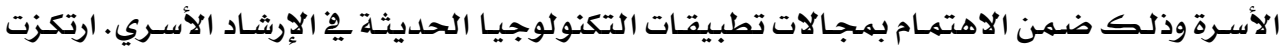

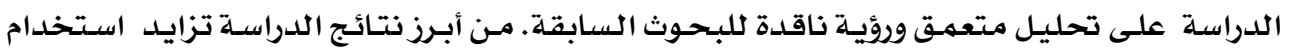

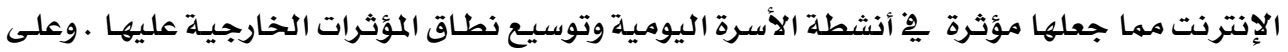

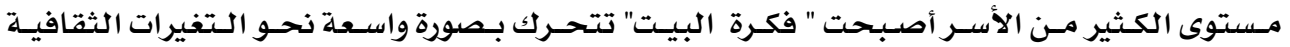

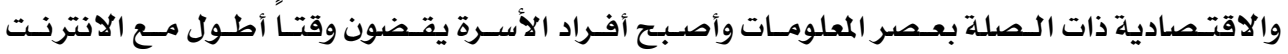

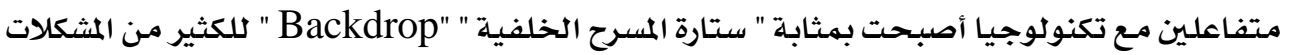

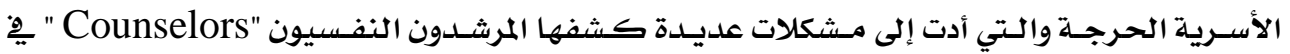

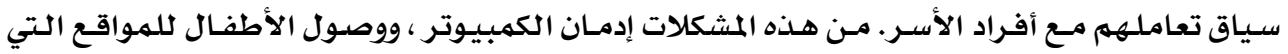

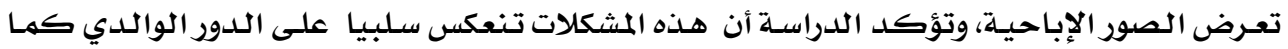

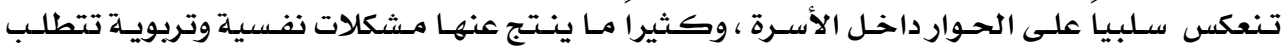

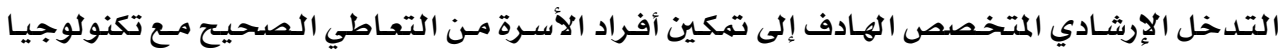
الاتصال الحديثة بما يدعم التفاعل المشبع فيما بينهم.

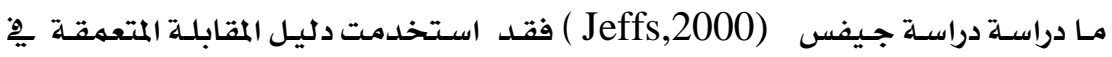

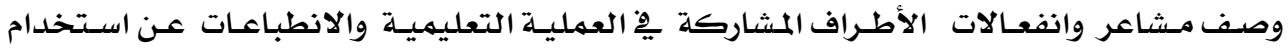

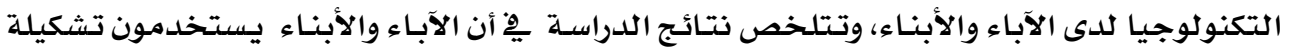

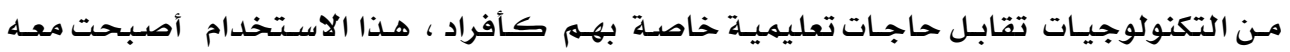

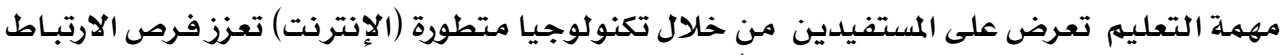

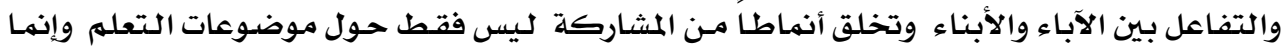

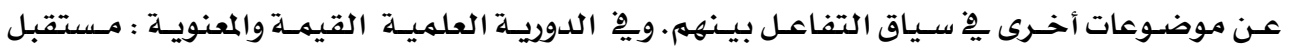

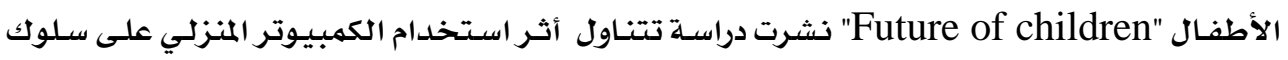

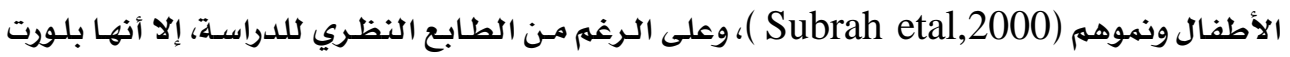

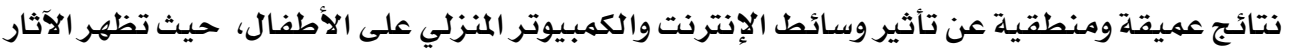

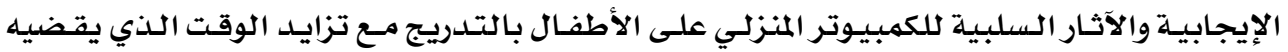

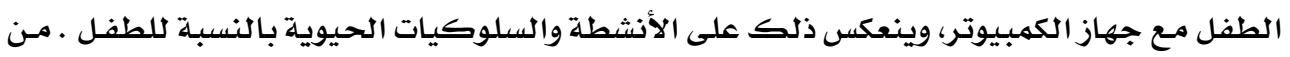

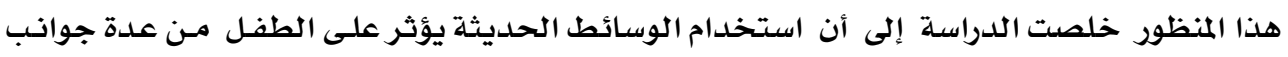

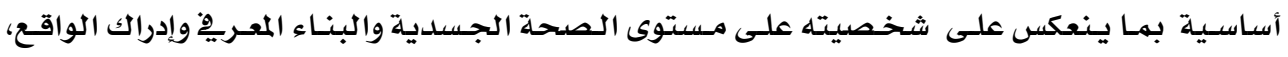

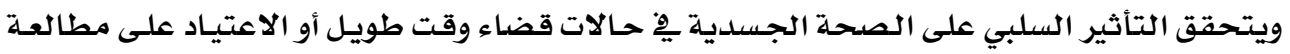

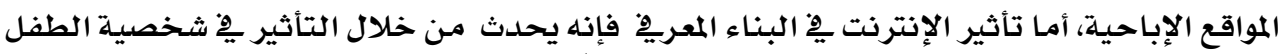

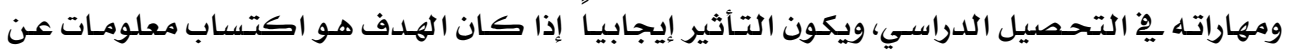

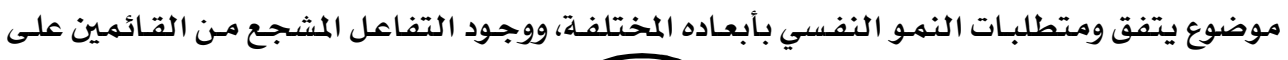


التربية والتنشئية. النتيجة نفسها فيما يخص التوافق الاجتماعي بما يِّ ذلك التوافق الأسـري، فهـن

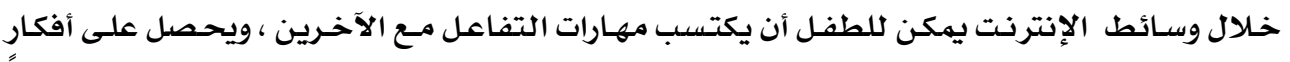

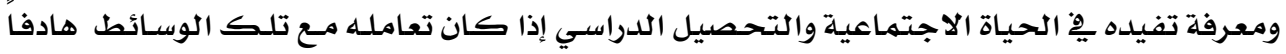

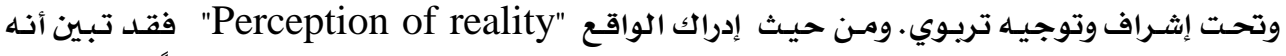

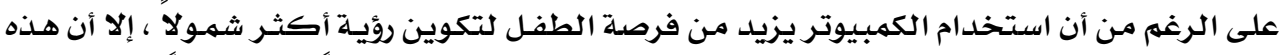

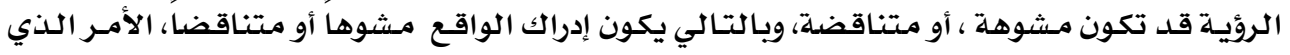

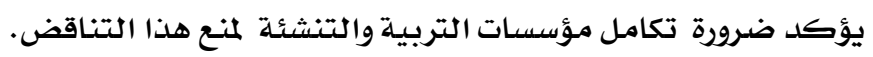

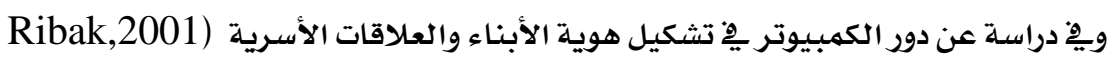

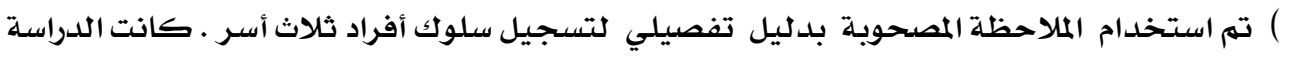

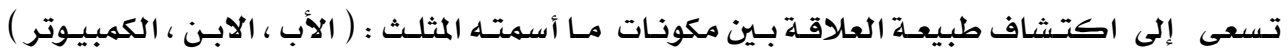

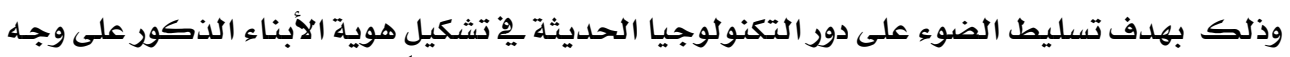

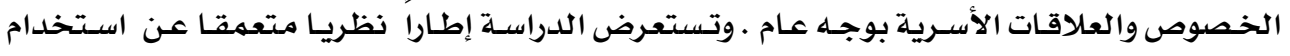

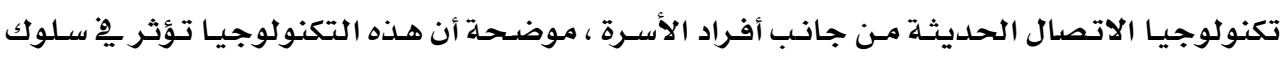

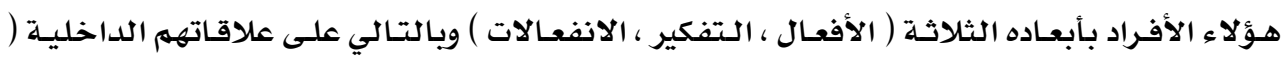

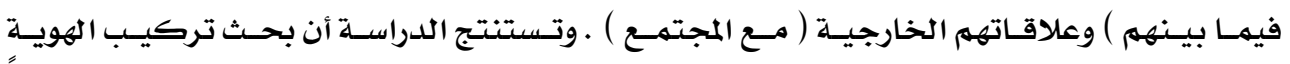

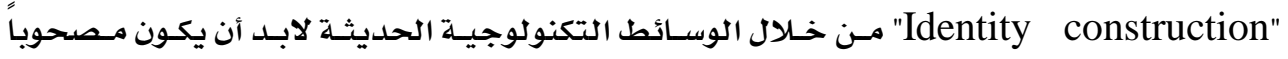

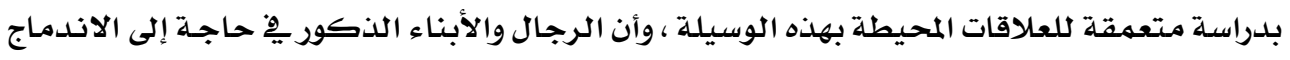

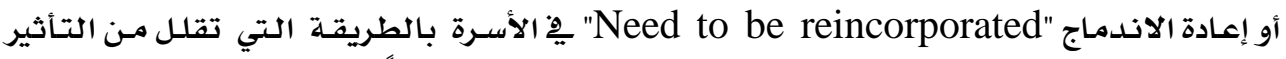

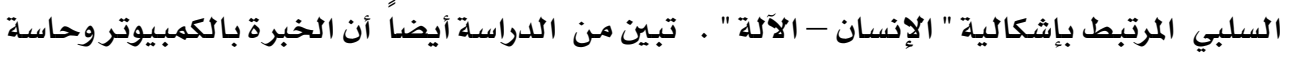

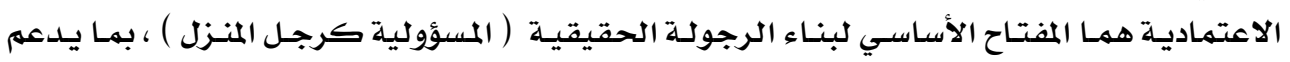

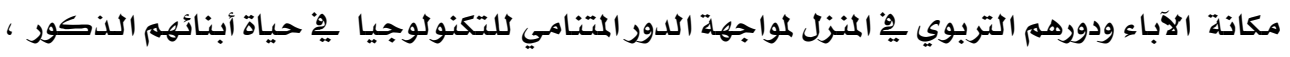

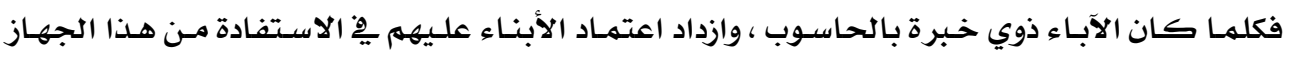

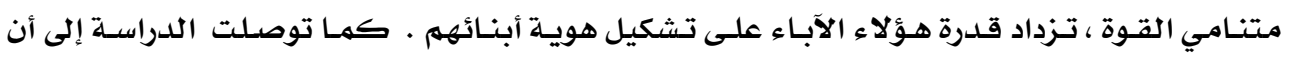

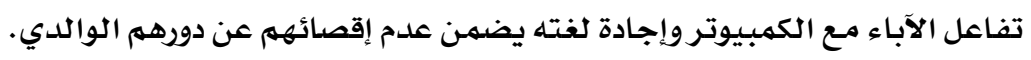

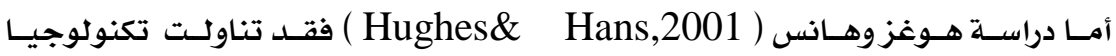

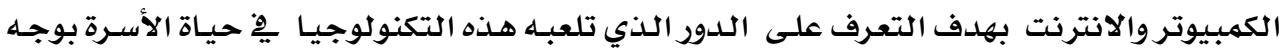

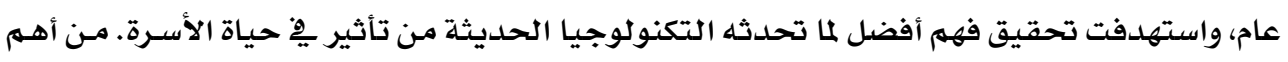

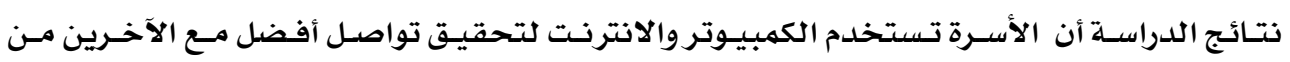

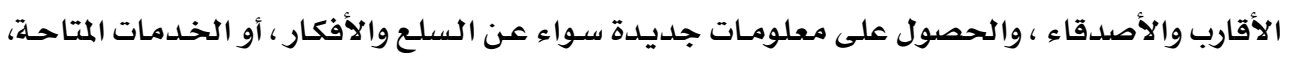

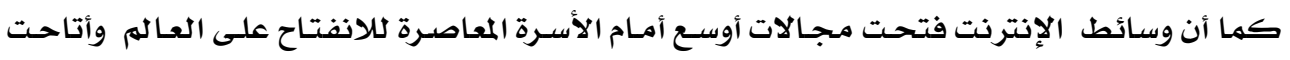

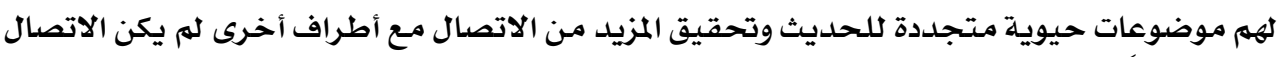

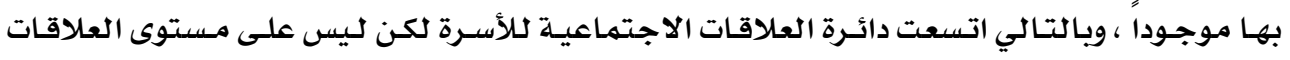

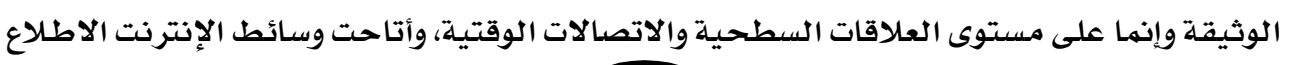




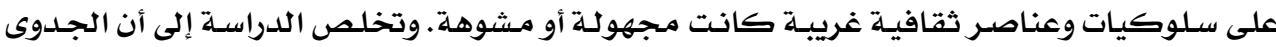

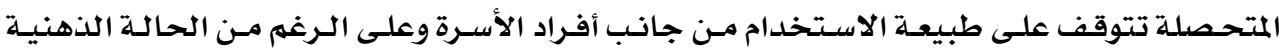

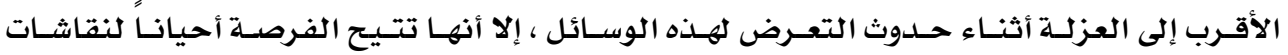

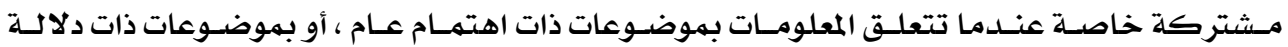
لمصلحة مباشرة أو شخصية وبحثت دراســة ويتزمسان (Weitzman,2001 ) أثـروسـائط الإنترنـت علسى الأسـرة

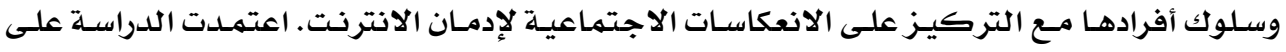

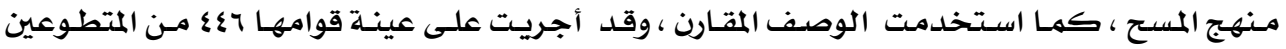

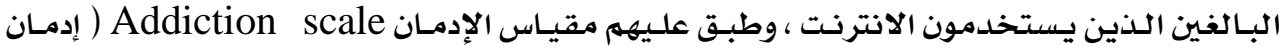

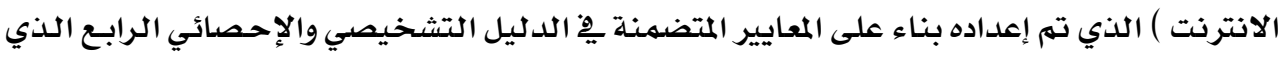

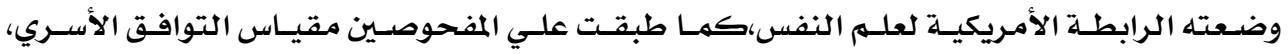

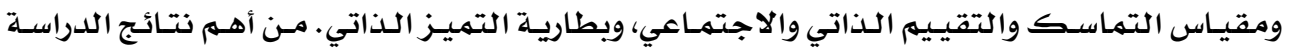

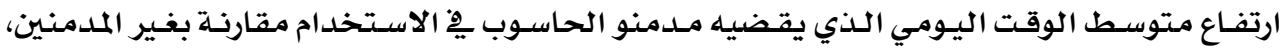

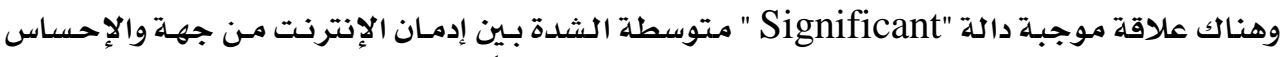

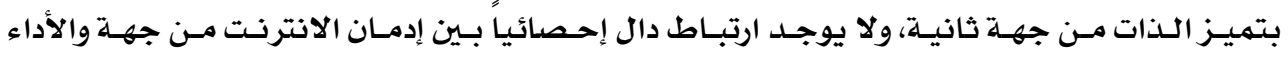

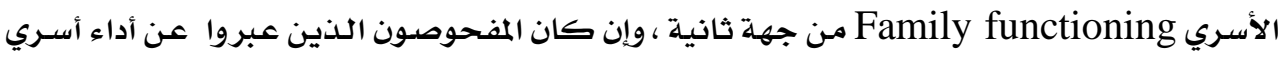

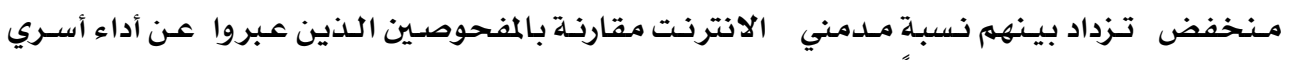

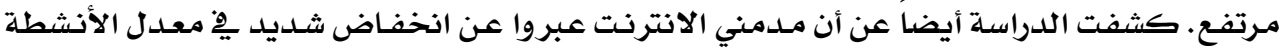

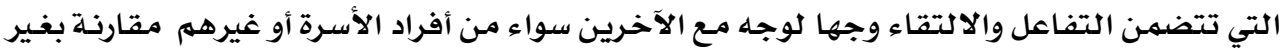

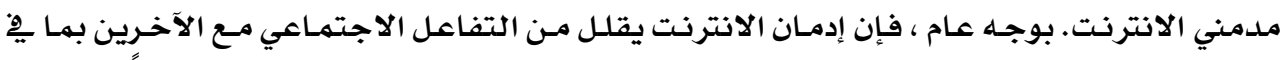

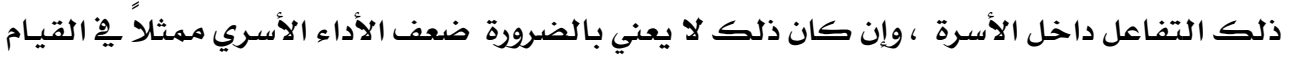
بالمسؤوليات الأسرية.

كما أجـرى كل مـن هول وشيفرن (Hall \& Schaverien,2001 ) دراسـة متعهقة

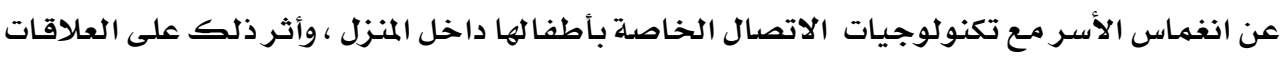

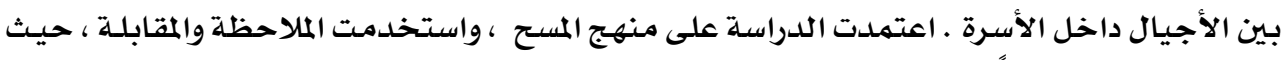

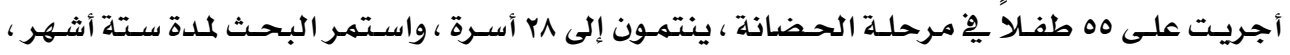

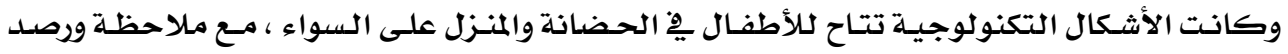

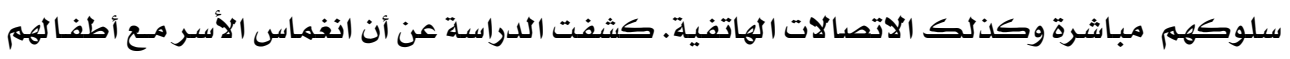

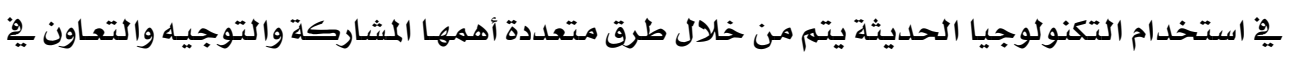

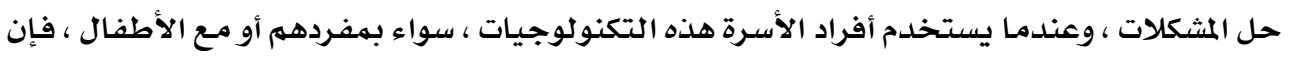

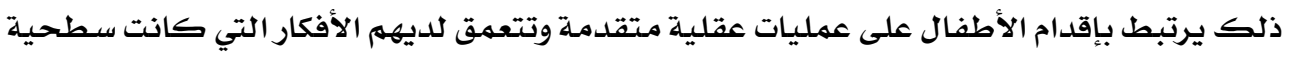

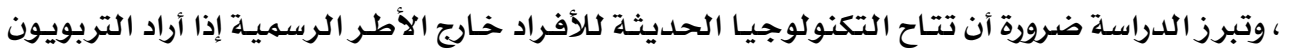

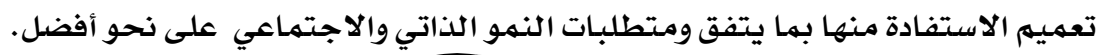


واهتمت دراسـة تورو (Turow,2002 ) بصياغة نموذج (Model)

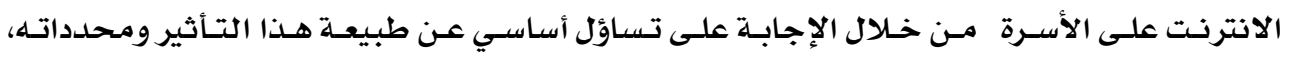

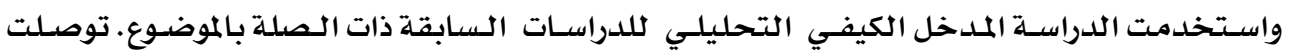
الدراسة إلى نموذج ثنائي البعد (Two-Dimensions Model) يجمل تأثير الإنترنت على الأسـرة

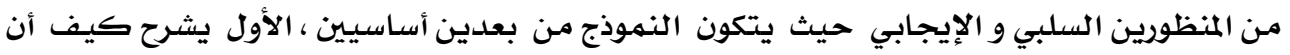

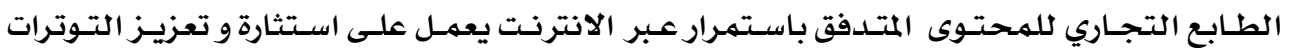

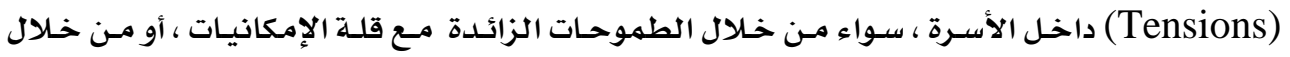

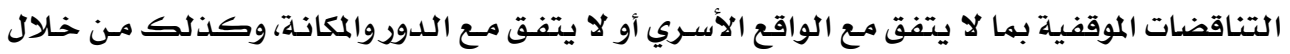

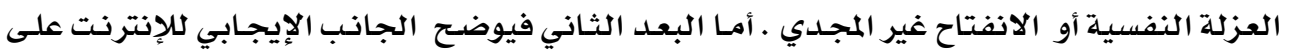

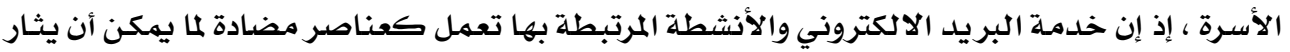

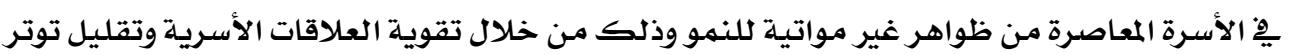
ريات البيوت.

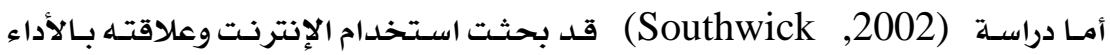

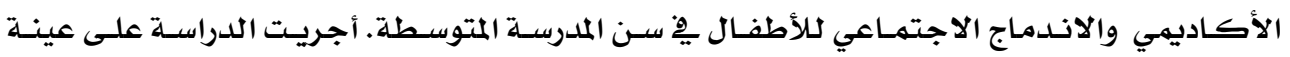

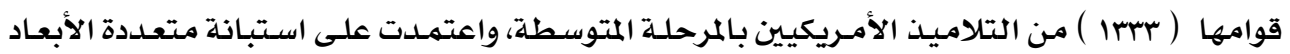

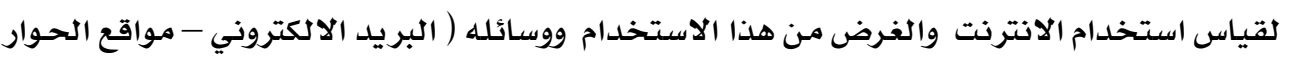

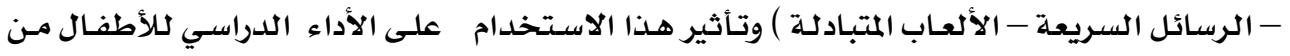

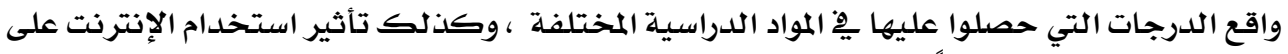

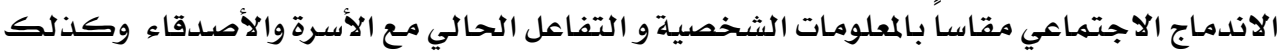

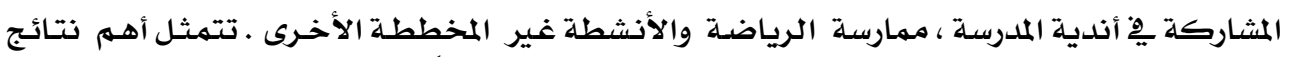

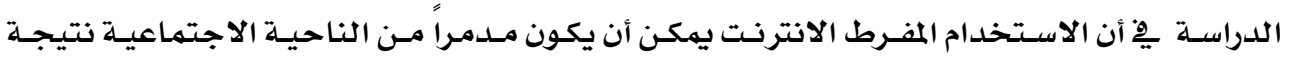

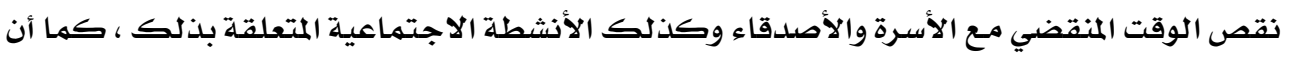

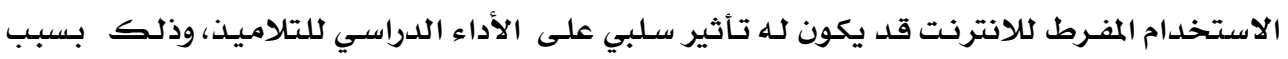

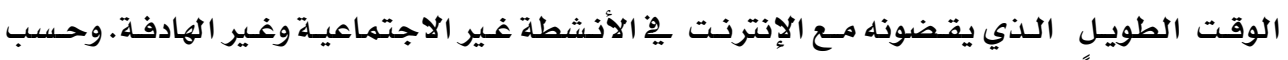

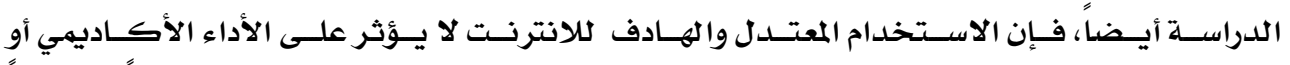

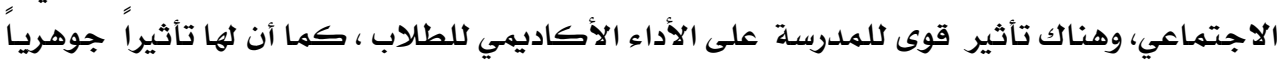

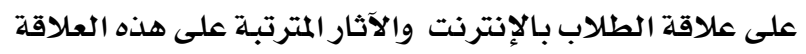

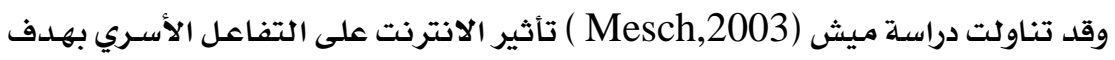

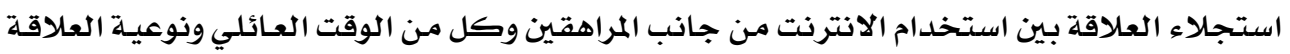

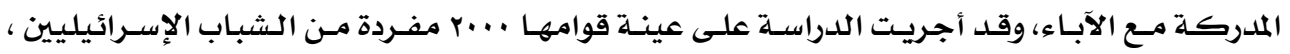

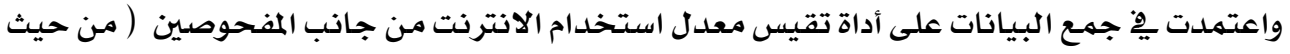

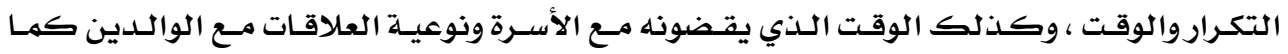

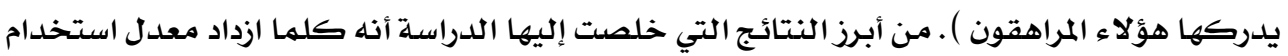


"

الانترِت من جانب المراهقين انخفض تقديرهم لإيجابية علاقاتهم مـع الوالدين ، أي أن هناك ارتباطاً

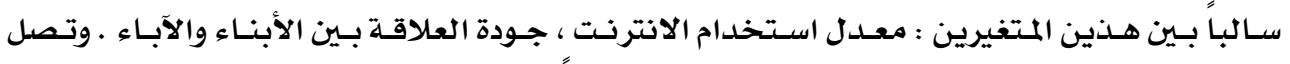

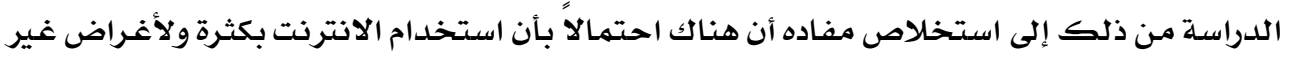

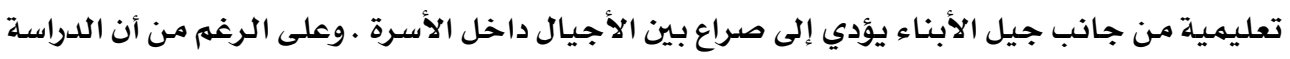

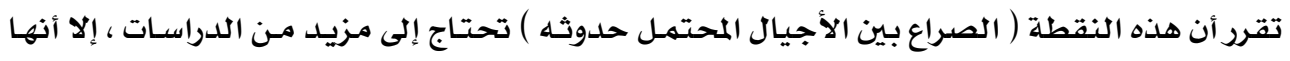

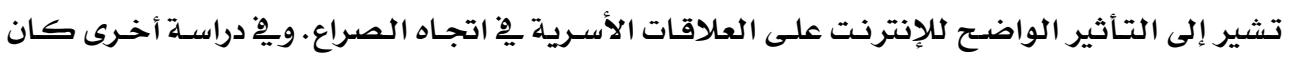

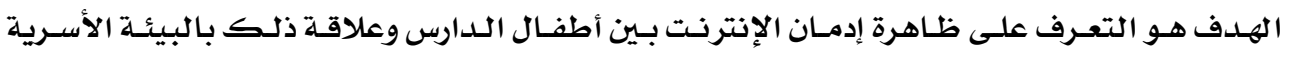

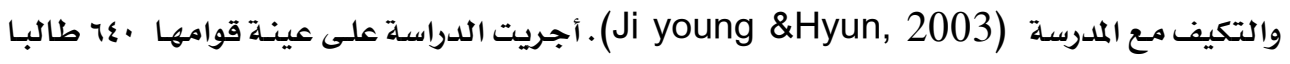

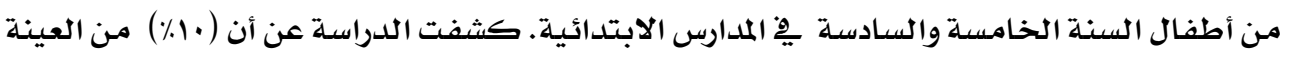

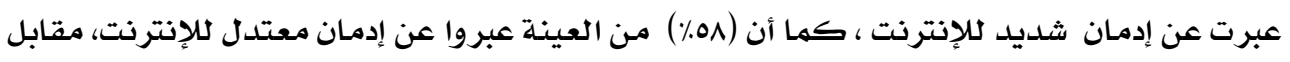

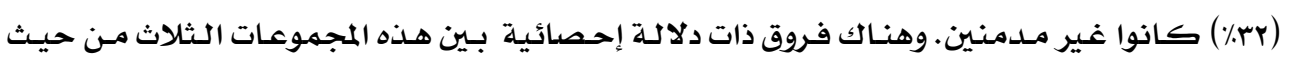

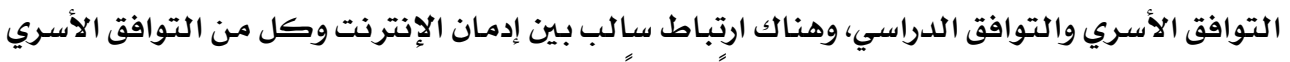

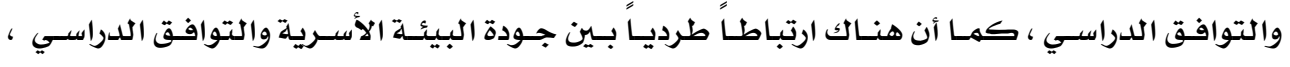

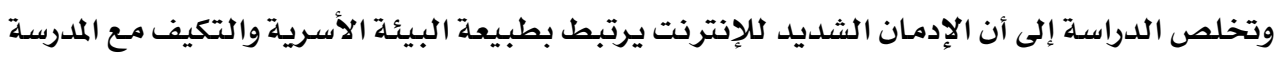

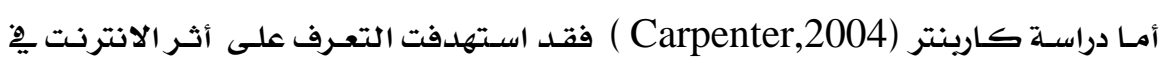

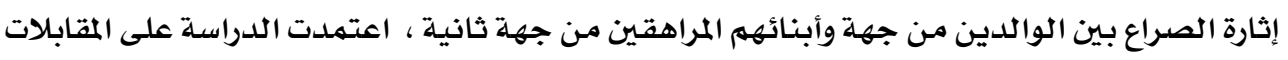

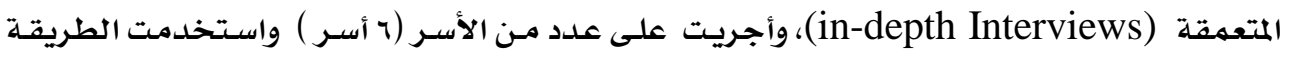

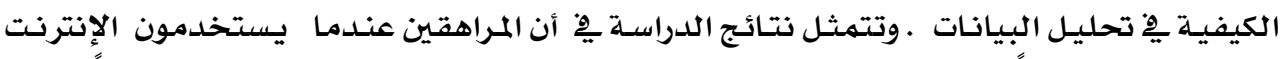

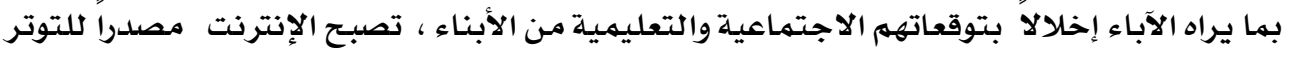

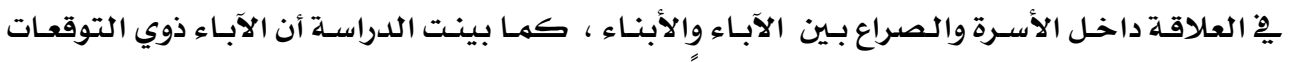

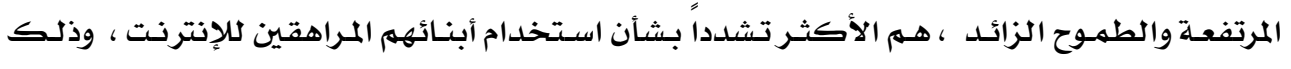
مقارنة بالآباء ذوي التوقعات المنخفضشة.

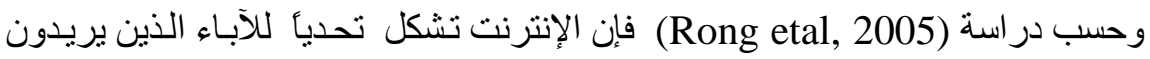

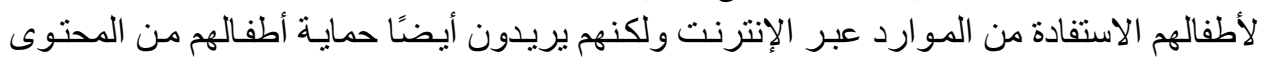

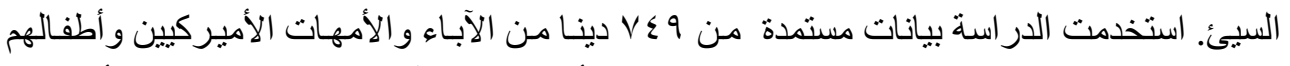

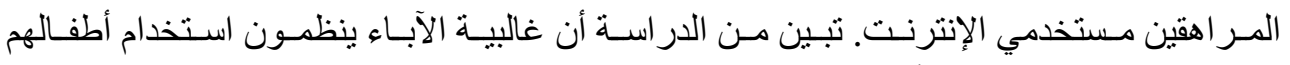

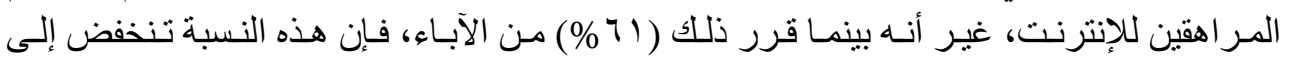

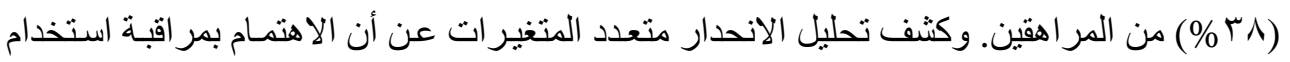

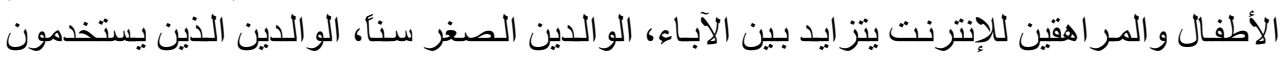

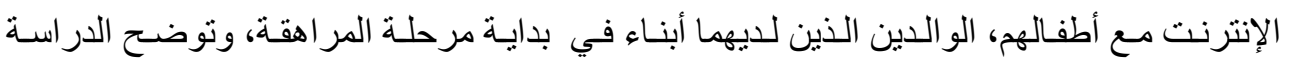

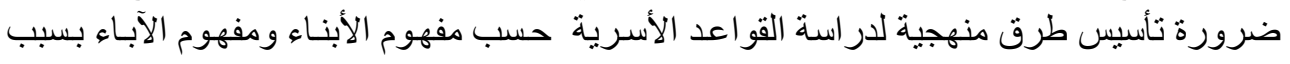

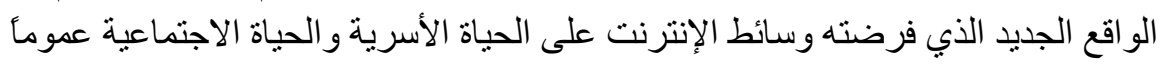


وحسب دراسـة جوستاف (Gustavo,2006) فإن التكنولوجيا وخاصسة الإنترنت - أحسدثت

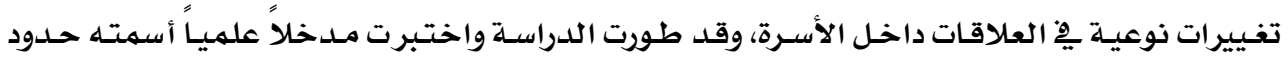

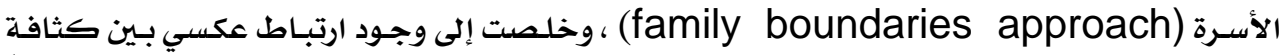

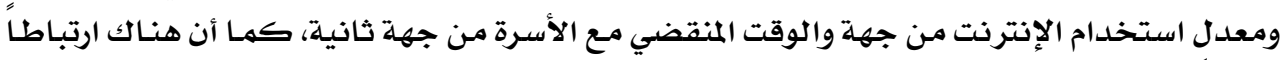

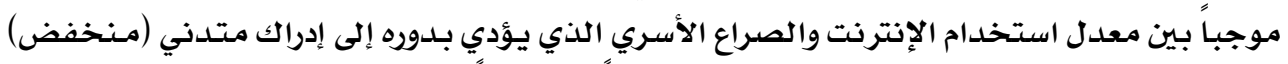

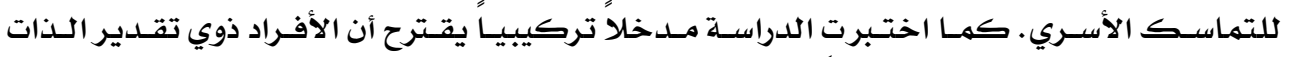

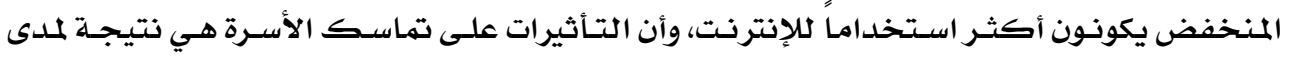

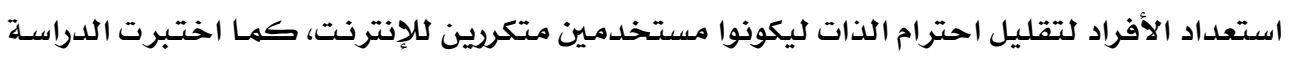

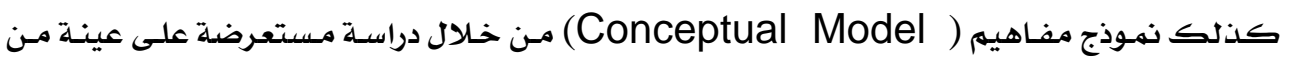

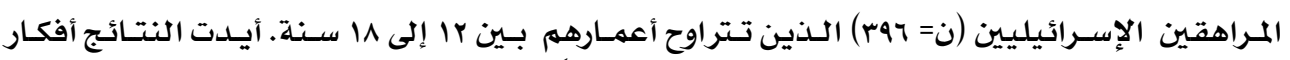

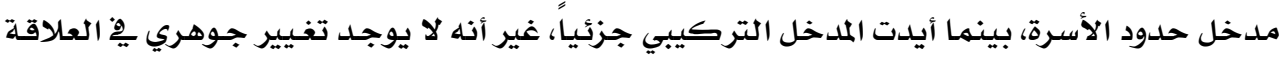

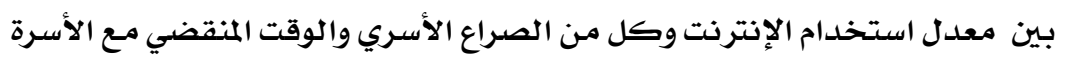
كما استهدفت دراسـة (Ju- YU Yen etal., 2007) بحث الاختلاففات الأسـرية بـين

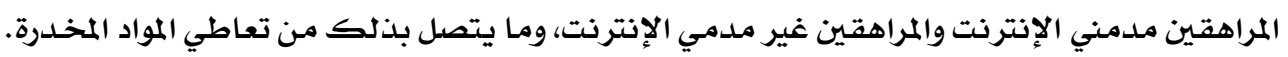

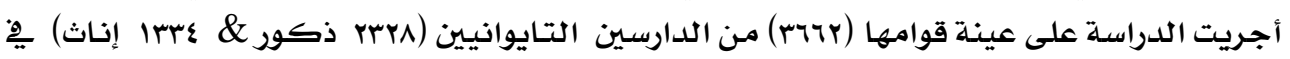

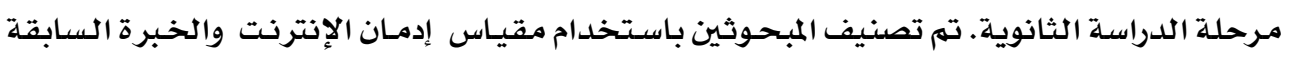

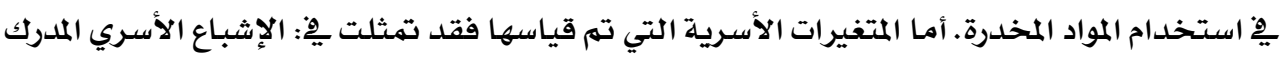

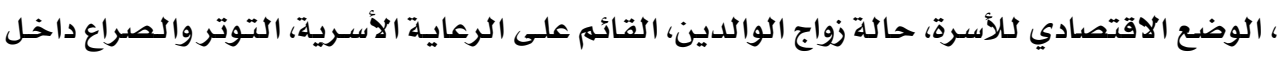

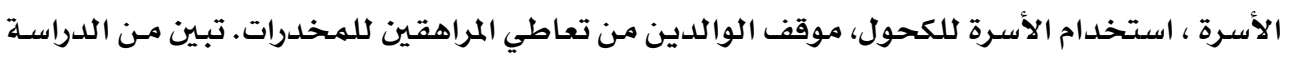

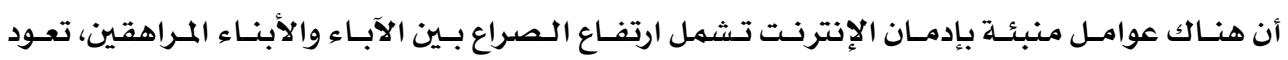

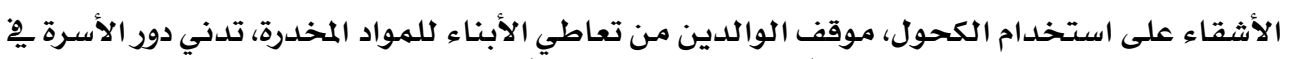

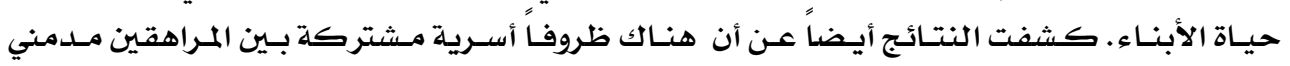

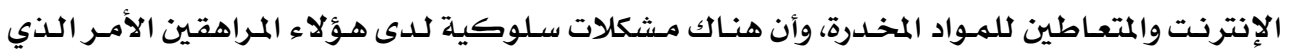

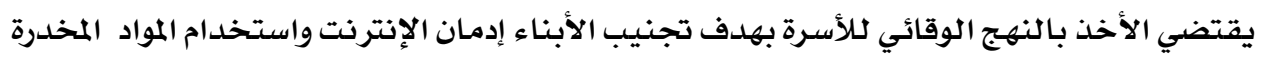

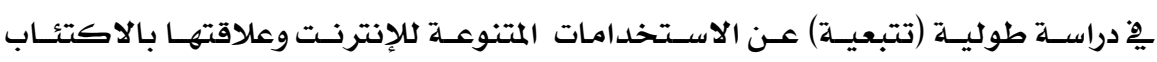

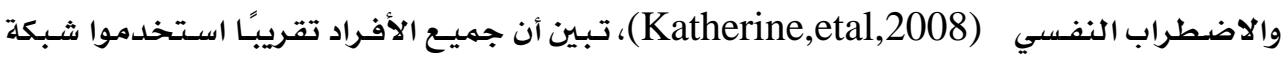

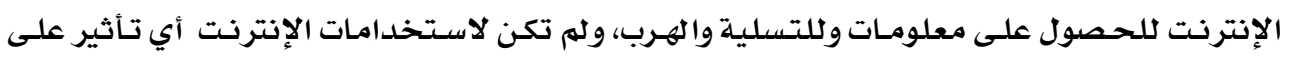

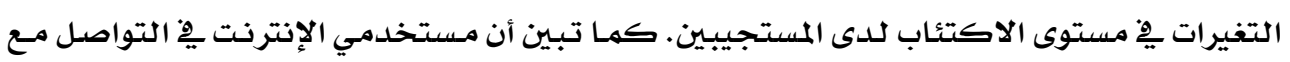

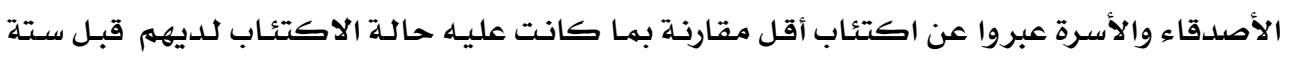

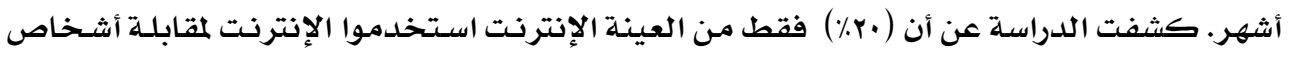

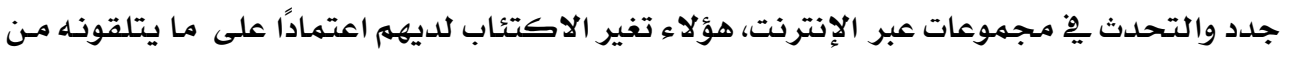

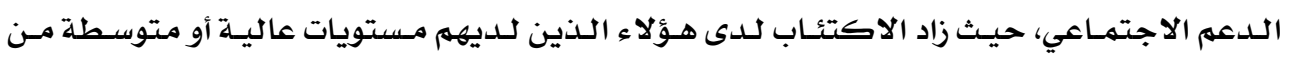

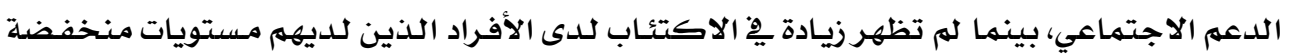


من الدعم الاجتماعي، وترى الدراسـة أن الفروق الفردية من حيث الدعم الاجتماعي واختيارات الأفراد

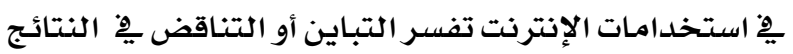
أمـا دراسـة (Wansen, etal., 2013) فقد انطلقت من حقيقة أن الأسرة عامـل جـوهري

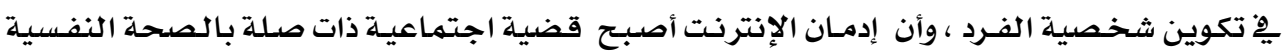

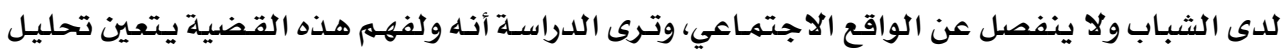

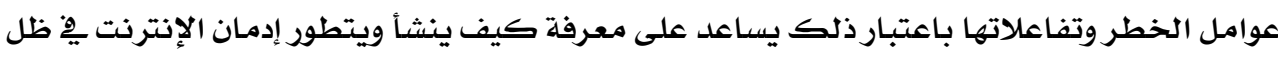

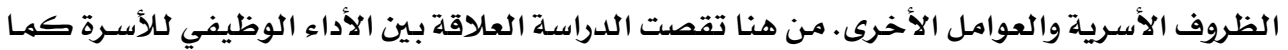

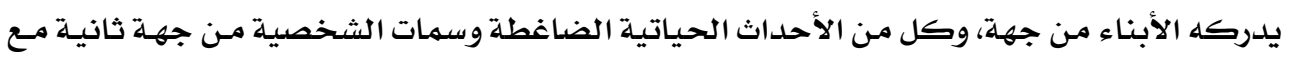

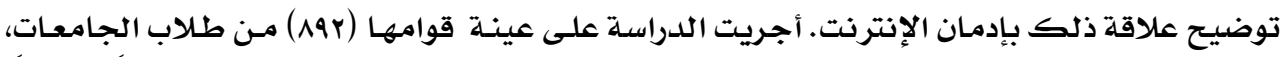

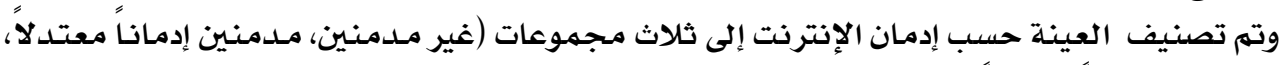

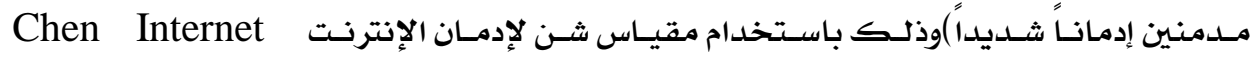
الاسيرة حdiction Scale.

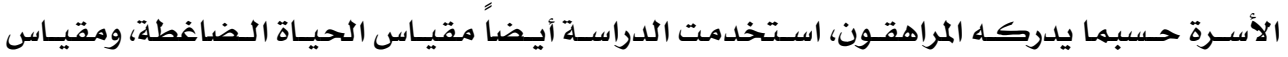

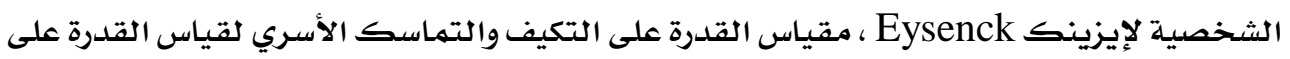

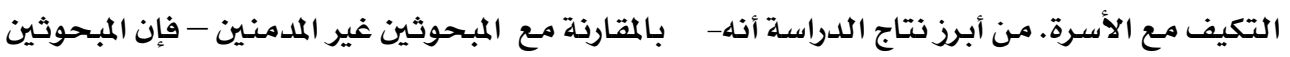

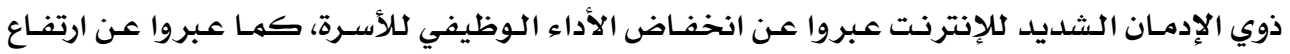

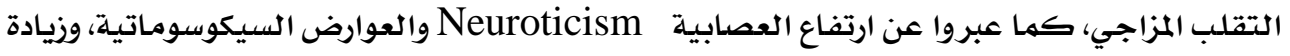

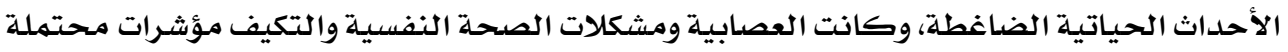

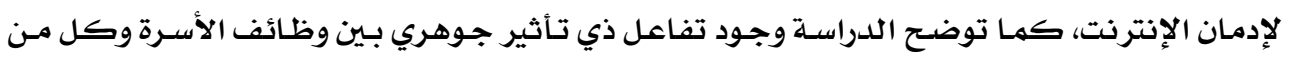

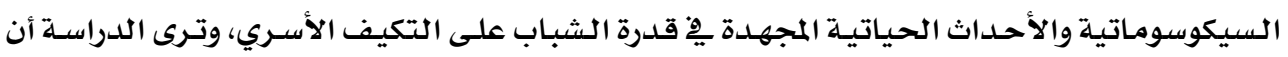

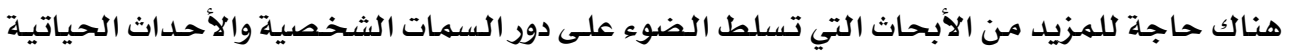

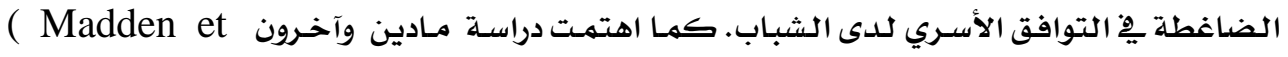

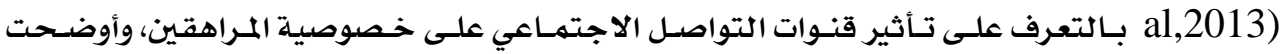

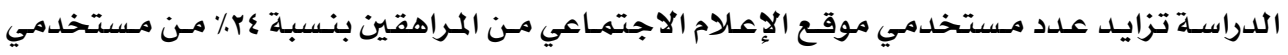

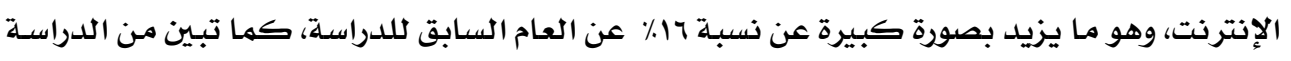

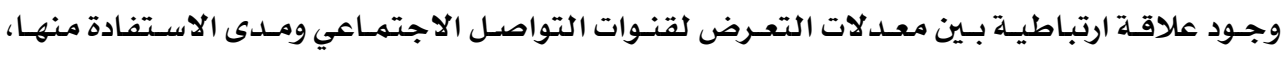

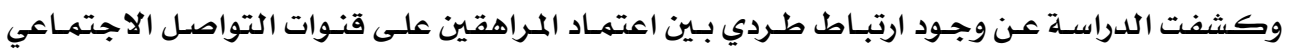

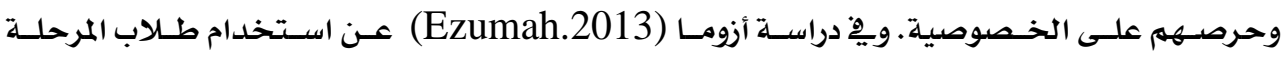

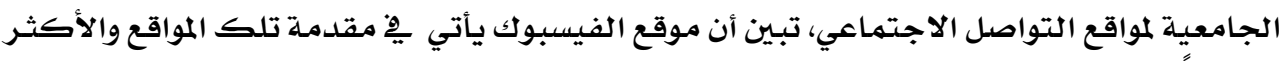

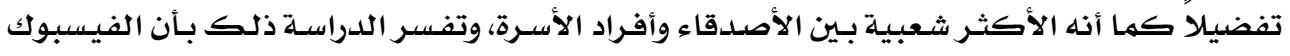

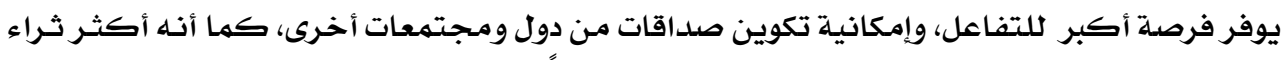

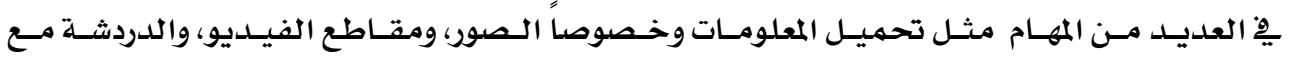

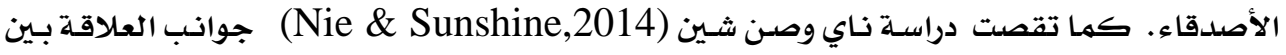


كثافة استخدام الإنترنت، والآثار الناتجة عن هذا الاستخدام فيما يخص حيـاة الأفراد الاجتماعيـة،

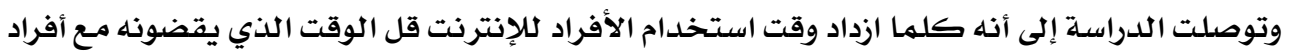

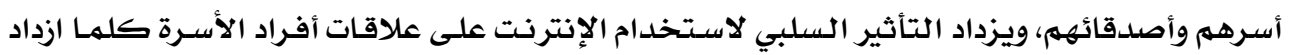
الاستخدام داخل المنزل وأيام الإجازات. كما اهتمت دراسة ها وكيم شى (Ha \& Kim Ch,2014)

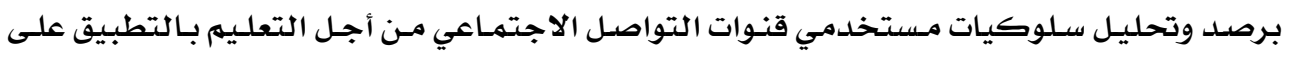

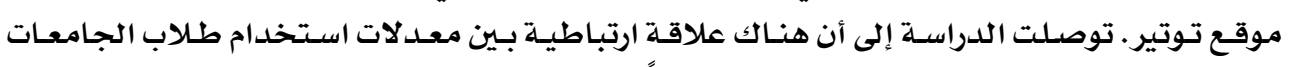

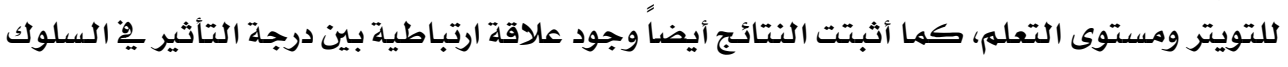

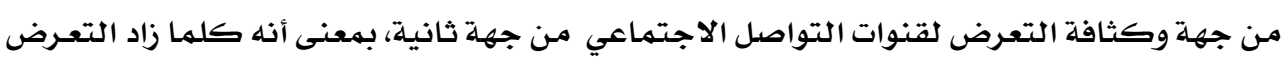

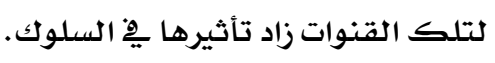

ويْ منطقة الأهـواز (إيـران) تم إجـراء دراسـة على طلاب المدارس الثانويـة لمعرفـة العلاقة

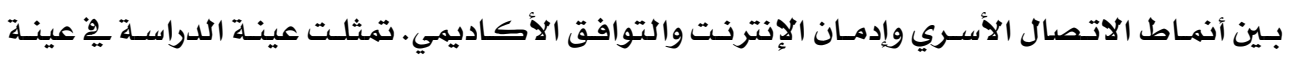

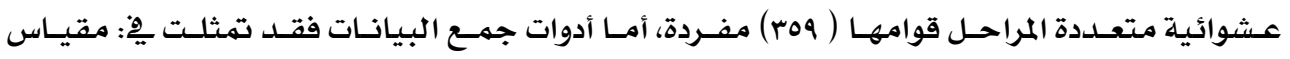

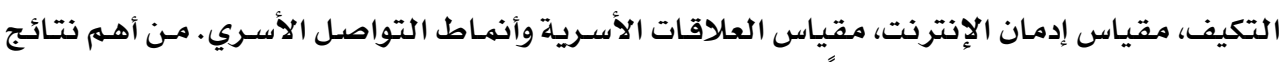

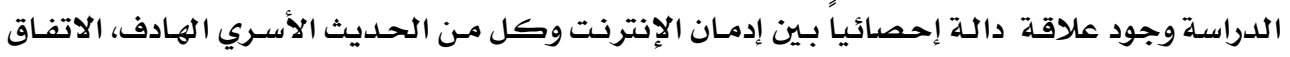

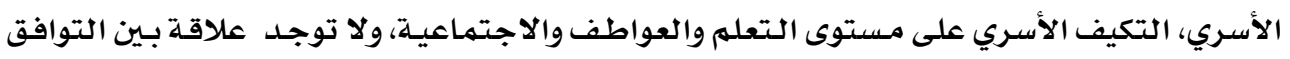

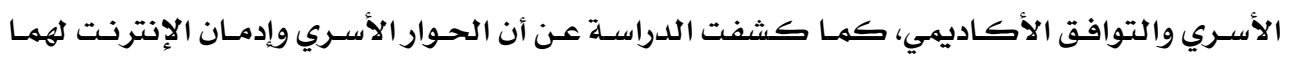

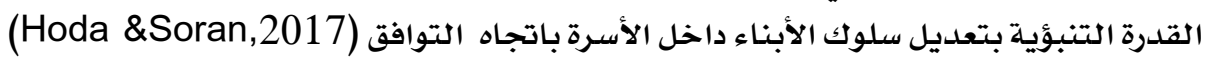

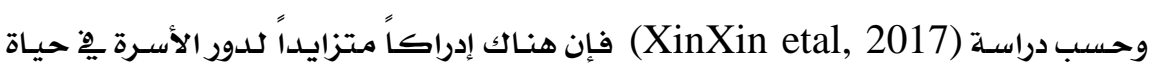

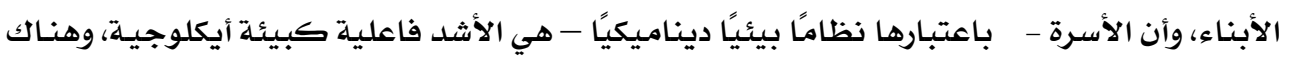

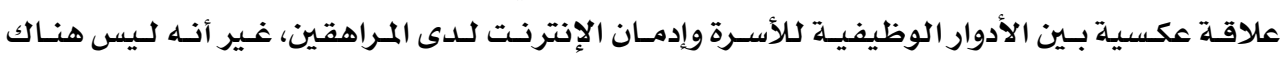

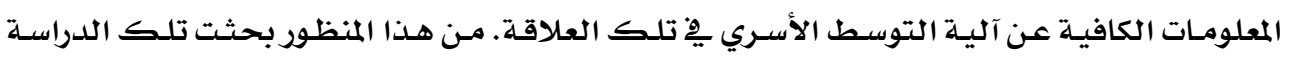

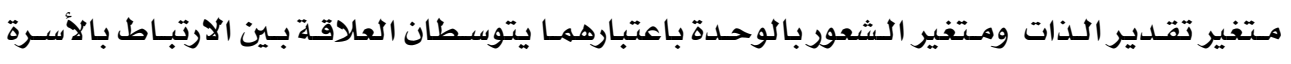

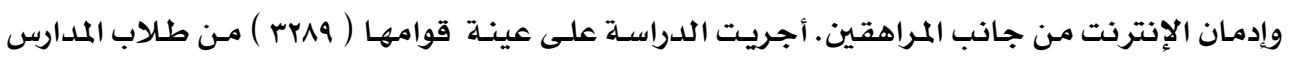

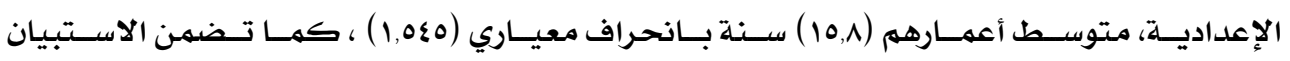

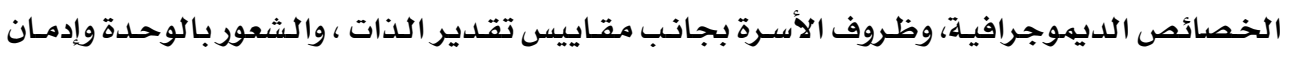

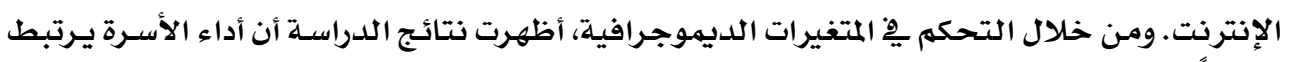

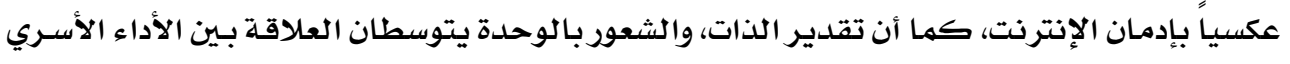

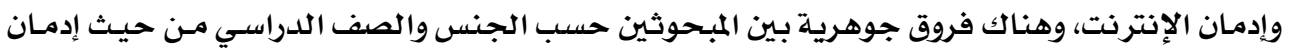
الإنترنت والأداء المدرك لكلأسرة.

من واقع هذا العرض لنماذج من دراسـات سابقة عن تأثير وسـائط الإنترنت على الأسـرة بها

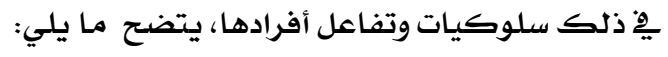




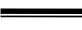

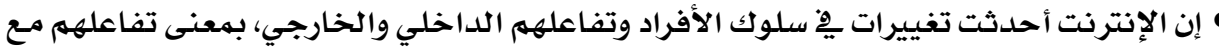
الأسرة، وتفاعلهم مـع الأفراد الآخرين

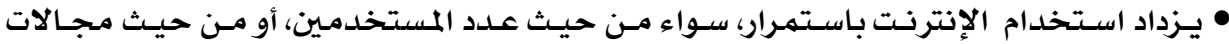

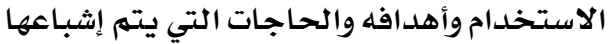

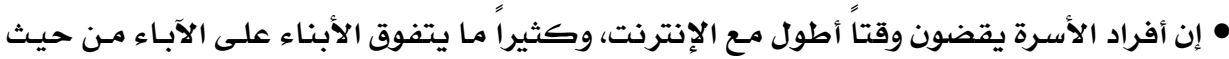
مهارات استخدام الإنترنت • إن كثرة استخدام الإنترنت ومعايشة ما تتضمنهه من تعددية يِّ المحتوى ، أتاحت الفرصدة لأفراد

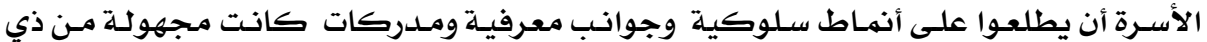

• هناك نتائج متناقضدة بشأن الإنترنت على سلوكك أفراد الأسـرة، وحسب نتائج الدراسـات السابق

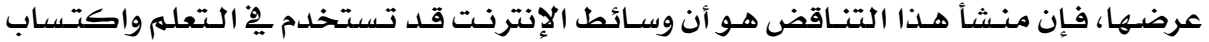

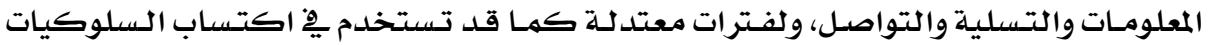

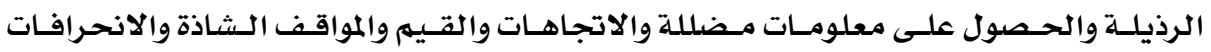

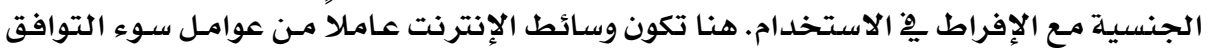

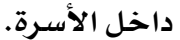

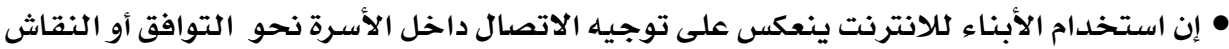

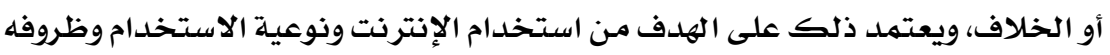

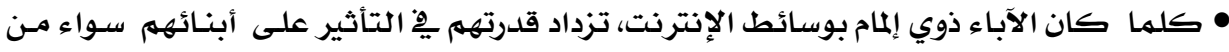

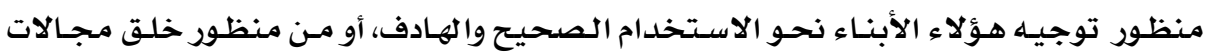

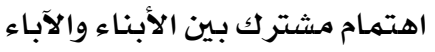

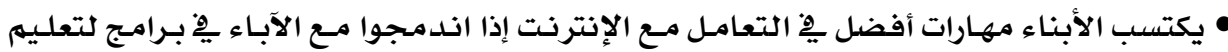

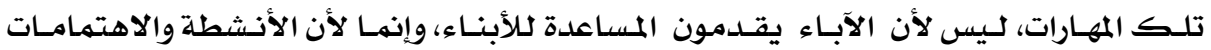

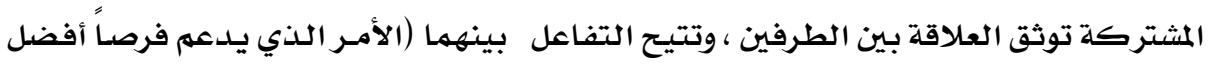

$$
\text { للتتوافق الأسري) . }
$$

• هناك أنهاط من الاتصال داخل الأسرة ترتبط باستخدام الانترنت، لكن ليس هنـاك علاقة بـين

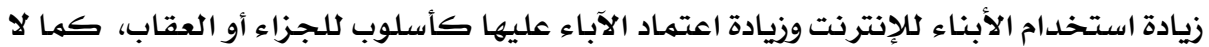

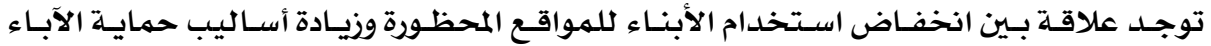

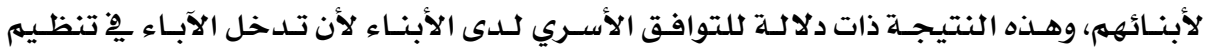

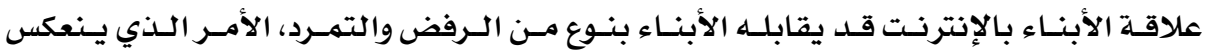

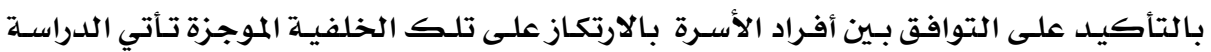


الحالية لتقصي العلاقة بين سوء استخدام الإنترنت والتوافق الأسري، بالتطبيق على عينـة مـن الشباب الكويتيين.

\section{أولاً: أهداف الدراسة الحالية}

إن الهدف الأسـاسي لهذه الدراسـة هو تقصي وتفسير العلاقة بين سوء استخدام الإنترنت مـن

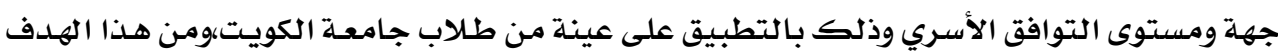
الأساسي تنبثق مجموعة الأهداف الآتية:

$$
\text { r) ) رصد مظاهر سوء استخدام الإنترنت لدى الشباب الكويتيين }
$$

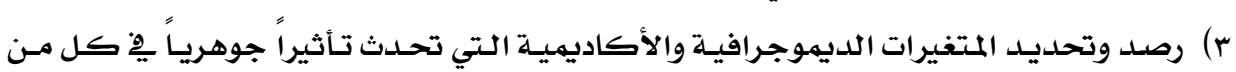

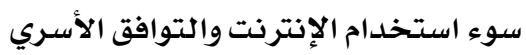

$$
\text { ع ) رصد شدة واتجاه الارتباط سوء استخدام الإنترنت والتوافتق الأستري الأنتري }
$$

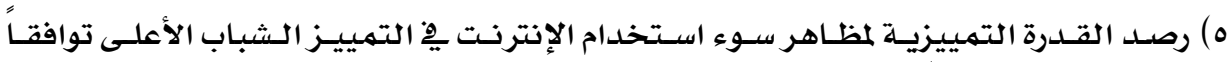

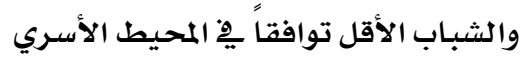

\section{ثانيًا: تساؤلات الدراسة وفروضها:}

(i) تساؤلات الدراسة

$$
\text { ( ) ما مظاهر سوء استخدام الإنترنت لدى الشباب الكويتيـين؟ }
$$

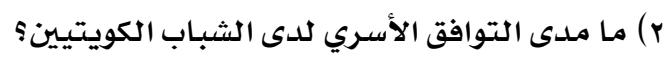

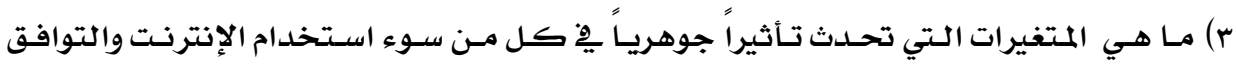

$$
\text { الأسري؟ هـ }
$$

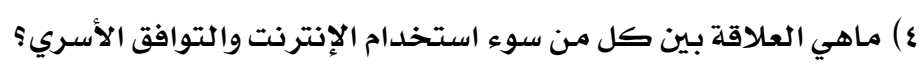

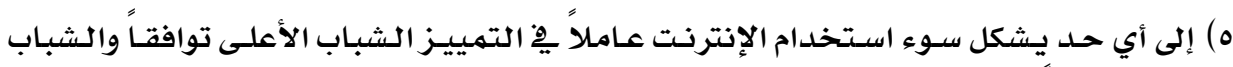

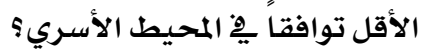

$$
\text { (ب) فروض الدراسة }
$$

(1) لا توجد فروق جوهرية بين مجموعات العينـة حسب الخصائص الديموجرافيـة والأكاديميـة

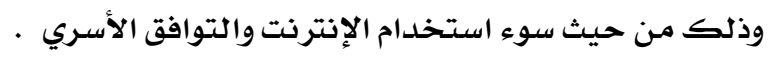

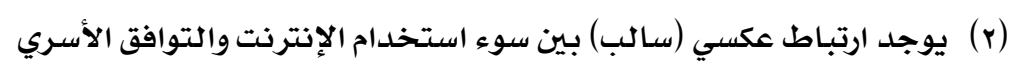

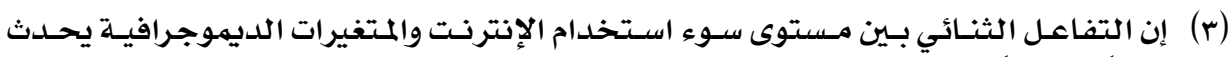

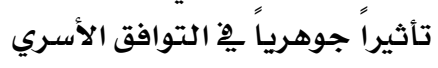




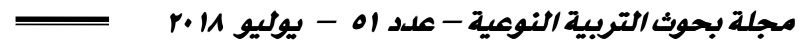

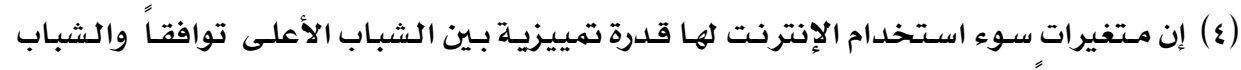

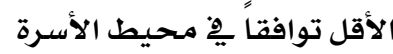

\section{ثالثًا: هنهجية الدراسة وإجراءاتها:}

حسب أهداف الدراسـة الحالية فإنها مـن نوع الدراسات التحليلية الوصفية، إنها تهتهم برصديد

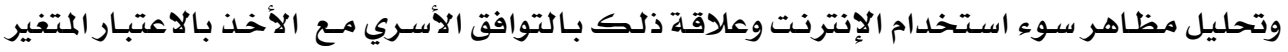

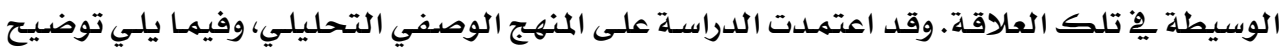

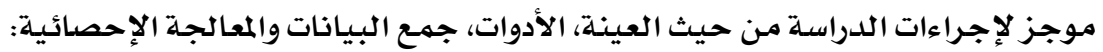

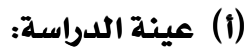

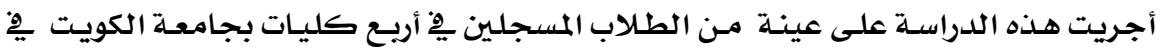

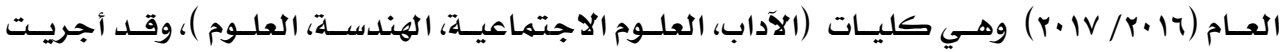

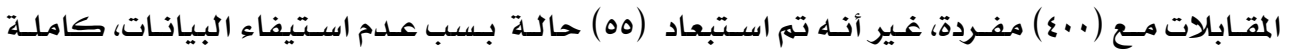

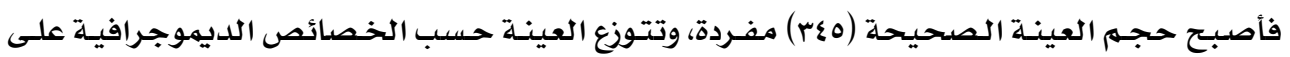
النحو الموضح بالجدول الآتي:

جدول رقم (1)

خصائص عينة الدراسة

\begin{tabular}{|c|c|c|}
\hline$\%$ & ك & المتفيرات الديموجرافية \\
\hline $\begin{array}{l}\sum \eta, Y \\
o r, r\end{array}$ & $\begin{array}{l}171 \\
1 \Lambda \varepsilon\end{array}$ & الجنس : ذكور \\
\hline $\begin{array}{l}\Lambda, \Lambda \\
\xi 1, r\end{array}$ & $\begin{array}{l}r . r \\
\text { rar }\end{array}$ & 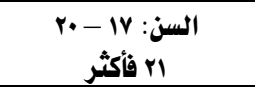 \\
\hline $\begin{array}{l}\text { Ar } \\
\text { in }\end{array}$ & $\begin{array}{l}\text { TAT } \\
\text { TH }\end{array}$ & نمط الوالدية: ثنائية \\
\hline 19,8 & Tr & المحافظة: العاصمة \\
\hline $\mathbb{I r}, \Lambda$ & $\llbracket$ & حولي \\
\hline $19, v$ & 71 & الفروانية \\
\hline $19, v$ & 71 & الجهراء \\
\hline 11 & ra & مبارك الكبير \\
\hline $\mid \mathrm{Y}, \boldsymbol{\xi}$ & 7. & الأحمدي \\
\hline$r \wedge, \mathfrak{\varepsilon}$ & 91 & السنة اللدراسية : الأولى \\
\hline$r r, \xi$ & $\wedge 1$ & الثانية \\
\hline$r \xi, 1$ & AT & الثالثة \\
\hline$r \xi, 1$ & Ar & الرابعة \\
\hline$\xi \bullet, r$ & 179 & مستوى التحصيل: منخفض \\
\hline rA, & irt & متوسط \\
\hline$r, r$ & rr & مرتفع \\
\hline $1 .$. & r\$o & المجموع \\
\hline
\end{tabular}




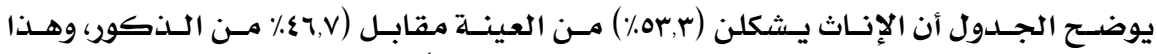

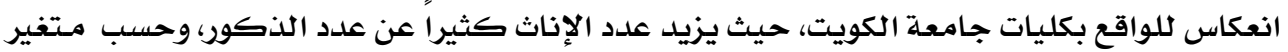

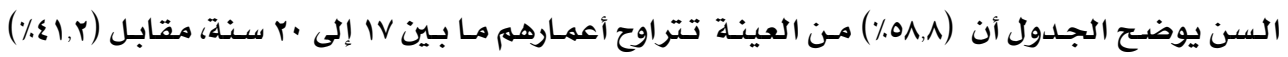

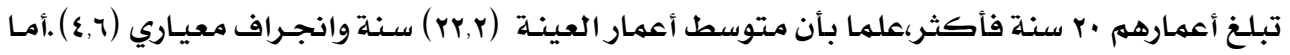

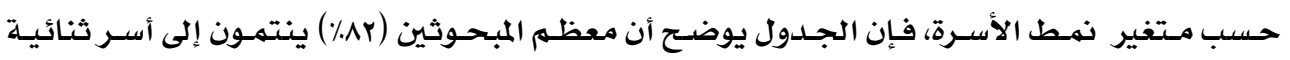

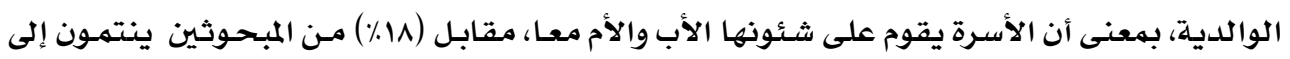

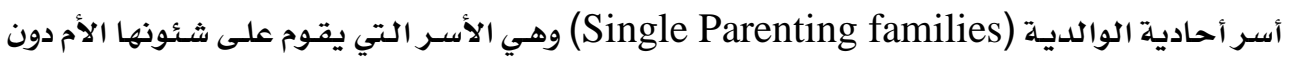

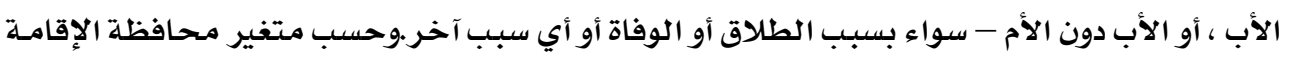

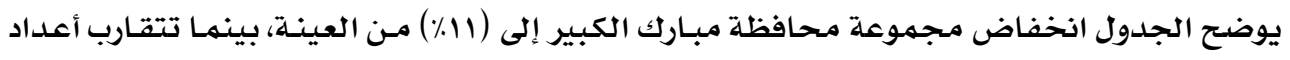

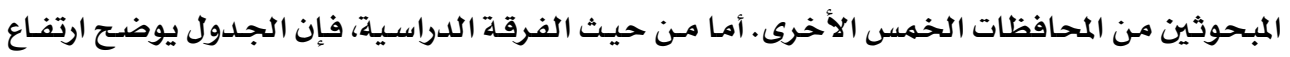

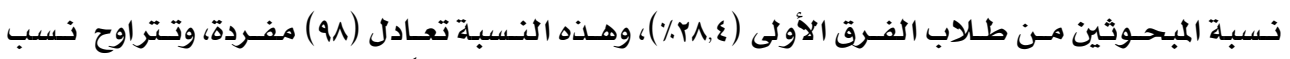

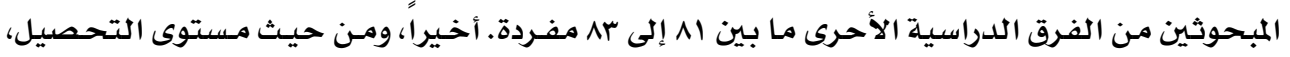

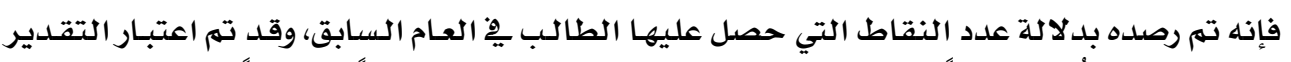

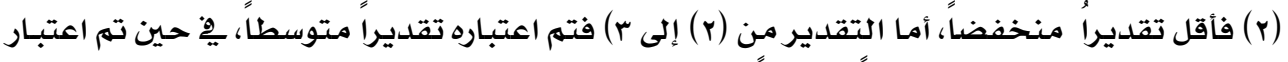

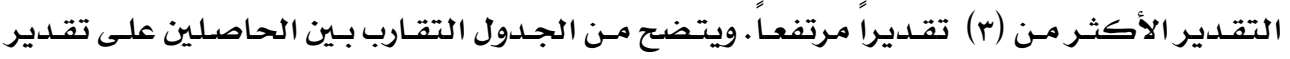

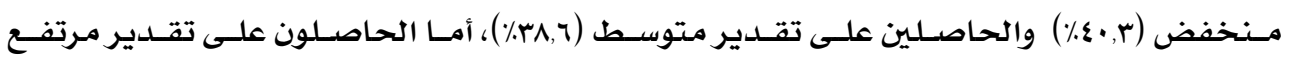

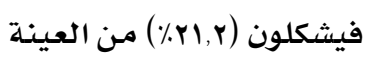

(ب) أدوات الدراسة:

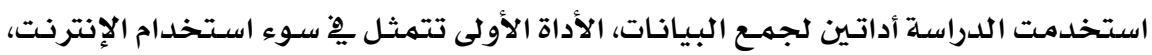

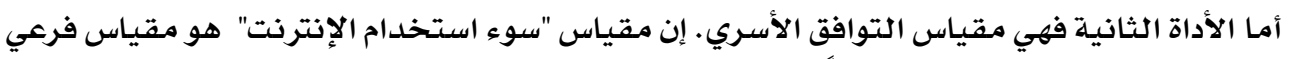

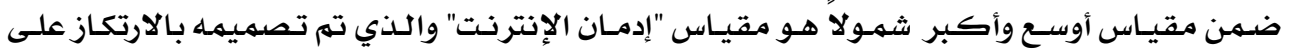

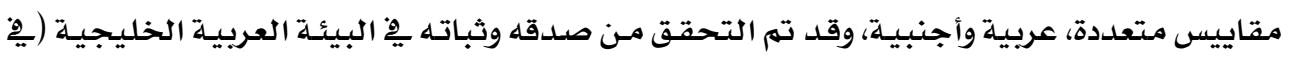

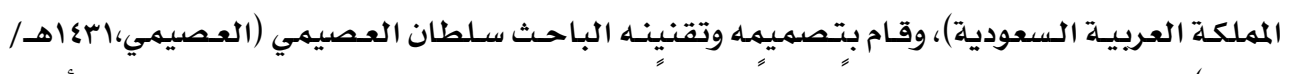

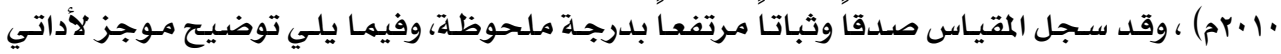
الدراسـة:

(1) مقيـاس سـوء اسـتخدام الإنترنت: يتكـون المقيـاس مـن إحسلى عشرة عبـارة تـدور حسول

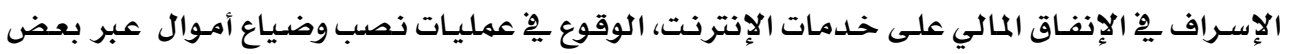

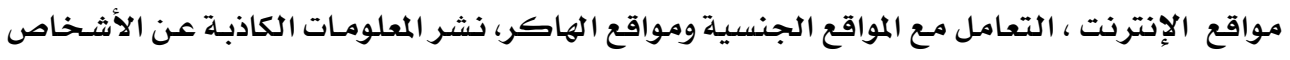

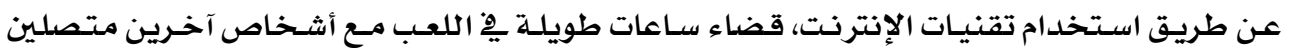

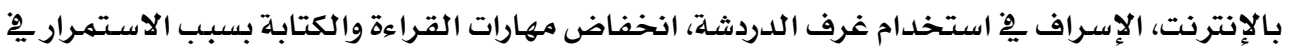

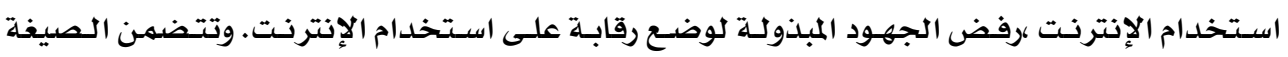

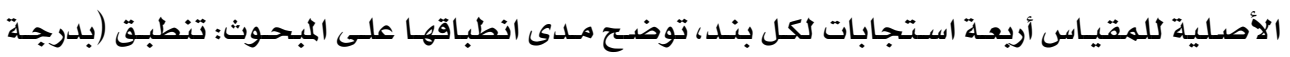




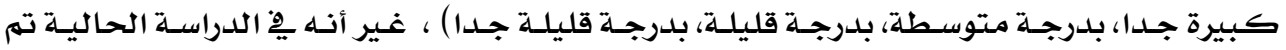

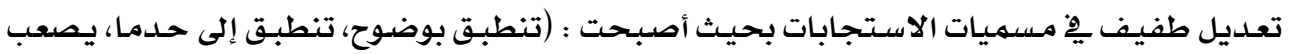

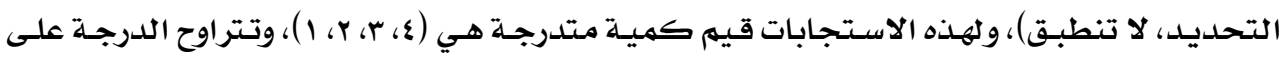

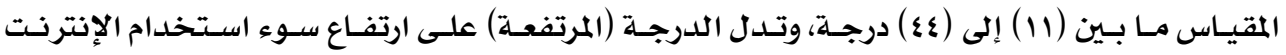

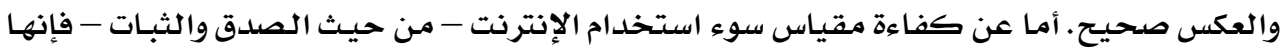

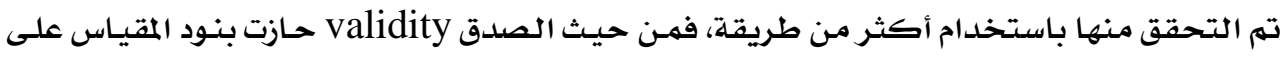

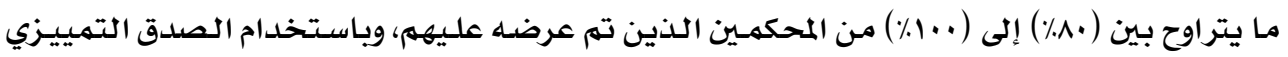

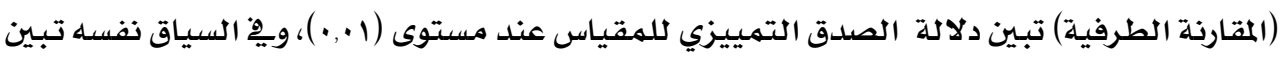

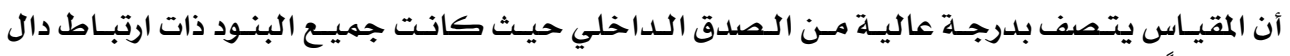

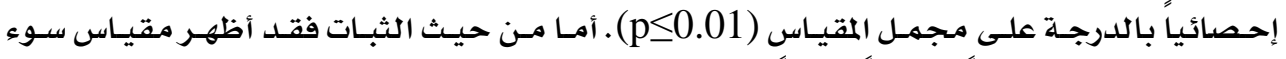

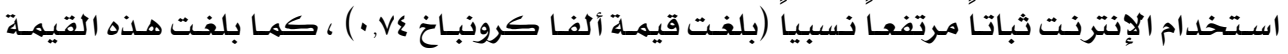

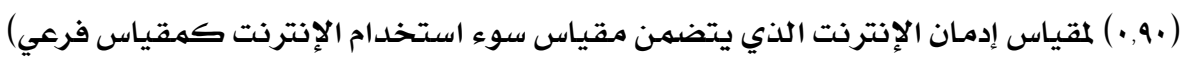

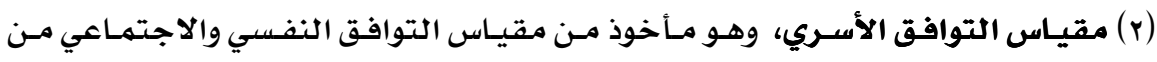

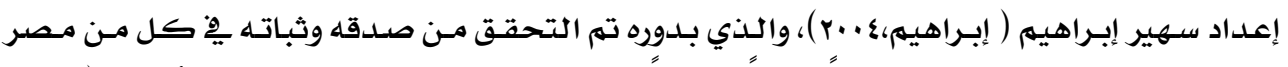

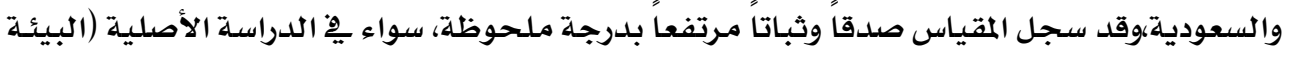

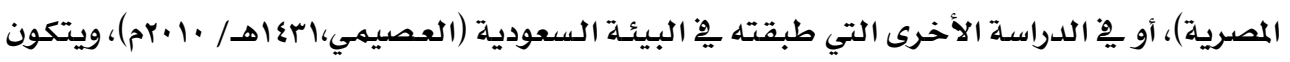

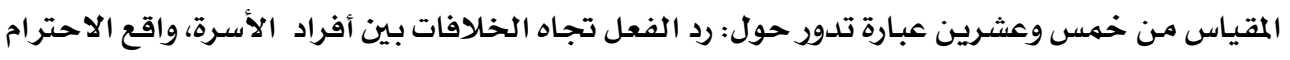

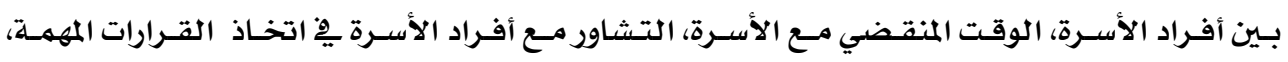

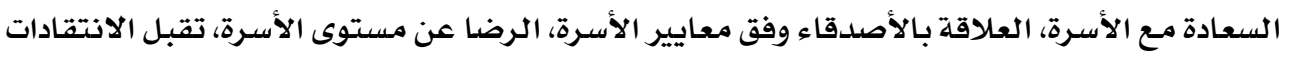

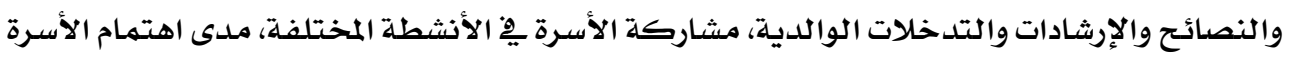

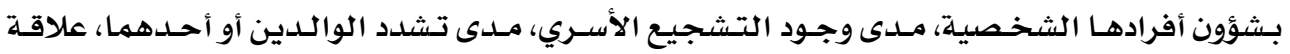

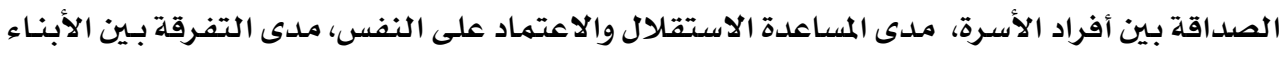

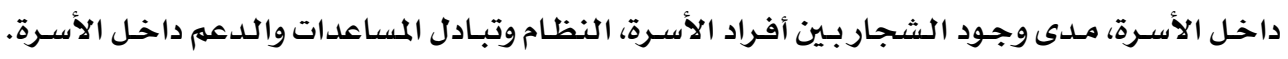

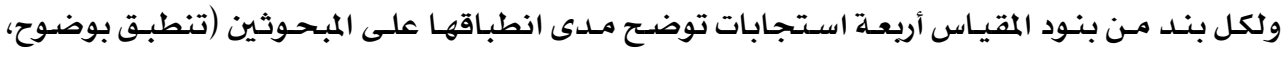

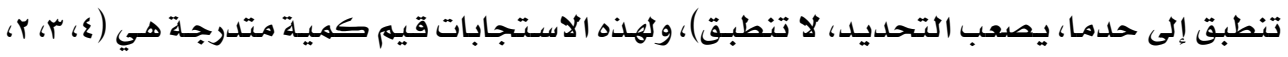

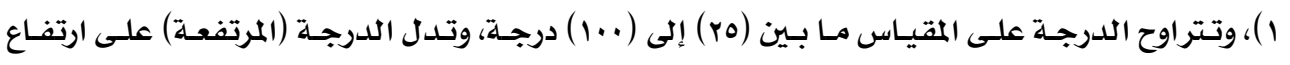

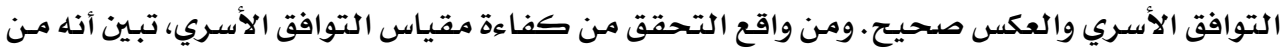

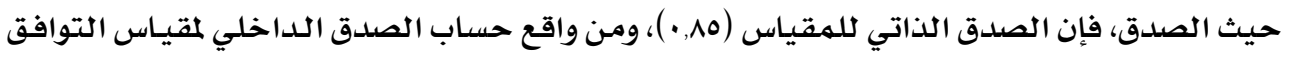

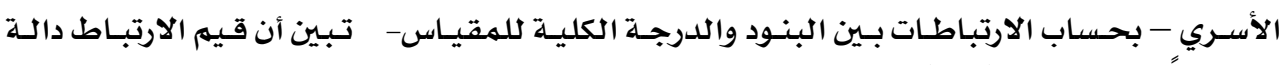

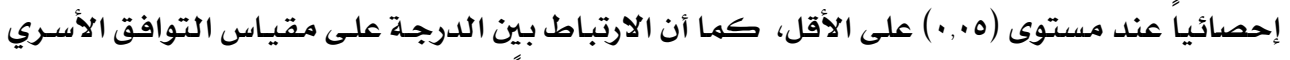

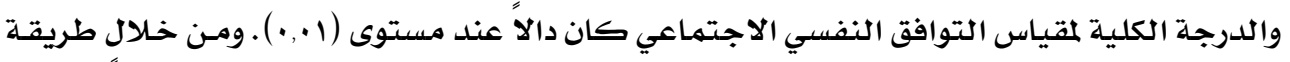

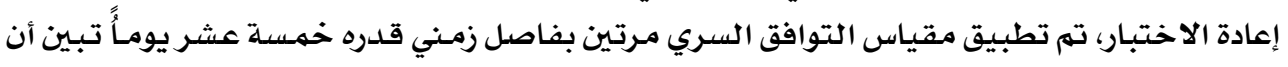

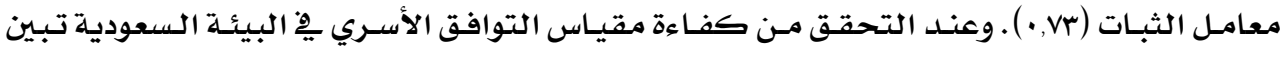




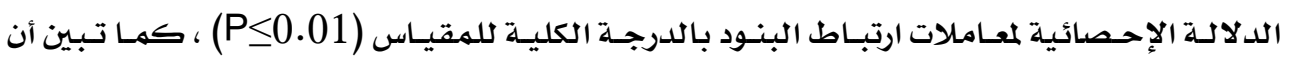

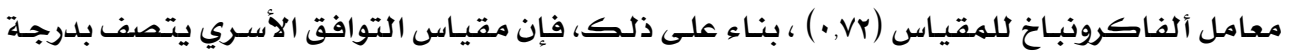

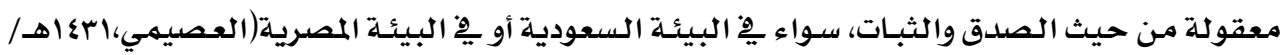

(ar+1.

(ج) جمع البيانات والمعالجة الإحصائية:

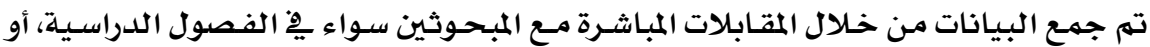

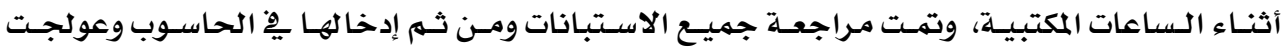

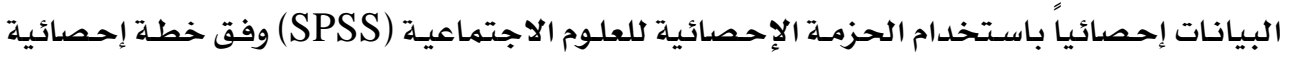

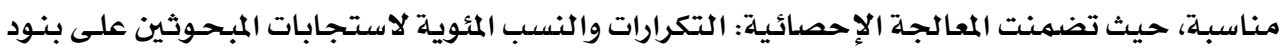

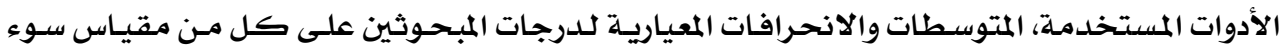

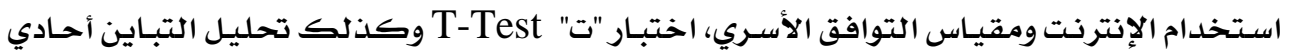

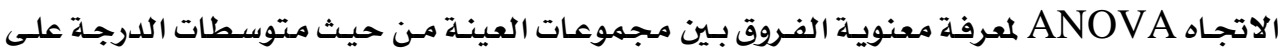

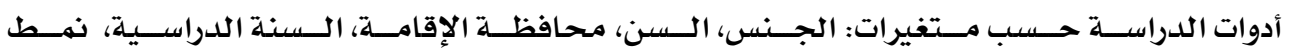

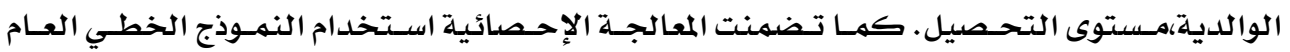

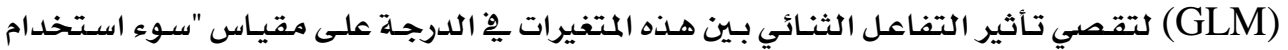

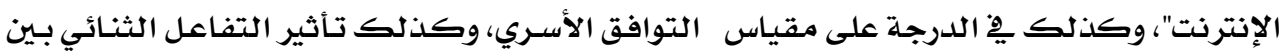

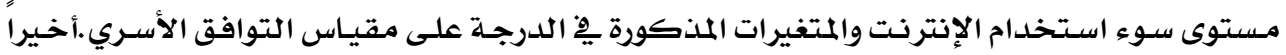

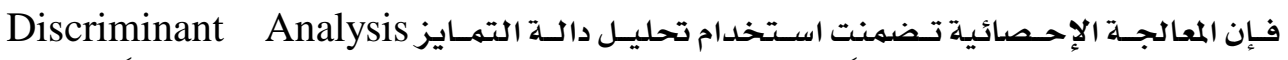
لتصنيف المبحـوثين الأعلى توافقـاً (High Adaptation) مقارنـة بـالمبحوثين الأقل توافقاً

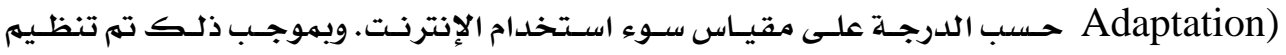

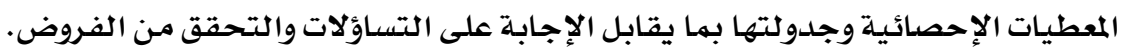

\section{نتائج الدراسة}

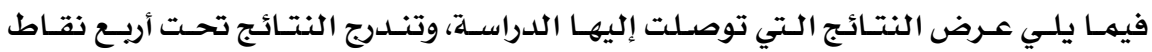

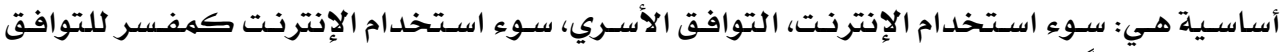

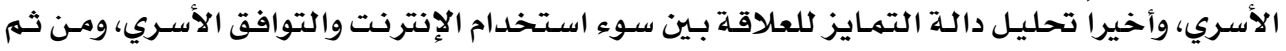

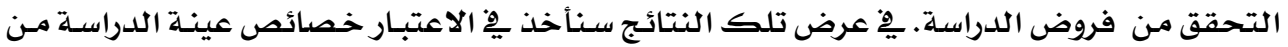

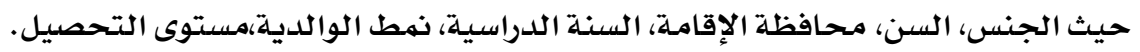
أولاً: سوء استخدام الإنترنت:

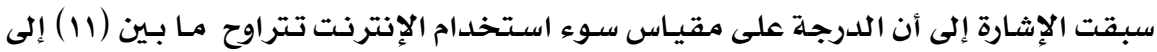

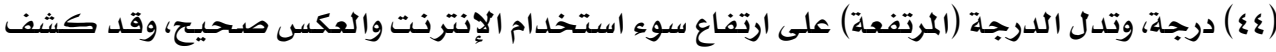

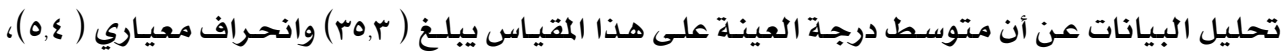

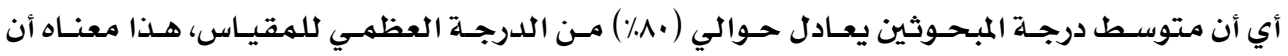


طلاب الجامعة عينة البحث يرتفع لديهم سوء استخدام الإنترنت، ويختلف متوسط درجـة المبحـوثين

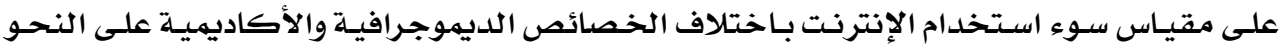

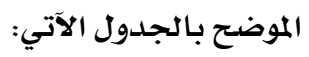

\section{جدول رقم (r)}

معنوية الفروق بين مجموعات العينة من حيث متوسط الدرجة على مقياس سوء استخدام الإنترنت

\begin{tabular}{|c|c|c|c|c|c|}
\hline \multicolumn{2}{|c|}{ Statistics } & \multirow{2}{*}{ STD } & \multirow{2}{*}{ Mean } & \multirow{2}{*}{$\mathbf{n}$} & \multirow{2}{*}{ مجموعات العينة } \\
\hline Sig. & Coefficient & & & & \\
\hline$\cdot, Y$ & $\mathrm{t}=0.4$ & $\begin{array}{l}0, r \\
0, \xi\end{array}$ & $\begin{array}{l}r o, 0 \\
r o, r\end{array}$ & $\begin{array}{l}171 \\
11 \varepsilon\end{array}$ & الجنس : ذكور \\
\hline$\cdot, \vee$ & $\mathrm{t}-0.4$ & $\begin{array}{l}0,0 \\
0,1\end{array}$ & $\begin{array}{l}r o, r \\
r o, 0\end{array}$ & $\begin{array}{l}r \cdot r \\
\text { IEr }\end{array}$ & 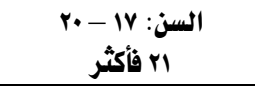 \\
\hline$\bullet, \cdot r$ & $\mathrm{f}=2.8$ & $\begin{array}{l}r, 1 \\
r, r \\
0, r \\
\xi, \Lambda \\
\eta, 1 \\
\xi, r\end{array}$ & $\begin{array}{l}r o \\
r q, \Lambda \\
r q, \varepsilon \\
r \varepsilon, 1 \\
r r, 0 \\
r 0,0\end{array}$ & $\begin{array}{l}Y \gamma \\
\$ \varepsilon \\
71 \\
71 \\
Y A \\
7 .\end{array}$ & المحافظة: العاصمة \\
\hline$\cdot, 7$ & $f=1.5$ & $\begin{array}{l}7, Y \\
\xi, 0 \\
0, Y \\
\xi, \eta\end{array}$ & $\begin{array}{l}0,1 \\
r 0,7 \\
r q \\
r q\end{array}$ & $\begin{array}{l}91 \\
A 1 \\
A r \\
A T\end{array}$ & السنة اللراسية : الأولى الثانية \\
\hline$\cdot, 1$ & $\mathrm{t}=1.5$ & $\begin{array}{l}0,0 \\
\xi, 7\end{array}$ & $\begin{array}{l}r 0,1 \\
r q, r\end{array}$ & $\begin{array}{l}\text { TAT } \\
\text { Tr }\end{array}$ & نهط الوالدرية: ثنائية \\
\hline$\cdot, \cdot 0$ & $f-2.7$ & $\begin{array}{l}0 \\
0,1 \\
7,8\end{array}$ & $\begin{array}{l}r o, q \\
r q, r \\
r \varepsilon, 1\end{array}$ & $\begin{array}{l}\text { Irq } \\
\text { Irr } \\
\text { rr }\end{array}$ & مستوى التحصيل: منخفض متوسط \\
\hline & & $0, \xi$ & $r o, r$ & $r \leqslant 0$ & المجموع \\
\hline
\end{tabular}

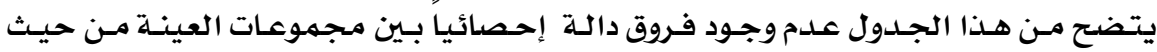

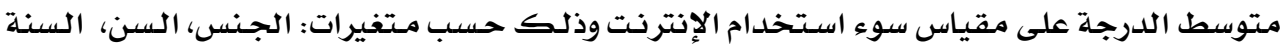

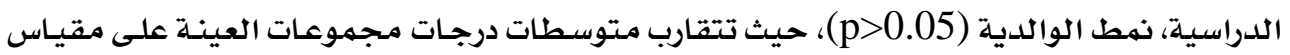

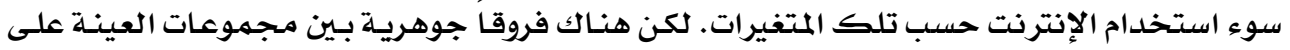

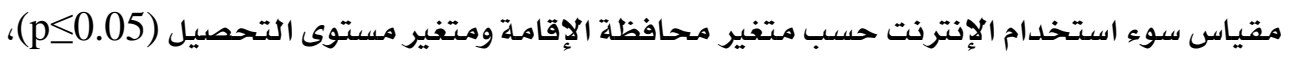

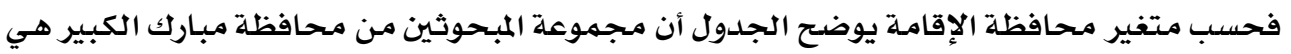

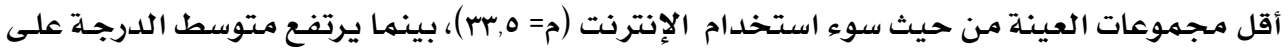

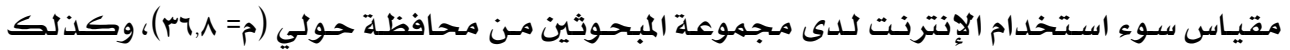

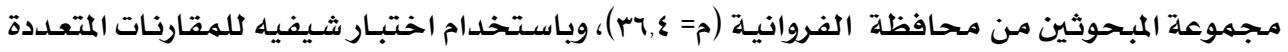
Chaffee Multi Comparison Test 
الكبير، وبقية المجموعات من المحافظات الأخرى. والخلاصة أن سوء استخدام الإنترنت ينـخفض لدى

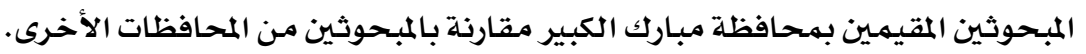

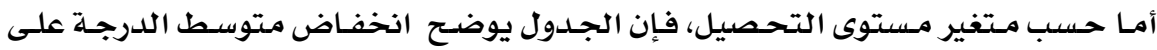

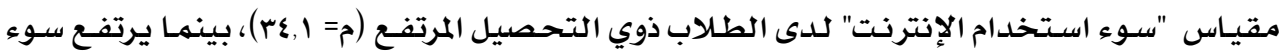

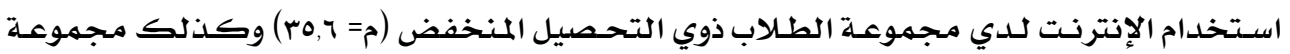

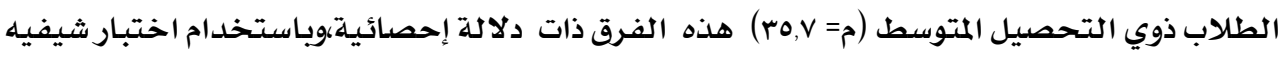

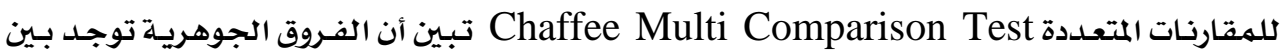

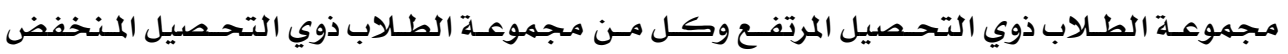

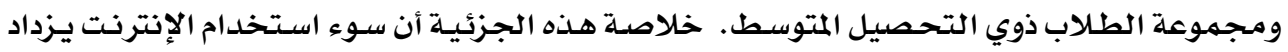

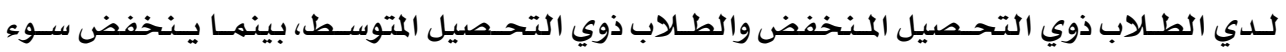

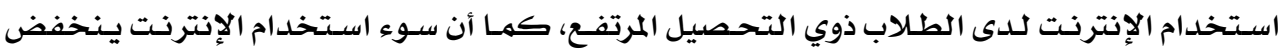

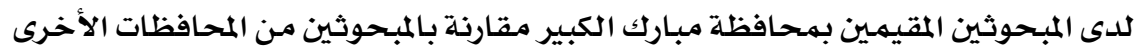

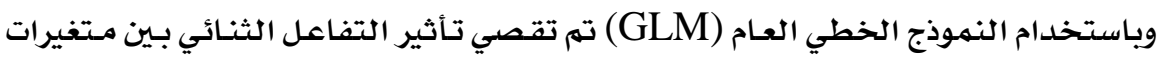

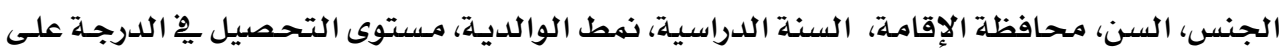

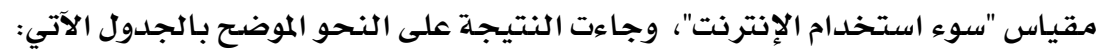

\section{جدول رقم (r)}

أثر التفاعل الثنائي بين المتغيرات المستقلة يِّ الدرجة على مقياس سوء استخدام الإنترنت

\begin{tabular}{|c|c|c|c|c|c|}
\hline Sig. & f. value & درجة الحرية & متوسط المربعات & مجموع المربعات & التفاعل الثنائي \\
\hline$\cdot r$ & $\cdot, \wedge \varepsilon$ & 1 & $r \xi, 1$ & rะ, & الجنس× السن \\
\hline$\cdot, r$ & $\cdot, A r$ & 0 & rr & $11 \mathrm{r}$ & الجنس × المحافظة \\
\hline$\cdot, 0$ & $\cdot, 79$ & $r$ & 19,1 & $\Delta 9, \xi$ & الجنس× السنة الدراسية \\
\hline$\cdot, 7$ & $\cdot, 07$ & $r$ & 17 & $\xi \vee, \wedge$ & الجنس× نهط الوالدية \\
\hline$\cdot, 0$ & $\cdot, 07$ & $r$ & 17,1 & rr, r & الجنس× مستوى التحصيل \\
\hline$\cdot, r$ & 1,0 & 0 & $\xi r, Y$ & rir,v & السن × المحافظة \\
\hline$\cdot, \cdot \wedge$ & $r, 1$ & $r$ & $71, Y$ & $110, r$ & السز × السنة الدراسية \\
\hline$\cdot, r$ & 1,1 & 1 & $r, \Lambda$ & $r i, \Lambda$ & السن × نهط الوالدية \\
\hline$\cdot, \wedge$ & $\cdot$, ir & $r$ & $r, 7$ & $v, r$ & السن × مستوى التحصيل \\
\hline$\cdot, 7$ & $\cdot, \wedge \varepsilon$ & 10 & $r r, O$ & orr & المحافظة × السنة الدراسية \\
\hline$\cdot, \wedge$ & $\cdot, Y 7$ & 0 & $v, r$ & $r q, \Lambda$ & المحافظة × نهط الوالدية \\
\hline$\cdot, \wedge$ & $\cdot, 0\}$ & 1. & 10,1 & 101 & المحافظة × مستوى التحصيل \\
\hline$\cdot, 7$ & $\cdot, 07$ & $r$ & 10,9 & $\xi \vee, \Lambda$ & السنة اللدراسية × نغط الوالدية \\
\hline$\cdot, \mathrm{Y}$ & $\cdot$, Vr & 9 & $r \cdot, 0$ & $M \uparrow, Y$ & السنة الدراسية × مستوى التحصيل \\
\hline$\bullet, 1$ & 1,9 & $r$ & $r \wedge, r$ & $171, r$ & نهط الواللدية× مستوى التحصيل \\
\hline
\end{tabular}




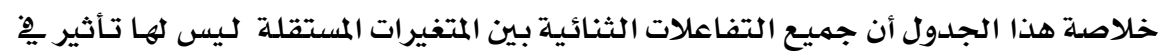

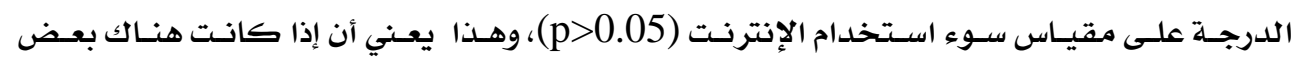

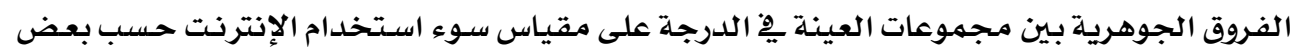

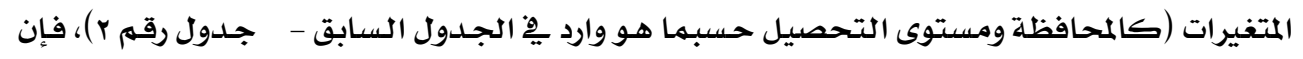

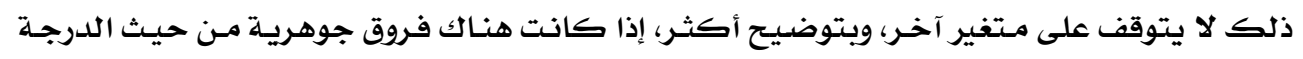

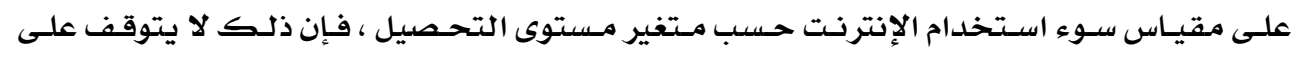

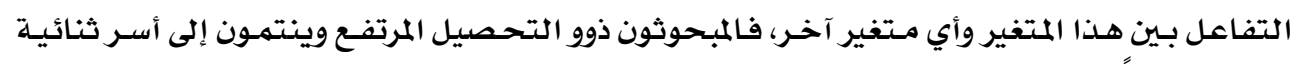

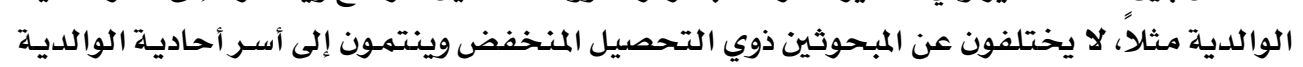

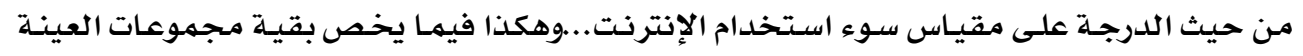

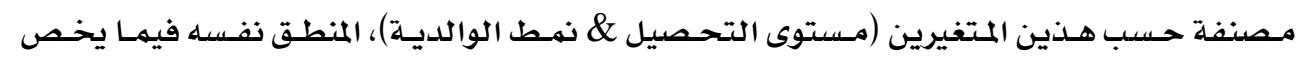

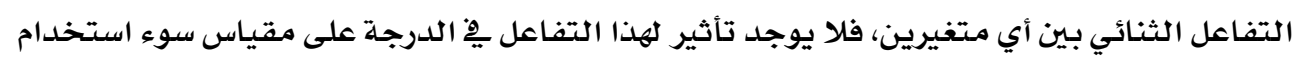
الإنترنت.

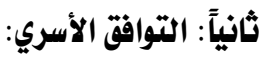

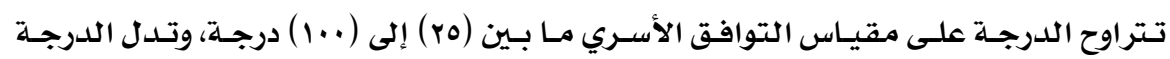

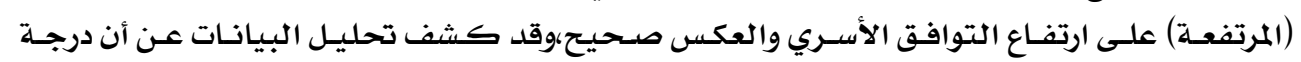

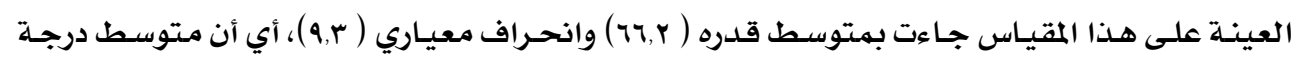

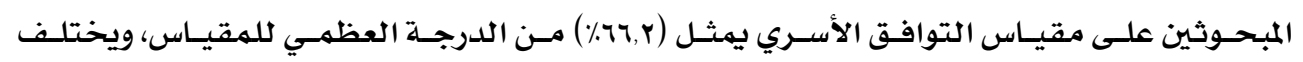

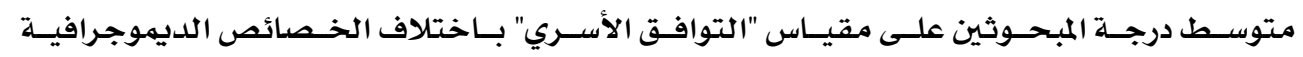

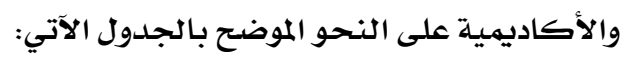


جدول رقم (ع)

معنوية الفروق بين مجموعات العينة من حيث متوسط الدرجة على مقياس التوافق الأسري

\begin{tabular}{|c|c|c|c|c|c|}
\hline \multicolumn{2}{|c|}{ Statistics } & \multirow[b]{2}{*}{ STD } & \multirow{2}{*}{ Mean } & \multirow{2}{*}{$\mathrm{n}$} & \multirow{2}{*}{ مجموعات العينة } \\
\hline Sig. & Coefficient & & & & \\
\hline \multirow{2}{*}{$\cdot, 9$} & \multirow{2}{*}{$t=0.7$} & 9,1 & 79,1 & 171 & الجنس : ذكور \\
\hline & & $\Lambda, \mathrm{V}$ & $70, r$ & $1 \wedge \varepsilon$ & إناث \\
\hline \multirow{2}{*}{$\cdot, r$} & \multirow{2}{*}{$\mathrm{T}=0.9$} & $\Lambda, 7$ & 79,7 & $r \cdot r$ & السز: r - r r \\
\hline & & $1 \cdot, 1$ & $70, \xi$ & IEr & 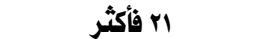 \\
\hline \multirow{6}{*}{$\cdot, r$} & \multirow{6}{*}{$f=1.5$} & $\Lambda, 0$ & $T V, r$ & Tr & المحافظة: العاصمة \\
\hline & & ir & $7 r, \Lambda$ & $\llbracket \xi$ & 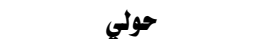 \\
\hline & & 9,7 & 79,1 & 71 & 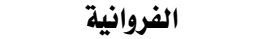 \\
\hline & & $\Lambda, \Lambda$ & IV & 71 & الجهراء - - ل الجهاي \\
\hline & & $\checkmark, 0$ & 79 & ra & مبارك الكبير \\
\hline & & $\Lambda$ & IV & 7. & الأحمدي \\
\hline \multirow{5}{*}{$\cdot, 7$} & \multirow{5}{*}{$f=0.6$} & & & & السنة الدراسية : الأولى \\
\hline & & $\vee, \xi$ & 14, $\vee$ & 91 & الثانية \\
\hline & & $1+, 0$ & 79,8 & A) & الثالثة \\
\hline & & A,Z & 11,0 & AT & الرابعة الرة \\
\hline & & II & 90 & AT & الخامسة \\
\hline \multirow{2}{*}{$\bullet, \cdots 1$} & \multirow{2}{*}{$t=3.4$} & $\Lambda, \vee$ & iv & rar & ننط الوالدية: ثنائية \\
\hline & & $1 \cdot, \Lambda$ & $\pi r, r$ & ir & منفردة \\
\hline \multirow{4}{*}{$\cdot, \mathrm{r}$} & \multirow{3}{*}{$f-.32$} & $1 \cdot, \xi$ & $70, \mathrm{r}$ & $1+9$ & مستوى التحصيل: منخفض \\
\hline & & $\Lambda, 0$ & 79,7 & IrT & متوسط \\
\hline & & $\Lambda, \varepsilon$ & $79, r$ & rr & مرتفع \\
\hline & & $9, r$ & $77, r$ & r\&o & 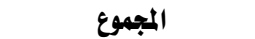 \\
\hline
\end{tabular}

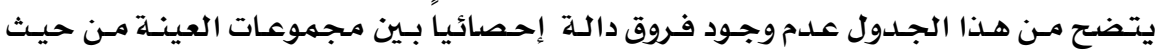

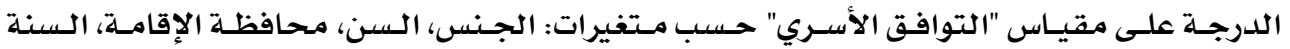

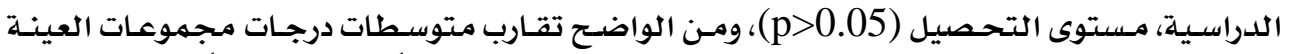

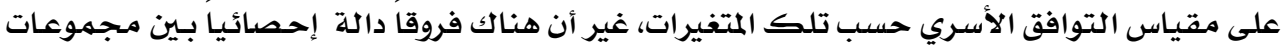

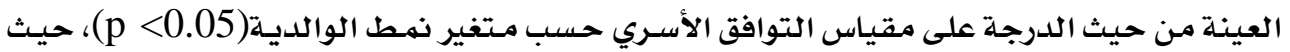

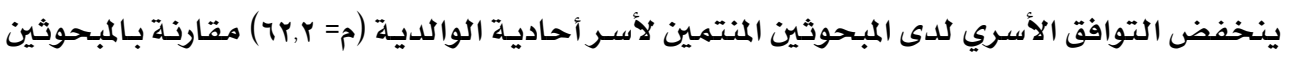

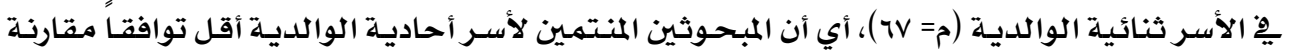

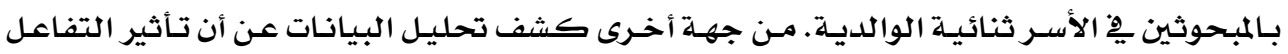

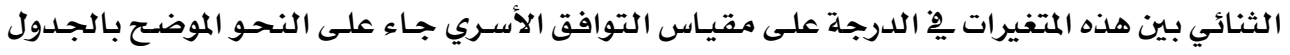


جدول رقم (0)

أثر التفاعل الثنائي بين المتغيرات المستقلة ـِ الدرجة على مقياس التوافق الأسري

\begin{tabular}{|c|c|c|c|c|c|}
\hline Sig. & f. value & درجة الحرية & متوسط & مجموع المربعات & التفاعل الثنائي \\
\hline$\cdot, r$ & 1,9 & 1 & 177,7 & 177,7 & الجنس× السز \\
\hline$\cdot, \cdot r$ & $r, 0$ & 0 & $r+, 0$ & $1.0 \xi$ & الجنس المحافظة \\
\hline$\cdot, r$ & $1, r$ & $r$ & $1 \cdot 1,0$ & $r \cdot \xi, 0$ & الجنس× السنة الدراسية \\
\hline$\cdot, \xi$ & $\cdot, 0$ & 1 & $\{r, \wedge$ & $\{r, \wedge$ & الجنس× نفط الوالدية \\
\hline$\cdot, 0$ & $\cdot, 7$ & r & $\varepsilon \wedge, 0$ & ar & الجنس × مستوى التحصيل \\
\hline , r & 1,7 & 0 & $1+\Lambda, 0$ & $79 r, 7$ & السن × المحافظة \\
\hline$\cdot, \vee$ & $\cdot, r$ & $r$ & $r q, 1$ & rA,r & السن × السنة الدراسية \\
\hline$\cdot, v$ & • Ir & 1 & $1 \cdot, 7$ & $1 \cdot, 7$ & السن × نمط الوالدية \\
\hline$\cdot r$ & $1, r$ & r & $1 \cdot v, 7$ & M10,1 & السن × مستوى التحصيل \\
\hline$\cdot, r$ & $1, r$ & 10 & $9 \Lambda, 7$ & levo & المحافظةج السنة الدراسية \\
\hline$\cdot, \mathrm{V}$ & $\cdot, 7$ & 0 & $\{7, \xi$ & rmr & المحافظة× نمط الوالدية \\
\hline$\cdot, 7$ & $\cdot, \Lambda$ & 1. & 79,0 & $770, r$ & المحافظة× مستوى التحصيل \\
\hline$\cdot, \mathrm{V}$ & $\cdot, \xi Y$ & $r$ & $\xi$ & ir. & السنة الدراسية × نمط الوالدية \\
\hline$\cdot, r$ & $1, r$ & 7 & $1 . \varepsilon$ & Trr, r & السنة الدراسية × مستوى التحصيل \\
\hline$\cdot, \vee$ & • & $r$ & rq & $\Delta \Lambda$ & نمط الوالدية × مستوى التحصيل \\
\hline
\end{tabular}

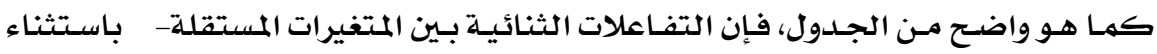

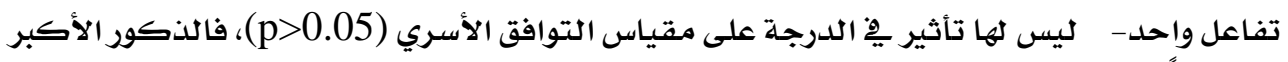

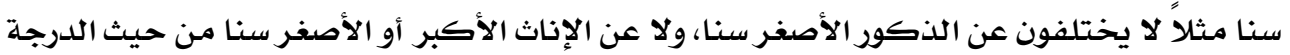

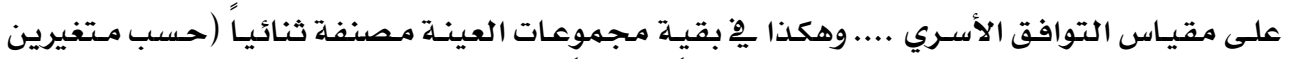

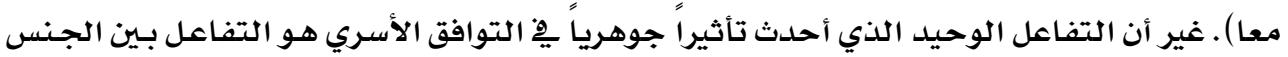

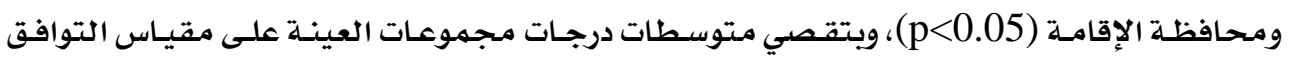

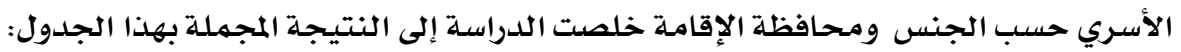


جدول رقم (7)

متوسطات درجات مجموعات العينة يِّ التوافق الأسري حسب الجنس ومحافظة الإقامة

\begin{tabular}{|c|c|c|c|c|}
\hline \multicolumn{4}{|c|}{ الجنس } & \multirow{3}{*}{ المحافظة } \\
\hline \multicolumn{2}{|c|}{ إناث } & \multicolumn{2}{|c|}{ ذكور } & \\
\hline$\varepsilon$ & م & $\varepsilon$ & A & \\
\hline$\Lambda, 0$ & 77,1 & $\Lambda, r$ & \urcorner$\wedge, \vee$ & العاصمة \\
\hline 11,7 & 70,8 & $1 \varepsilon$ & $o v, r$ & حولي \\
\hline $9, Y$ & $7 \xi, \xi$ & 9,8 & Tr, & الفروانية \\
\hline$v, 7$ & IV,r & $9, \vee$ & 79,0 & الجهراء \\
\hline$\wedge$ & 70,8 & $v, r$ & 79,0 & مبارك الكبير \\
\hline$\eta, \Lambda$ & 71,0 & 9 & $70, r$ & الأحمدي \\
\hline
\end{tabular}

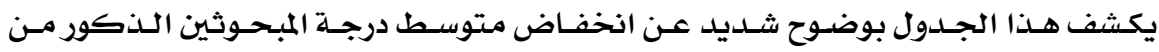

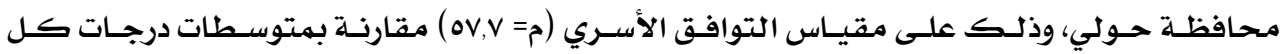

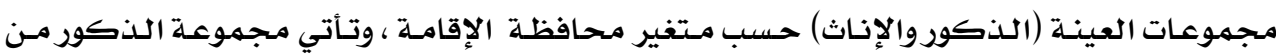

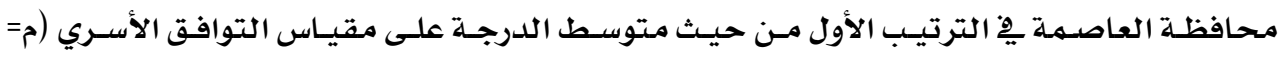

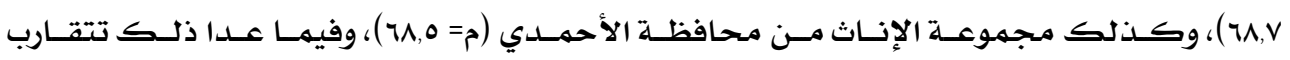

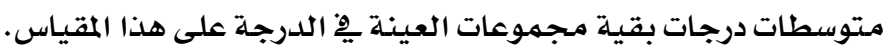
ثالثاً: سوs استخلام الإنترنت كمفسر للتوافق الأسري:

نظراً للأهمية الجوهريـة لهذه النقطة فقد تم فحصها مـن خـلال مستويـين، المستوى الأول

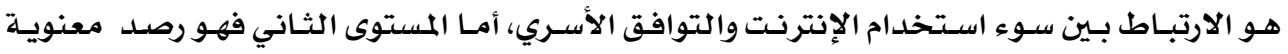

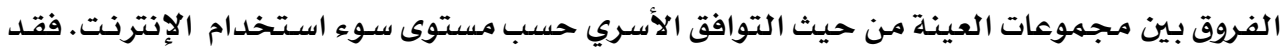

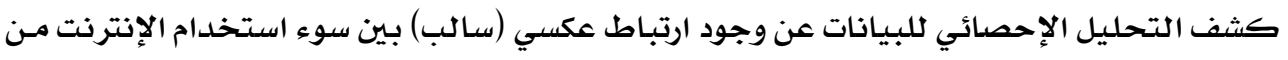

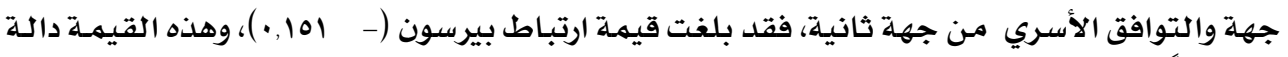

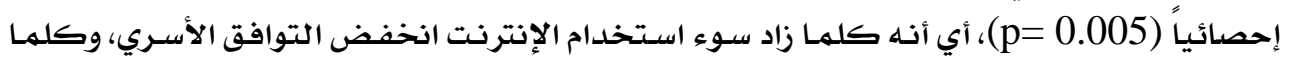

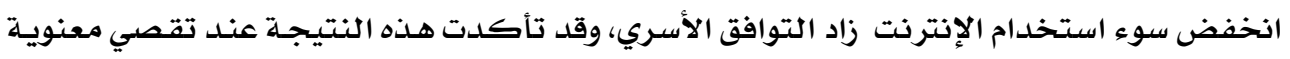

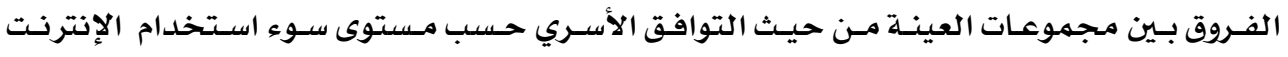

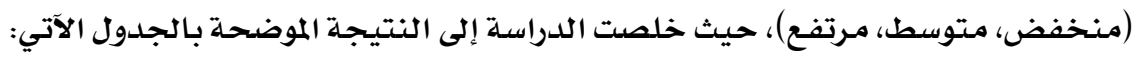


جدول رقم (v)

معنوية الفروق بين مجموعات العينة من حيث س التوافق الأسري حسب مستوى سوء استخدام الإنترنت

\begin{tabular}{|c|c|c|c|c|c|}
\hline Sig. & f. value & الانحراف المعياري & المتوسط & j & مستوى سوى استخدام الإنترنت \\
\hline \multirow{4}{*}{$\cdot, \cdot \bullet$} & \multirow{3}{*}{$0, v$} & $\Lambda, 0$ & $\eta \Lambda, \gamma$ & $7 \varepsilon$ & 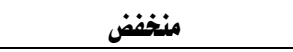 \\
\hline & & $9, \S$ & 77,1 & rma & متوسط \\
\hline & & $\Lambda, 0$ & $M r, v$ & $\varepsilon r$ & مرتفع \\
\hline & & $9, r$ & $77, r$ & r\&० & المجموع \\
\hline
\end{tabular}

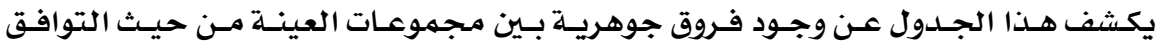

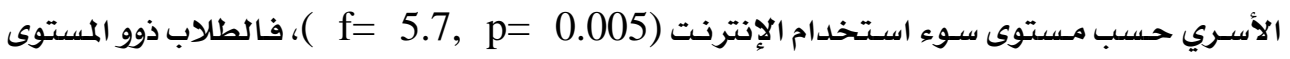

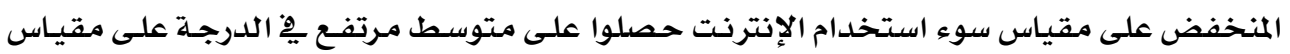

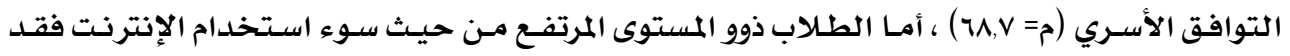

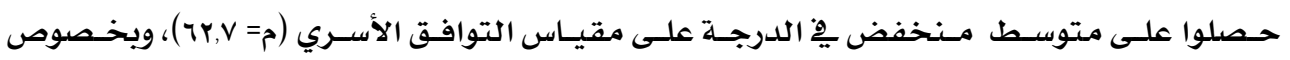

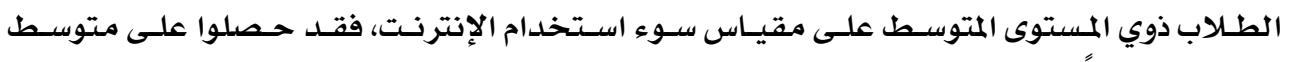

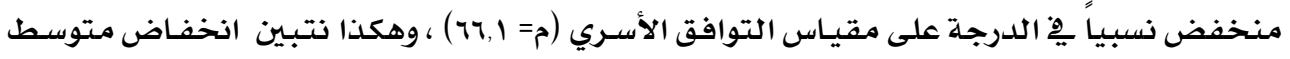

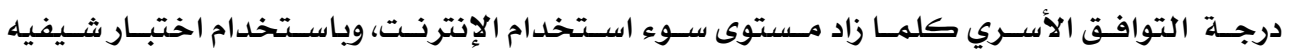

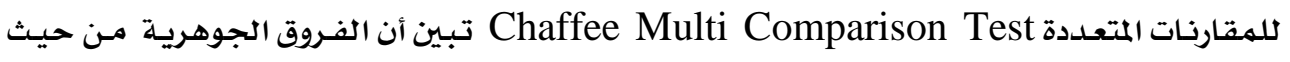

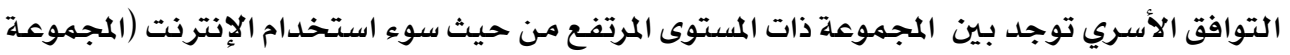

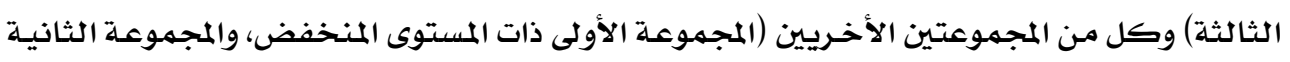

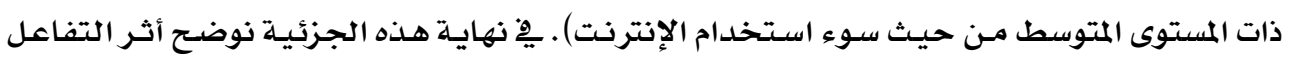

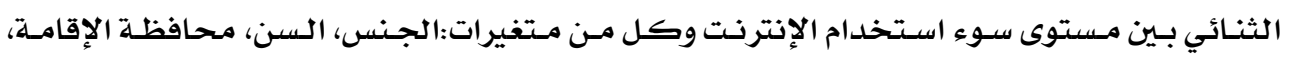

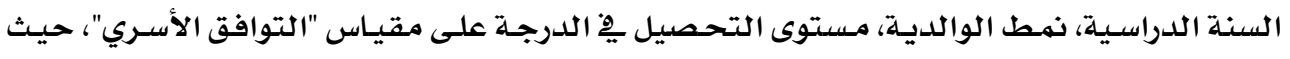

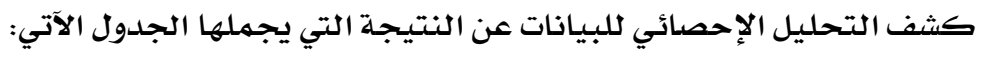
جدول رقم (A)

أثر التفاعل الثنائي بين مستوى سوء استخدام الإنترنت والمتغيرات المستقلة فِ الدرجة على مقياس التوافق الأسري

\begin{tabular}{|c|c|c|c|c|c|}
\hline Sig. & f. value & درجة الحرية & متوسط المربعات & مجموع المربعات & التفاعل الثنائي \\
\hline$\bullet, \cdot+9$ & $0, r$ & $r$ & $\{r \mid, 1$ & $\Lambda \neg r, r$ & مستوى سوs الاستخدام× الجنس \\
\hline$\cdot, r$ & 1,1 & $r$ & 101,7 & $r \cdot r, \xi$ & مستوى سوى الاستخدام× السن \\
\hline$\cdot, 9$ & $\bullet, \S 1$ & 1. & ro, r & ror & مستوى سوs الاستخدام× المحافظة \\
\hline$\cdot, 0$ & $\cdot, 9$ & 9 & vo,1 & $\$ 0 \cdot, \Lambda$ & مستوى سوs الاستخدام× السنة الدراسية \\
\hline$\cdot, \wedge$ & $\cdot, 11$ & r & 10,1 & $r \cdot, 0$ & مستوى سوs الاستخدام× نفط الواللدية \\
\hline$\cdot, \Lambda$ & $\cdot, r$ & $\varepsilon$ & $r v, 0$ & 11. & مستوى سوى الاستخدام× مستوى التحصيل \\
\hline
\end{tabular}


باستثناء تفاعل ثنائي واحد (وهو التفاعل الأول يِّ الجـدول)، فإن التفـاعلات الثنائيـة بـين

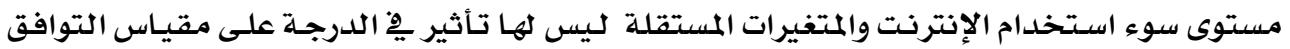

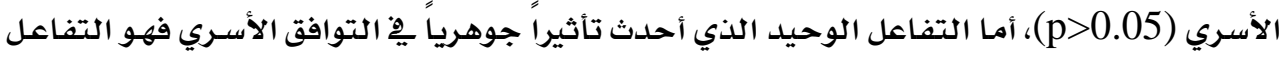

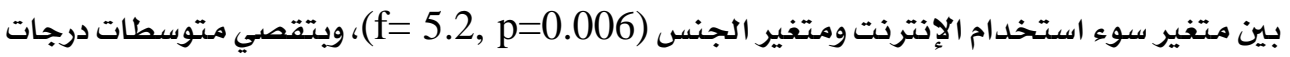

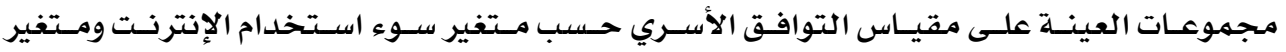

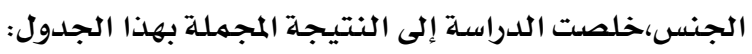

جدول رقم (a)

متوسطات درجات مجموعات العينة يِ التوافق الأسري حسب الجنس ومستوى سوء استخدام الإنترنت

\begin{tabular}{|c|c|c|c|c|}
\hline \multicolumn{4}{|c|}{ متوسط الدرجة على مقياس التوافق الأسري حسب الجنس } & \multirow{3}{*}{ سوك الاستخدام } \\
\hline \multicolumn{2}{|c|}{ إناث } & \multicolumn{2}{|c|}{ 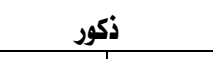 } & \\
\hline$\varepsilon$ & 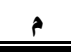 & $\varepsilon$ & 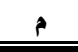 & \\
\hline$\checkmark, q$ & $\mathrm{r}, \mathrm{\Lambda}$ & $\Lambda, r$ & 70,8 & 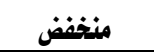 \\
\hline$\Lambda, \wedge$ & $70, \mathrm{~V}$ & $1 \cdot, r$ & $77, \vee$ & متوسط \\
\hline $7, r$ & $7 \cdot, 1$ & $1 \cdot, r$ & $7 \xi, 0$ & 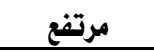 \\
\hline
\end{tabular}

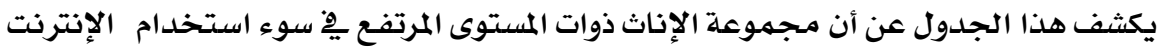

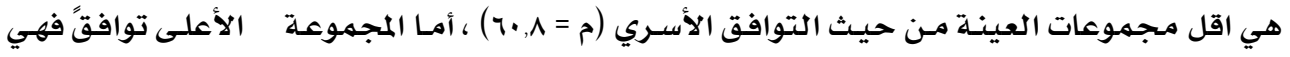

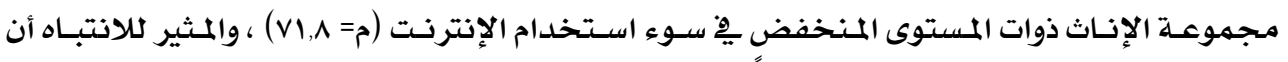

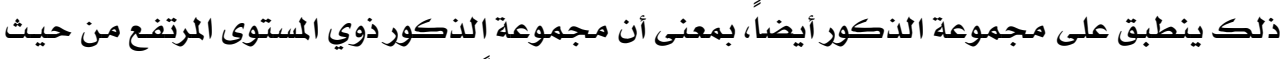

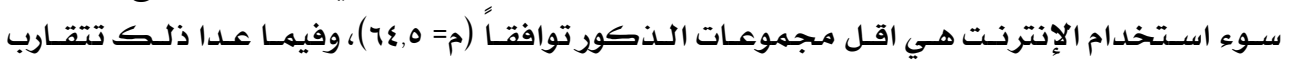

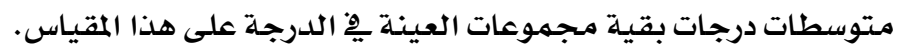
رابعاً: تحليل دالة التمايز للعلاقة بيز سور استخدام الإنترنت والتوافق الأسري:

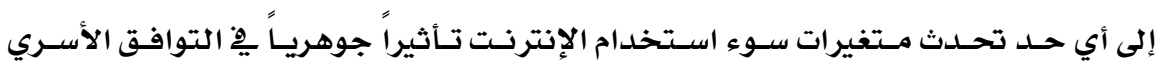

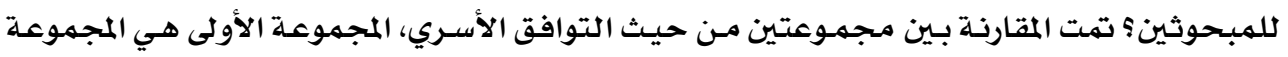

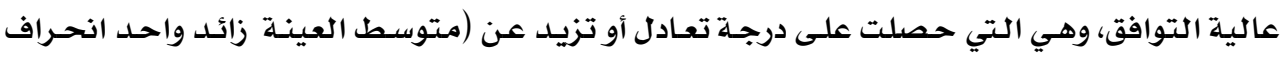

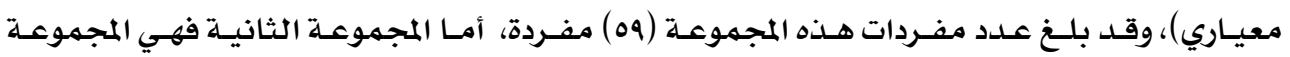

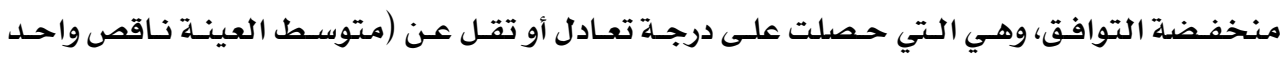

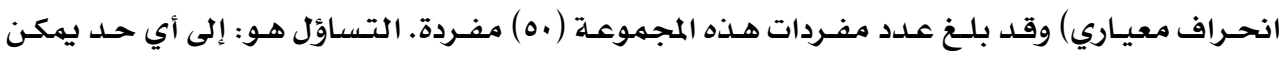

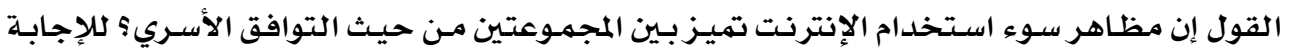

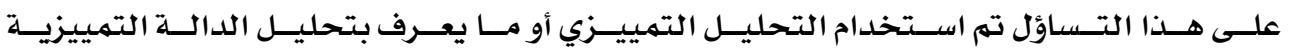
وفيما يلي توضيح إجراءات هذا التحليل: (Discriminant function analysis) 


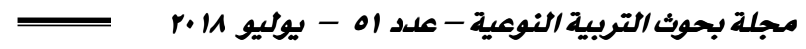

(أ) الفروق بين المجموعة مرتفعة التوافق الأسري والمجموعة منخفضة التوافق الأسري من حيث سوء

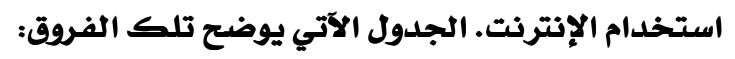

$$
\text { جدول رقم (1.) (1) }
$$

معنوية الفروق بين المجموعة مرتفعة التوافق والمجموعة منخفضة التوافق الأسري

من حيث الدرجة على مقياس سوء استخدام الإنترنت

\begin{tabular}{|c|c|c|c|c|c|c|}
\hline \multicolumn{2}{|c|}{ معنوية الفروق } & \multicolumn{2}{|c|}{ المجموعة منخفضة } & \multicolumn{2}{|c|}{ 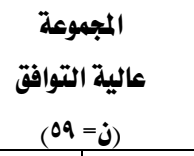 } & \multirow[t]{2}{*}{ متفيرات سوء استخدام الإنترنت } \\
\hline Sig. & $\mathrm{t}$ & $\varepsilon$ & م & $\varepsilon$ & f & \\
\hline$\cdot, \bullet \xi$ & $r, r$ & 1,1 & $r, r$ & $\cdot, 9$ & $1, Y$ & ـ زيادة مصروفات الإنترنت \\
\hline$\cdot, \cdot r$ & $r, r$ & 1 & $r, 1$ & $1, r$ & $r, Y$ & ـ اقتراض أموال بسب مصاريف الإنترنت \\
\hline$\cdot, \cdot r$ & $r, r$ & $\cdot, 7$ & $r, \Lambda$ & $\cdot, \wedge$ & $r, r$ & ـ ـ الدخول على المواقع الجنسية \\
\hline$\cdot, \cdot \bullet$ & $r, \Lambda$ & $\cdot, 9$ & $r, \Lambda$ & $\cdot, 7$ & $r, \xi$ & ـ ـ التدرب على أعمال الهاكر \\
\hline$\cdot, r$ & $1, r$ & $\cdot, \xi$ & $r, q$ & $\cdot, \wedge$ & $r, r$ & ـ ـشر أخبار كاذبة عن بعض الأشخاص \\
\hline$\cdot, \S$ & $\cdot, r$ & $1, r$ & $r, q$ & $1, r$ & $r, \mathfrak{\xi}$ & ـ قضاء ساعات طويلة مع متصلين \\
\hline$\cdot, r$ & $1, \mathfrak{\varepsilon}$ & $1, r$ & $r, q$ & 1,1 & $r, 0$ & ـ ـ انغفاض مهارات القراءة والكتابة \\
\hline$\cdot, 1$ & 1,7 & $\cdot, 9$ & $\boldsymbol{r}, \wedge \mathfrak{\varepsilon}$ & $\cdot, 9$ & $r, 0$ & ـ ـ تحميل الصور الجنسية \\
\hline$\cdot, 1$ & 1,0 & $\cdot, 1$ & $r, v$ & $\cdot, 9$ & $r, r$ & ـ إقامة علاقات مع الجنس الآخر \\
\hline$\bullet, 9$ & $\cdot, r$ & 1,1 & r,A & $1, r$ & $r, \wedge$ & ـ رفض الرقابة على الإنترنت \\
\hline$\cdot, 9$ & $\cdot, 0$ & 1,1 & $r, \xi$ & 1,1 & $r, r$ & ـ ـ الوقوع في عمليات نصب \\
\hline$\cdot, \bullet \xi$ & $r, r$ & 0,1 & ro, r & $7, \vee$ & $r r, r$ & مجموع مقياس سوء الاستخدام \\
\hline
\end{tabular}

يتضـح مـن هـذا الجـدول أن هنـاك فروقـاً جوهريـة بــين المجموعـة مرتفعـة التوافق الأسـري،

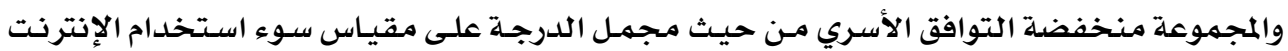

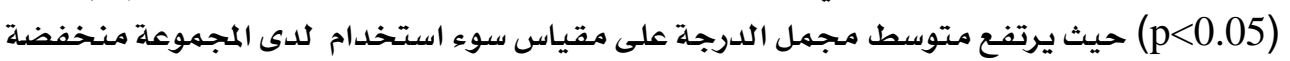

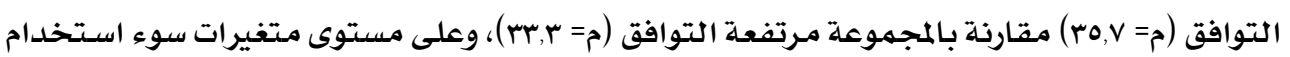

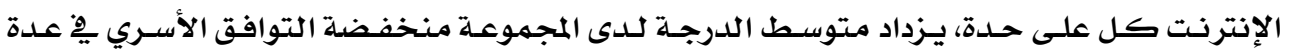

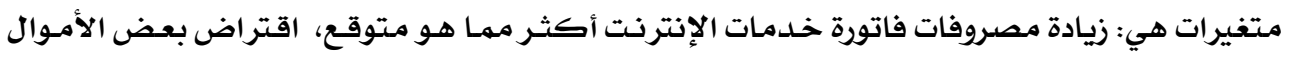

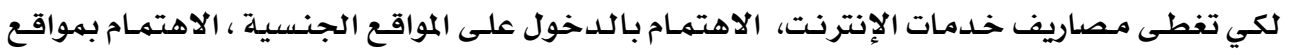

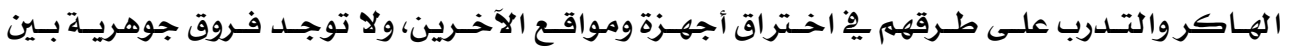

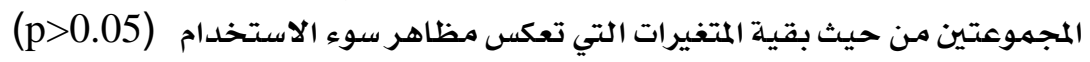


(ب) مظاهر سوء استخدام الإنترنت ذات التأثير ـِ تمايز المجموعتين من حيث التوافق الأسري

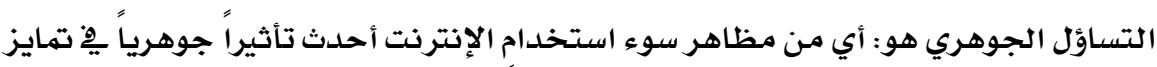

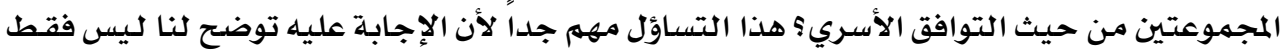

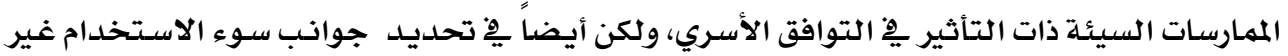

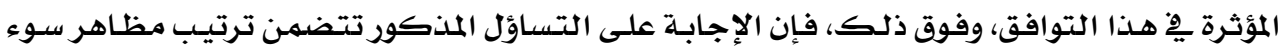

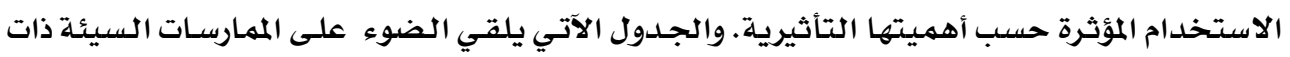

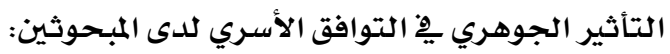

\section{جدول رقم (ii)}

مظاهر سوء استخدام الإنترنت ذات التأثير الجوهري ِِ التوافق الأسري

\begin{tabular}{|c|c|c|c|c|c|}
\hline Sig. & df2 & df1 & $\mathrm{F}$ & $\begin{array}{l}\text { Walk's } \\
\text { lambda }\end{array}$ & مظاهر سوs الاستخدام \\
\hline$\bullet, \bullet \xi$ & $1 \cdot v$ & 1 & $\varepsilon, 1$ & $\cdot, 97$ & زيادة مصروفات الإنترنت \\
\hline$\bullet,+r$ & $1 \cdot v$ & 1 & 0 & $\cdot, 90$ & اقتراض أموال بسب مصاريف الإنترنت \\
\hline$\cdot, \cdot r$ & $1 \cdot v$ & 1 & $0, \S$ & $\cdot, 90$ & الدخول على المواقع الجنسية \\
\hline$\cdot, \cdot \bullet$ & $1 \cdot v$ & 1 & $\wedge, 1$ & $\cdot 94$ & التدرب على أعمال الهاكر \\
\hline$\bullet, \cdot \xi$ & $1 \cdot v$ & 1 & $\xi\rceil$, & $\cdot, 99$ & نشر أخبار كاذبة عن بعض الأشخاص \\
\hline$\cdot, \bullet \xi$ & $1 \cdot v$ & 1 & $\xi, \uparrow$ & $\cdot, 91$ & قضاء ساعات طويلة مع متصلين \\
\hline$\bullet, 乏$ & $1 \cdot v$ & 1 & $r, 1$ & $\cdot, 9 r$ & انخفاض مهارات القراءة والكتابة \\
\hline$\cdot, r$ & $1 \cdot v$ & 1 & $r, Y$ & $\cdot, 99$ & تحميل الصور الجنسية \\
\hline$\cdot, 1$ & $1 \cdot v$ & 1 & $r, Y$ & $\cdot, 97$ & إقامة علاقات مع الجنس الآخر \\
\hline$\cdot, 1$ & $1 \cdot v$ & 1 & $\cdot, r$ & 1 & رفض الرقابة على الإنترنت \\
\hline$\cdot, 0$ & $1 \cdot v$ & 1 & $\cdot, \cdot \cdot r$ & 1 & الوقوع في عمليات نصب \\
\hline$\bullet, \bullet \xi$ & $1 \cdot v$ & 1 & $\S, 1$ & $\cdot, 90$ & المجموع \\
\hline
\end{tabular}

يكشف هـذا الجـدول بوضـوح عن أن هنـاك عدة جوانب سـوء استخدلـام الإنترنت ذات التأثير

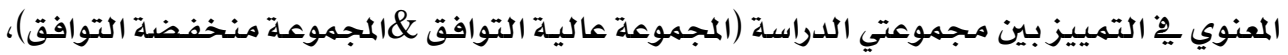

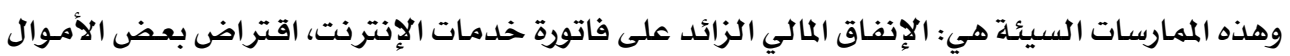

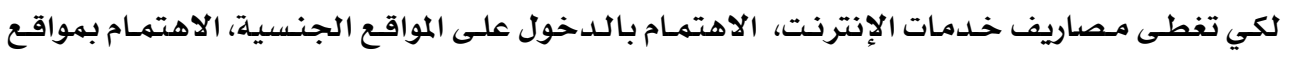

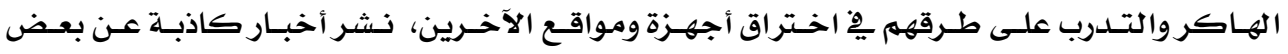

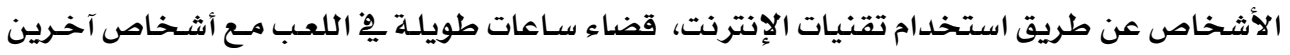

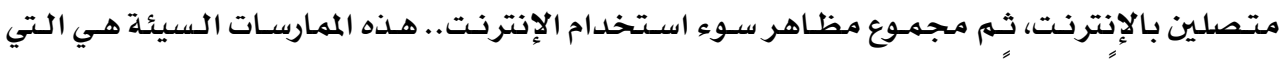

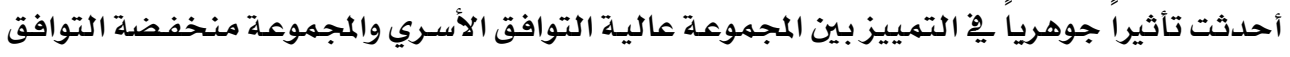

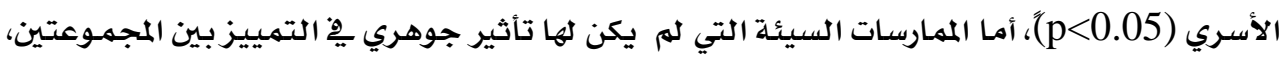


فإنها : انخفـاض مهارات القـراءة والكتابـة بسببـ الاسـتمرار فِ اسـتخدام الإنترنت، تحميـل الـصور

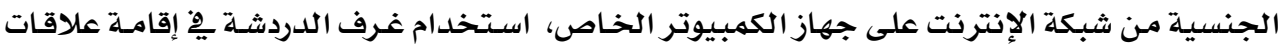

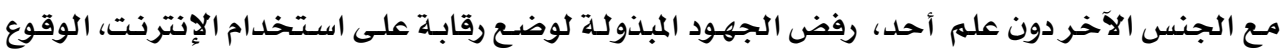

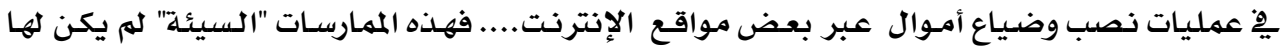

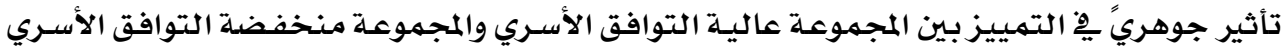

\section{(ج) اختبار معنوية دالة التمييز المستخرجة:}

تم اختبار معنوية دالة التمايز المستخرجة، وقد كشف تحليل البيانات عن أن مؤشرات قوة

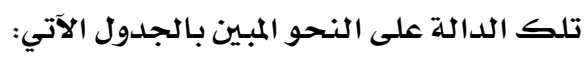

\section{جدول رقم (ir)}

\section{اختبار قوة الدالة التمييزية المستخرجة}

\begin{tabular}{|c|c|}
\hline القيمة & المؤشرات الإحصائية \\
\hline •, ror & الجذر الكامن \\
\hline$\%$ & \% من التباين المفسر \\
\hline$\cdot, \leqslant \leqslant q$ & الارتباط القانوني \\
\hline$\cdot, \vee \vee 99$ & Wilk's Lambda \\
\hline ir & YIS \\
\hline$\cdot, \cdots$ & الدلالة \\
\hline
\end{tabular}

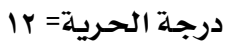

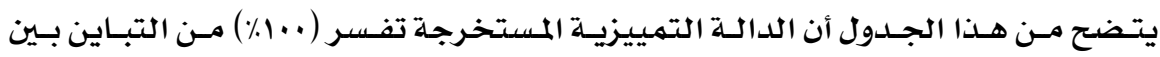

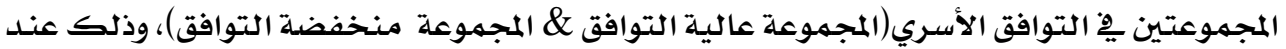

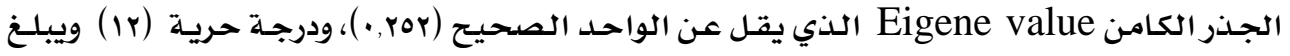

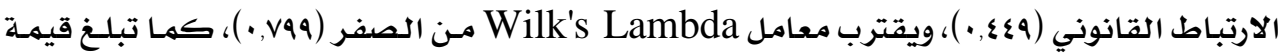

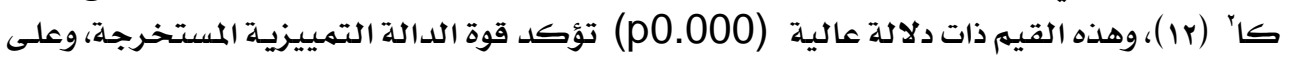

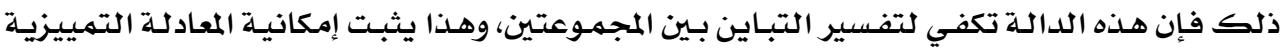

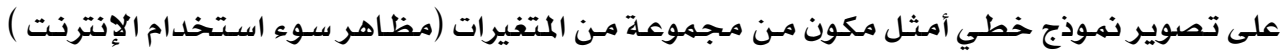

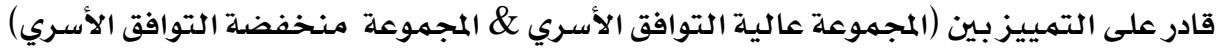

\section{(د) تفسير المعاملات التمييزية المعيارية:}

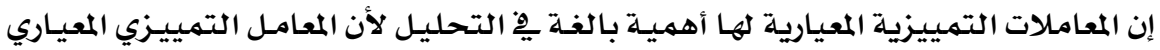

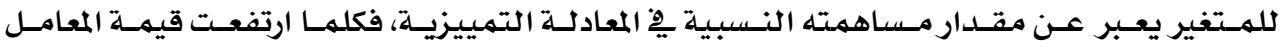

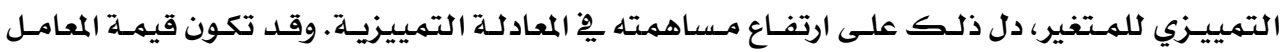


المعياري التمييزي موجبة أو سالبـة، والجدول الآتي يوضح المعاملات التمييزية المعيارية لكل متغير من متتغيرات سوء استخدام الإنترنت:

\section{جدول رقم (ir)}

المعاملات التمييزية المعيارية لمتغيرات سوء استخدام الإنترنت

\begin{tabular}{|c|c|}
\hline المعامل التمييزي & مظاهر سوء استخدام الإنترنت \\
\hline$\cdot, r \leqslant 0$ & ـ زيادة مصروفات الإنترنت \\
\hline$\cdot, \cdot v$ & ـ اقتراض أموال بسب مصاريف الإنترنت \\
\hline$\cdot, r r$ & ـ الدخول على المواقع الجنسية \\
\hline$\cdot,\{\wedge\rceil$ & ـ التدرب على أعمال الهاكر \\
\hline$\cdot, \mid r \wedge$ & ـ نشر أخبار كاذبة عن بعض الأشخاص \\
\hline$\bullet$, rII. & ـ قضاء ساعات طويلة مع متصلين \\
\hline$\cdot, V_{-}$ & ـ ـ انخفاض مهارات القراءة والكتابة \\
\hline$\cdot, \cdot \xi r_{-}$ & ـ ـ تحميل الصور الجنسية \\
\hline$r,+1$ & ـ إقامة علاقات مع الجنس الآخر \\
\hline •,rir. & ـ ـ رفض الرقابة على الإنترنت \\
\hline$\cdot$, rA_ & ـ ـ الوقوع في عمليات نصب \\
\hline$\cdot, \wedge \mathrm{V}$ & 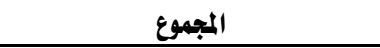 \\
\hline
\end{tabular}

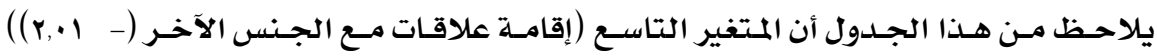

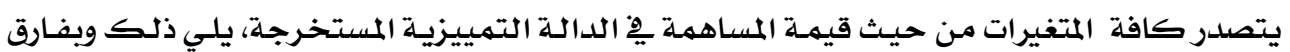

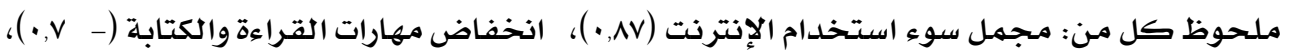

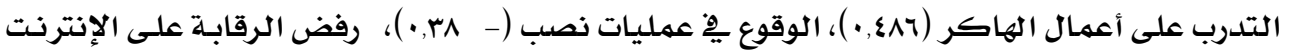

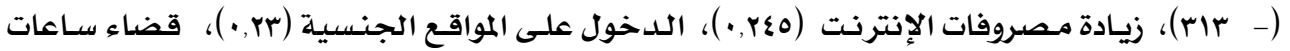

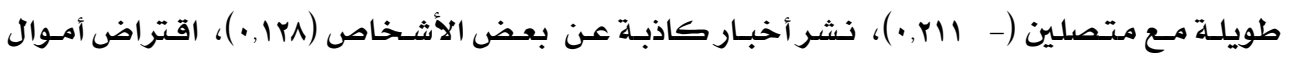

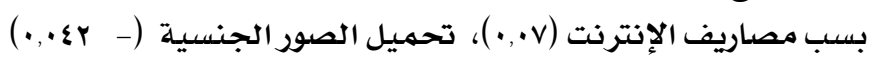
(ه) حساب احتمال التصنيف الصحيح

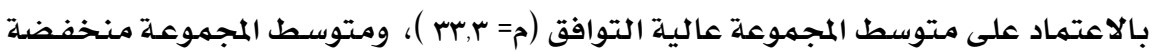

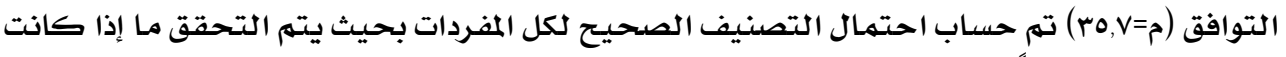

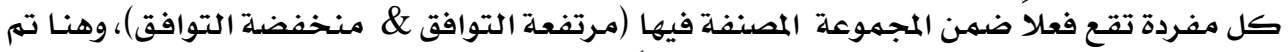

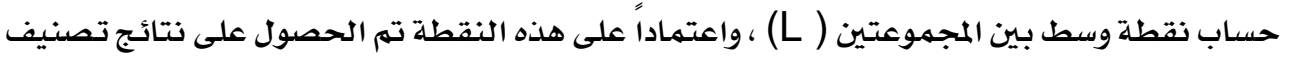

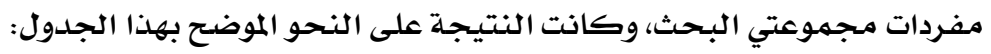




$$
\text { جدول رقم ( } 1 \text { (1) }
$$

احتمال التصنيف الصحيح لمفردات مـجموعتي البحث

\begin{tabular}{|c|c|c|c|}
\hline \multirow[b]{2}{*}{ المجموع } & \multicolumn{2}{|c|}{ عضوية المجموعة المتنبأ بها } & \multirow{2}{*}{ المجموعة } \\
\hline & منخفضة التوافق & عالية التوافق & \\
\hline$\Delta 9$ & 19 & $\xi$. & عالية التوافق \\
\hline 0. & rq & 11 & منخفضة التوافق \\
\hline
\end{tabular}

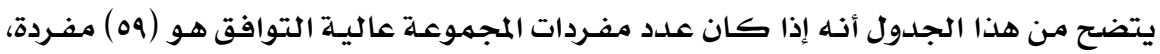

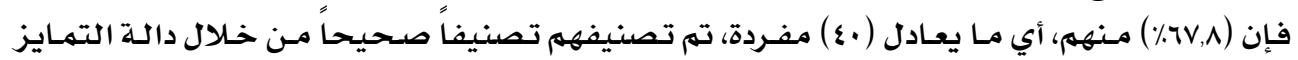

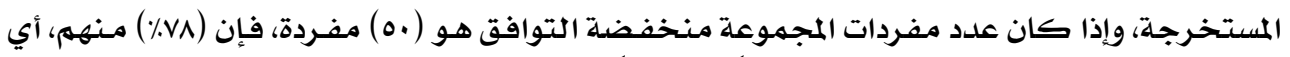

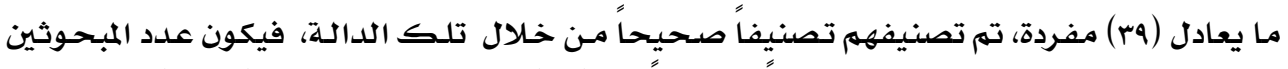

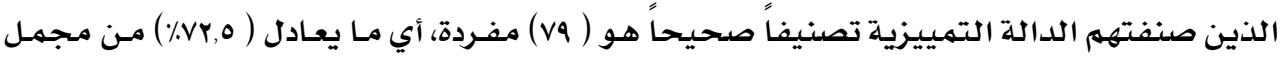

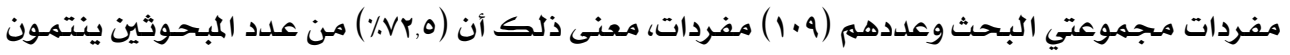

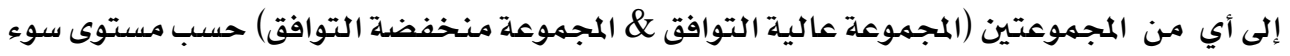

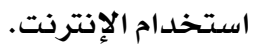

\section{التحقق من فروض الدراسة:}

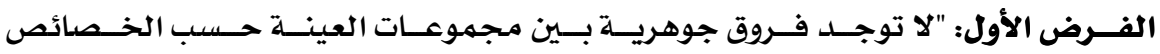

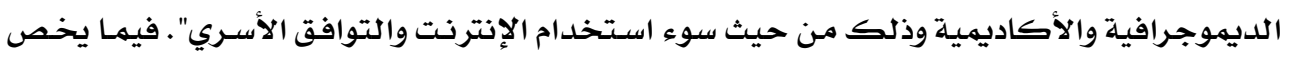

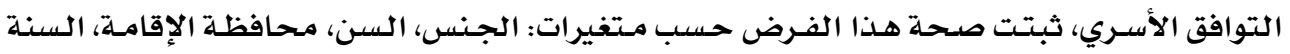

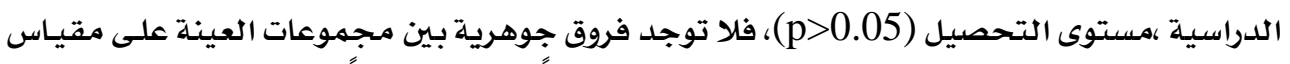

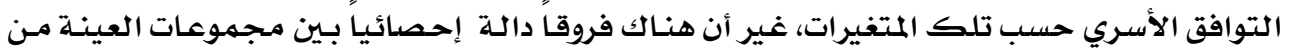

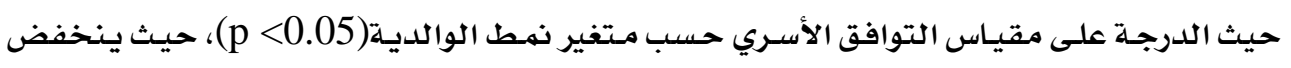

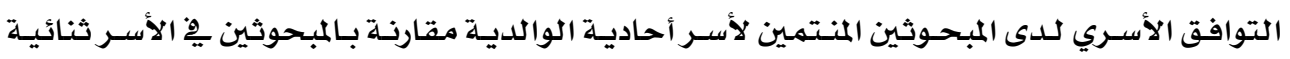

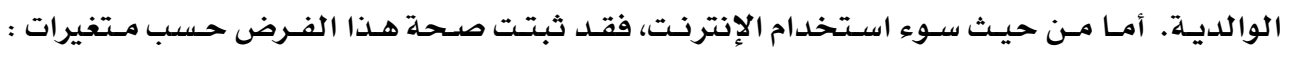

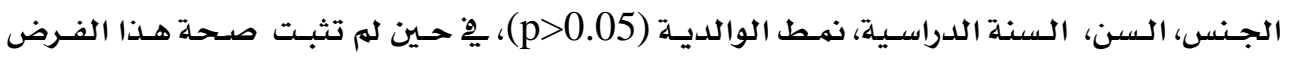

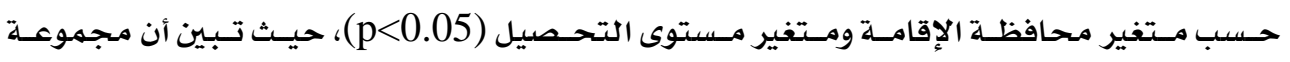

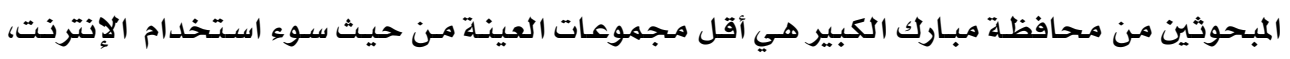

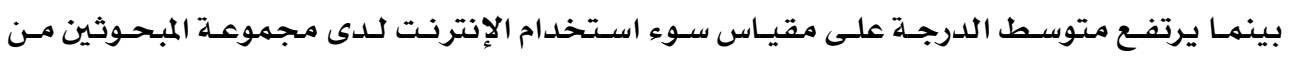

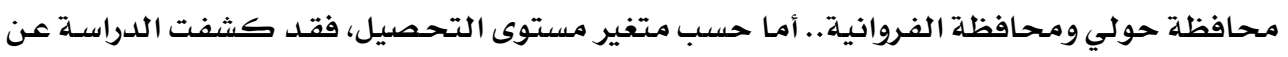

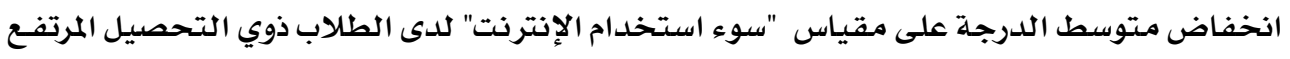

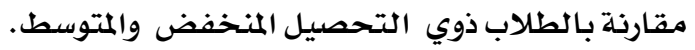




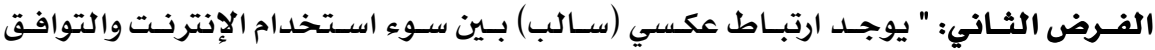

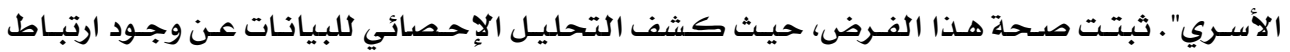

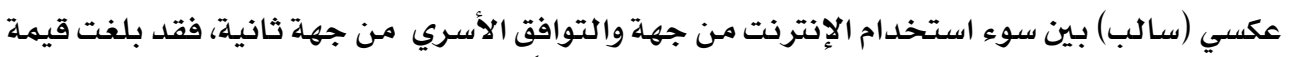

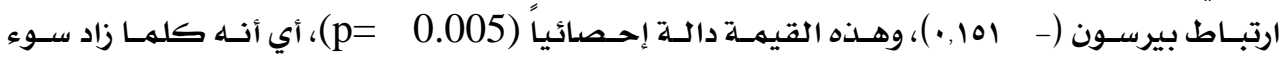

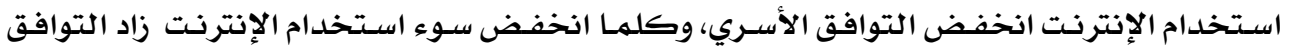
الأسري.

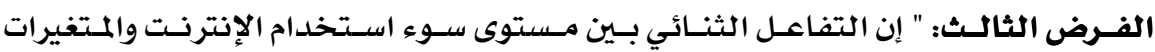

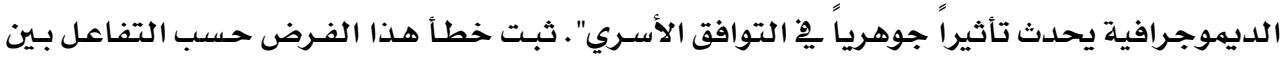

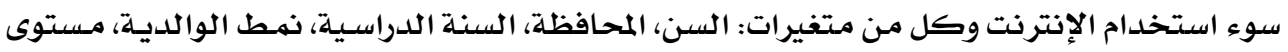

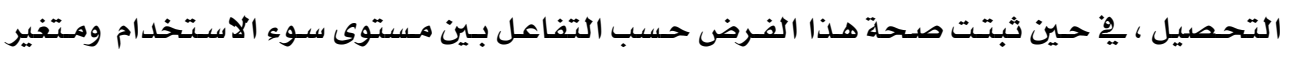

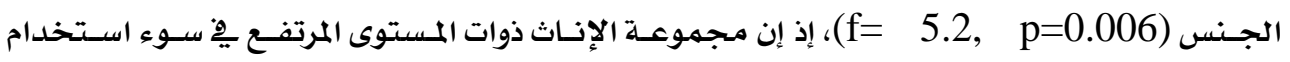
الإنترنت هي اقل مجموعات العينة من حيث التوافق الأسري.

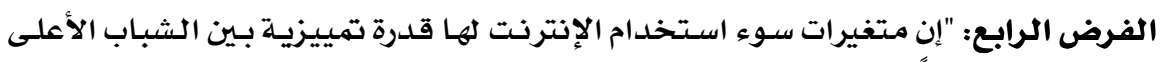

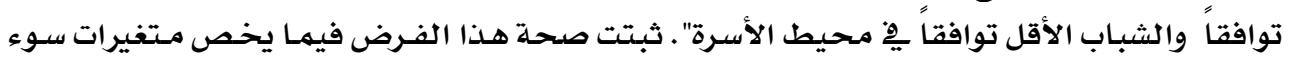

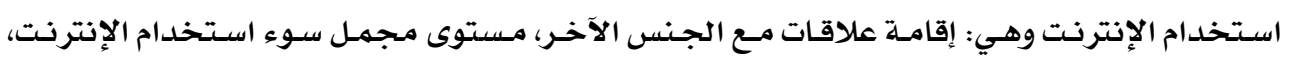

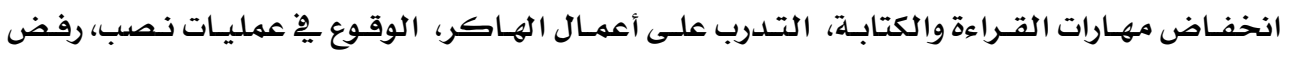

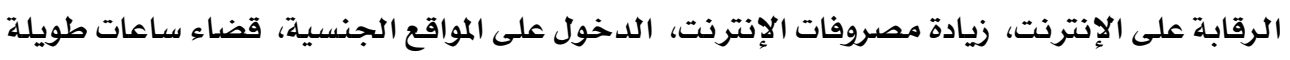

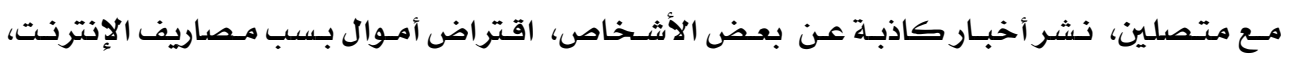

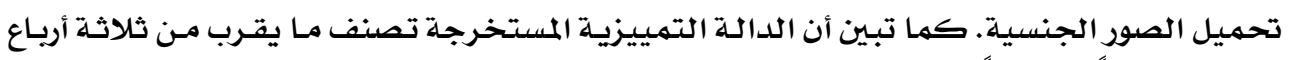

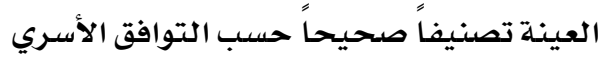
خلاصة اللدراسة:

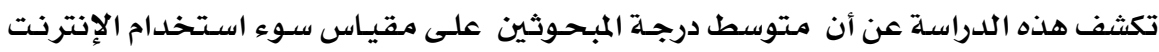

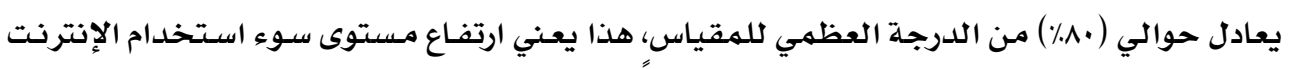

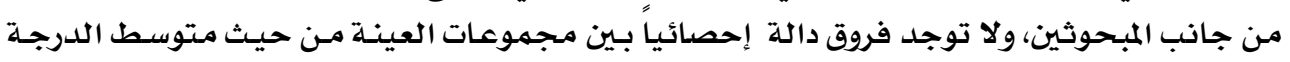

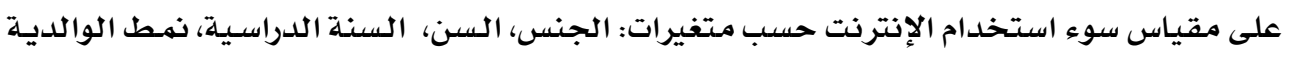

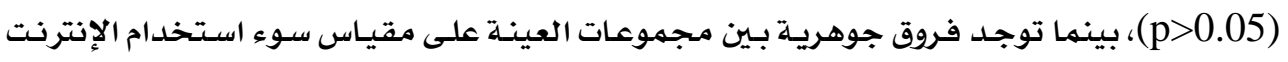

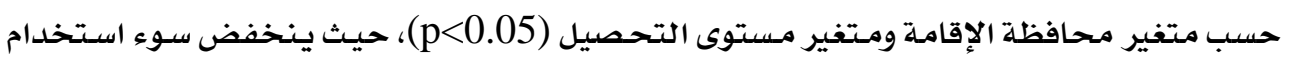

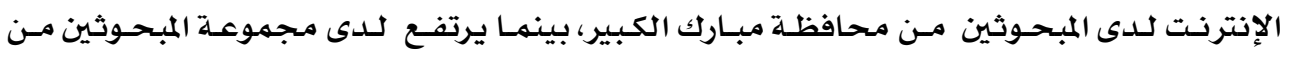

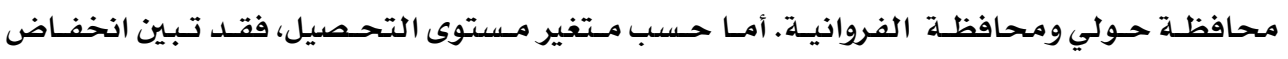

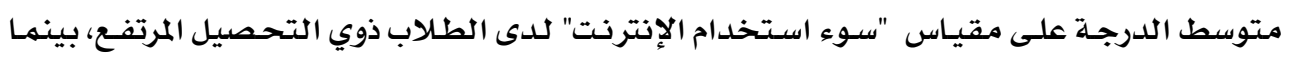

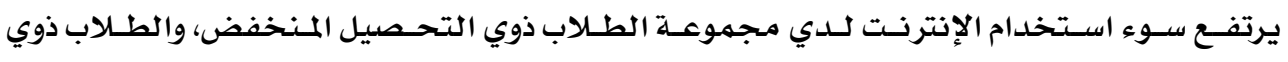

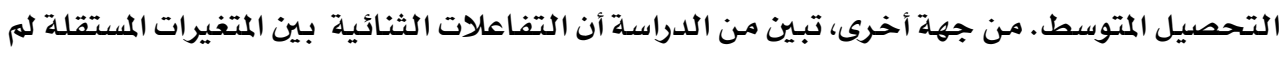


يكن لها تأثير يِّ الدرجة على مقياس سـوء اسـتخدام الإنترنت. ومـن حيث التوافق الأسـري تبين مـن

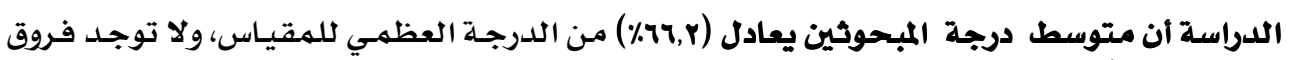

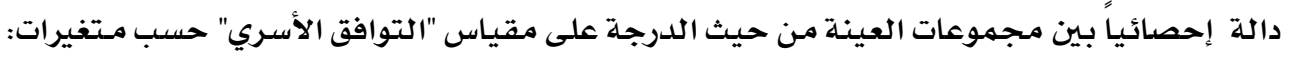

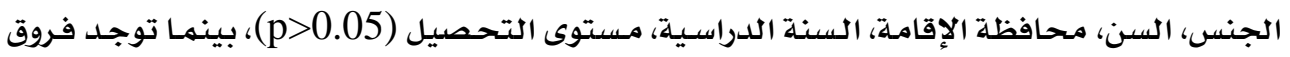

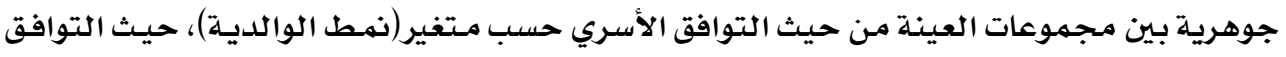

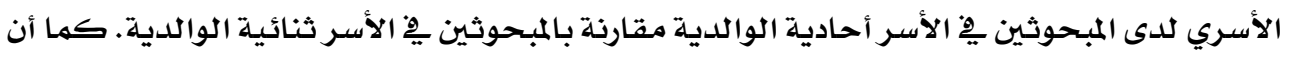

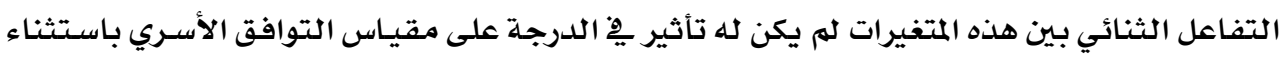

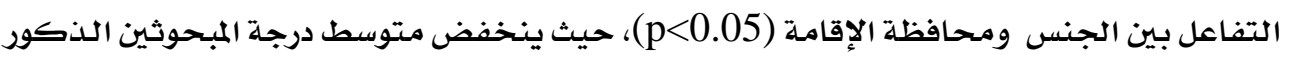

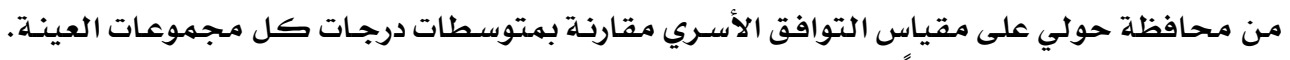

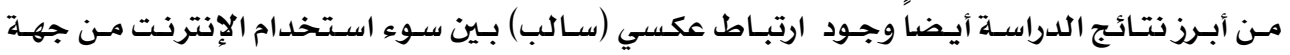

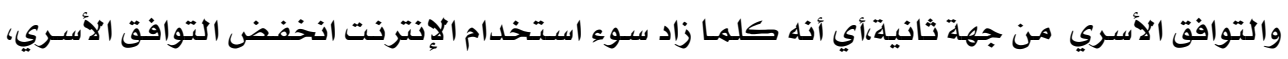

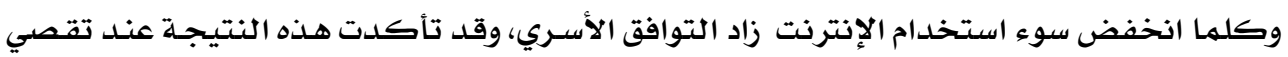

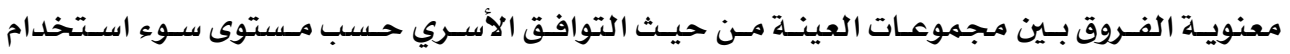

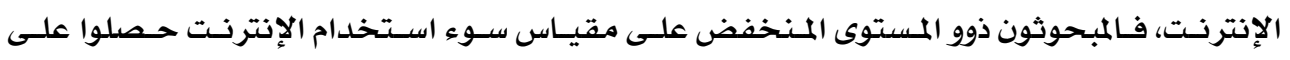

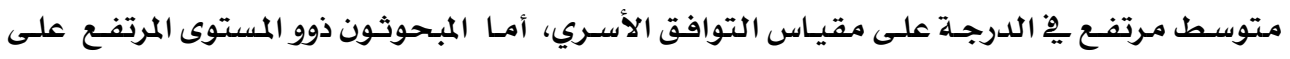

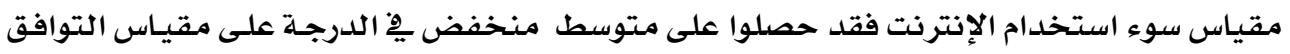

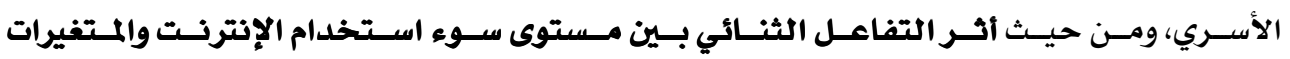

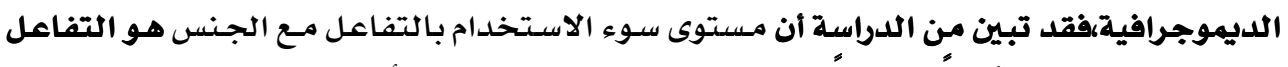

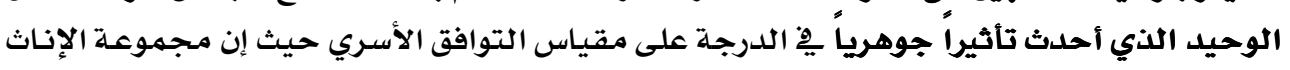

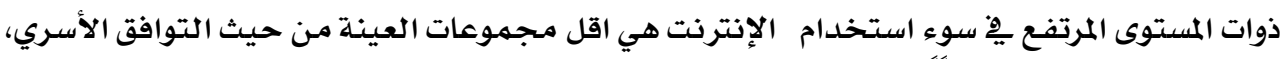

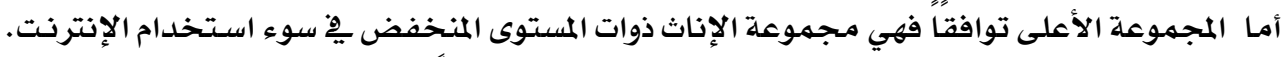

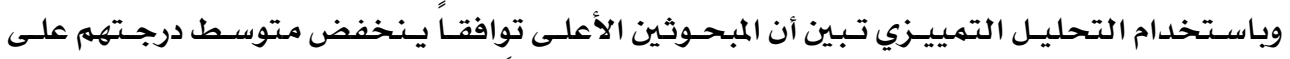

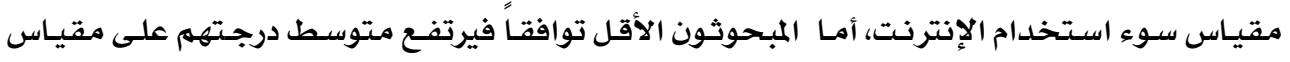

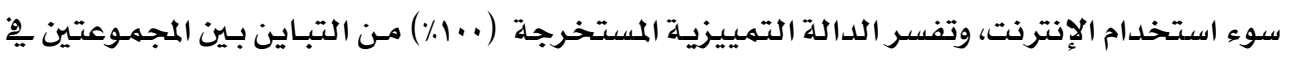

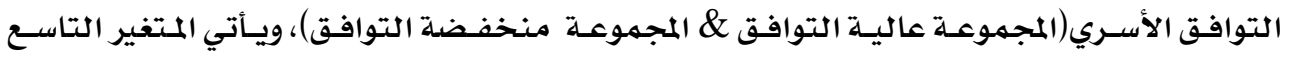

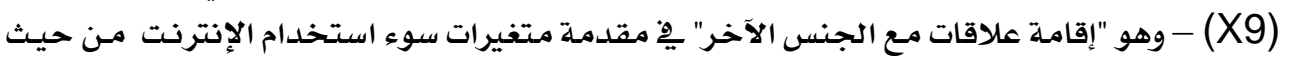

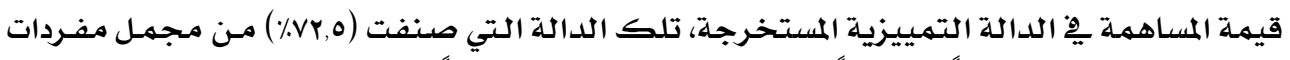

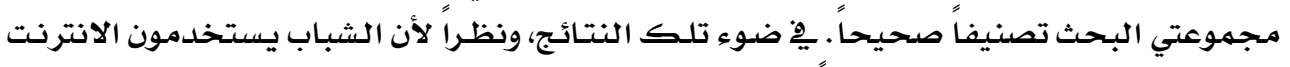

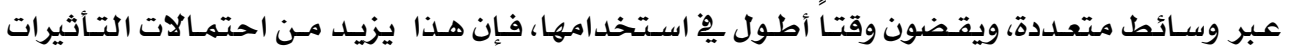

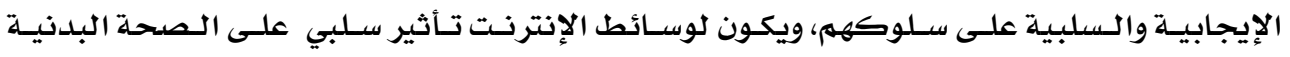

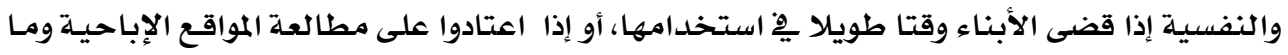

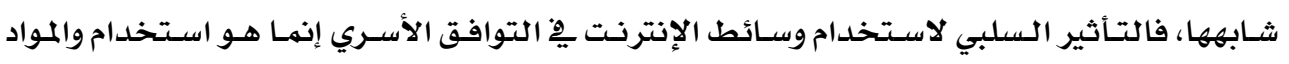

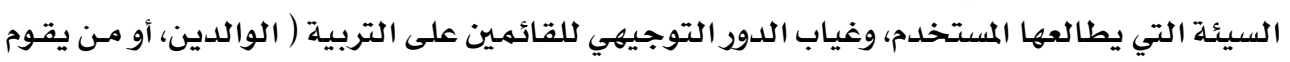


مقامها ) .ومن حيث التوافق الأسري يمكن للشباب اكتساب مهارات التفاعل الاجتمـاعي، والحصول

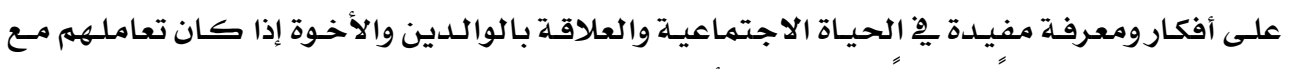

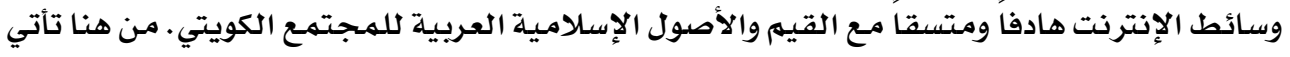

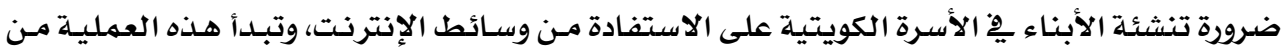

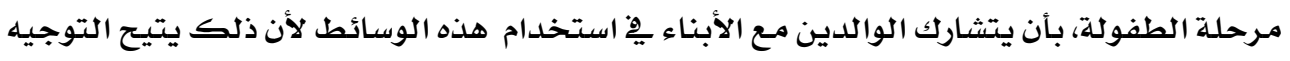

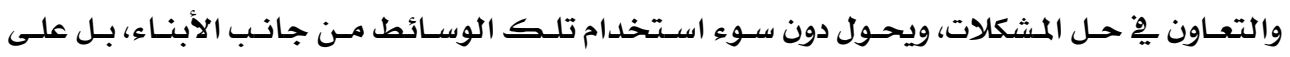

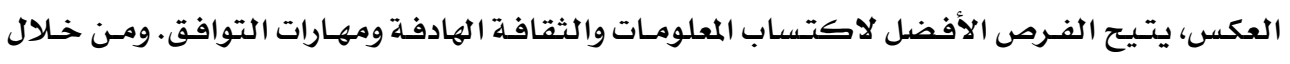

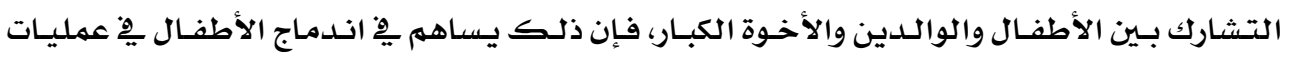

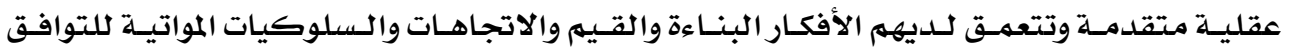

$$
\text { الأسـري }
$$

استخلاص Conclusion

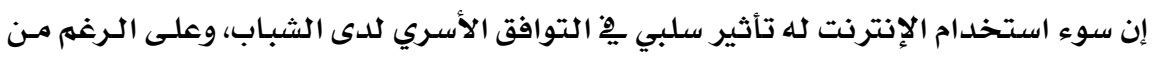

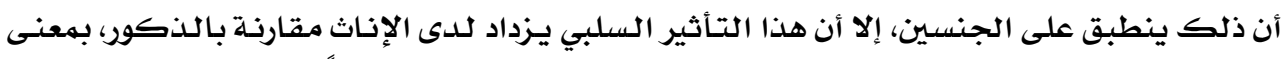

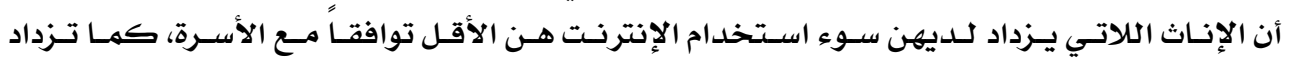

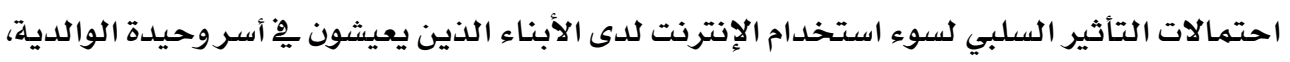

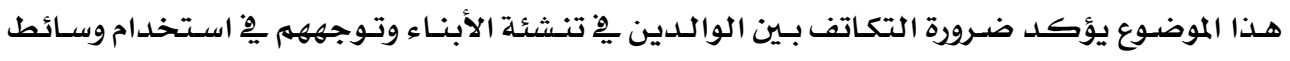
الإنترنت

\section{همادر البحث وهراجعه:}

(أ) مصادر ومراجع عربية:

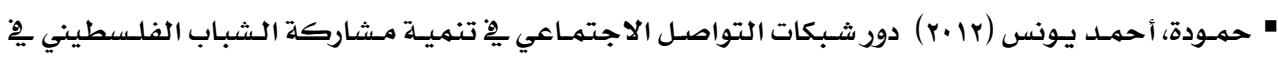

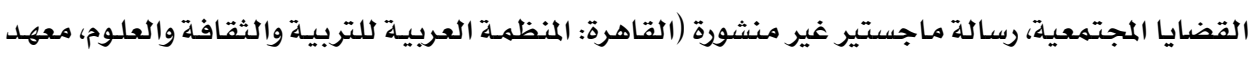

$$
\text { البحوث والدراسات العربية. }
$$

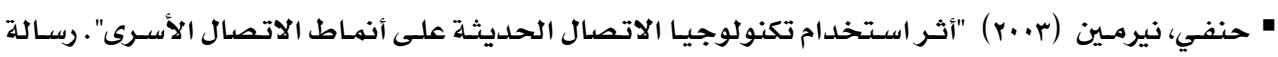

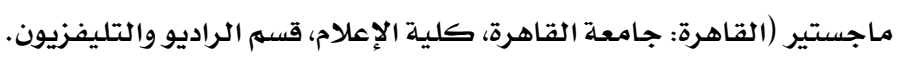

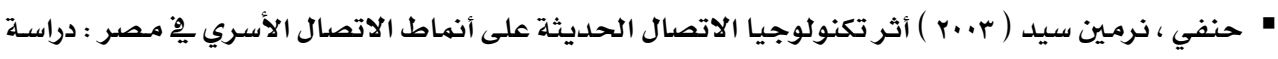

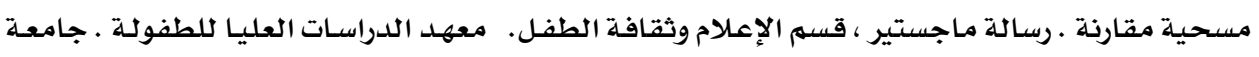
عين شمس.

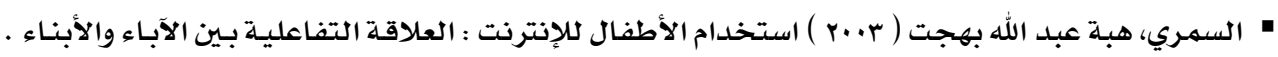

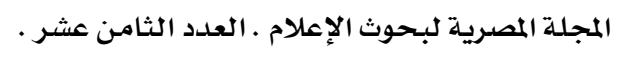

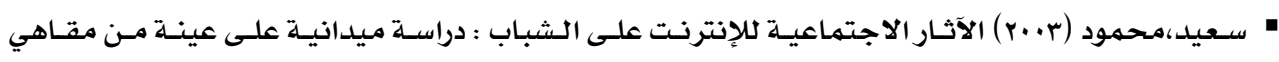
الإنترنت. القاهرة: دار المصطفي للنشر والتوزيع. 


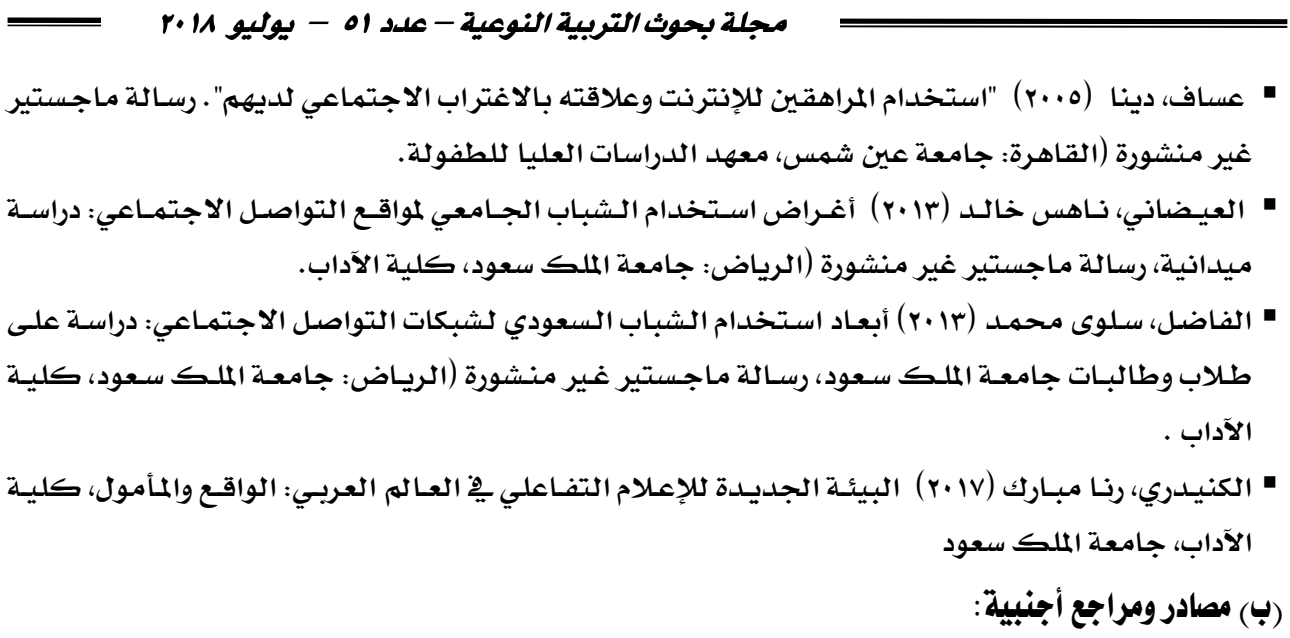

- Carlson, Jon et al ( 1999 ) The influence of technology on families : an Asian perspective family journal counseling $\&$ therapy for couples and families . vol. 7 (3) pp 231-235

- Carpenter, Erika M(2004)Internet Treatment Delivery of Parent-Adolescent Conflict Training for Families with an ADHD Teen: A Feasibility Study. Child \& Family Behavior Therapy, Vol 26(3), pp. 1-20.

- Cynthia Sau Ting Wu etal(2016) Parenting approaches, family functionality, and internet addiction among Hong Kong adolescents. NCBIBMC pediatr. 2016,Agust

- Desantis, James P.\& Youniss James ( 1995 ) family contributions to adolescents attitudes toward new technology . Journal of adolescent research . vol 6 (4) pp 410-422

- Ezumah, B. (2013) Use of Social Media: Site Preferences, Uses and Gratifications Theory Revisited, International Journal of Business and Social Science, Vol. 4.

- Gustavo S. Mesch ( 2006) Family Relations and the Internet: Exploring a Family Boundaries Approach, Journal of Family Communication, Volume 6, Issue 2, pp119-138 . https://doi.org/10.1207/s15327698jfc0602_2

- Ha K. \& Kim CH. (2014) Understanding User Behaviors in Social Networking Service for Mobile Learning: a Case Study with Twitter, Malaysian Journal of Computer Science, Vol. 27, pp14- 20. 
- Hall Robin, L.\& Schaverien, Lynette ( 2001 ) Families engagement with young children's science and technology learning home . science education . vol. 85 (4) pp 454-481

- Hoda Abdi \&Soran Derakhshani (2017) The relationship of family Communication, Internet Addiction and academic patterns adjustment of high schools Students. Ahwaz Article 2(26), volume 7,pp39-57

- Hughes, Robert ,Jr.\& Hans, Jason,D. (2001) Computers, the internet and families: a review of the role new technology plays in family life. Journal of Family Issues. Vol . 22 (6) pp 776-790

- Jeffs- Tara-Lane (2000) “ Characteristics, interactions, and attitudes of parentohild dy'ads and their use of assistive technology in a literacy experience on the internet ". PHD . George Mason university.

- Ji young Kim \& \& Hyun Sook Ryu (2003) Relationships among School Children's Internet Addiction, Family Environment and School Adjustment, Korean Journal of Child Health Nursing 2003;9(2):198-205

- Ju- YU Yen etal.( 2007) Family Factors of Internet Addiction and Substance Use Experience in Taiwanese Adolescents, Published Online:26 Jun 2007https://doi.org/10.1089/cpb.2006.9948, CyberPsychology \& BehaviorVol. 10, No. 3Original Articles

- Katherine Bessière etal ( 2008) Internet use, Depression, social support, extraversion and interpersonal interaction: alongitudinal study. NSF grant\#IIS0208900.Internet2, https://doi.org/10.1207/s15327698jfc0602_2

- Kraut,Robert et al ( 1998 ) Internet paradox : a social technology that reduce social involvement and psychological well-being .http://web 14.epnet. Com/citation. Asp

- Lee S, Chae Y. (2007) Children's internet use in a family context: Influence on family relationships and parental mediation. Cyberpsychol Behav. 10:640-644

- Leung L, Lee SN. (2011) The influences of information literacy, internet addiction and parenting styles on internet risks. New Media Soc. 2011;8:1-21

- Madden M. et al. (2016) Teens, Social media, and privacy. Pew Research Center. http://www.pewinternet.org/2013/05/21/teens-social-media-and-privacy.

- Mesch, Gustave, S. ( 2003 ) the family and the internet the Israeli case . social science quarterly. Vol . 84 (4) pp. 1038-1050 
- Nie, N. \& Sunshine, D. (2002) "The Impact of Internet Use on Sociability: TimeDiary Findings". In: IT \& Society, 2002, Vol. I, Issue 1, pp. 1-20.

- Oravec, Joann ( 2000 ) Internet and computer technology hazards : perspectives for family counseling. British journal of guidance and counseling . vol . 28 (3) pp 309-324

- Ribak ,Rivka ( 2001 ) Like immigrants : negotiating power in the face of the home computer . new media\& society .vol.3(2) pp 220-238

- Rong Wang etal. (2005) Teenagers' Internet Use and Family Rules: A Research Note. Journal Of Marriage and Family, https://doi.org/10.1111/j.17413737.2005.00214.x

- Southwick, sarah Loretta (2002) “ Internet use, academic performance, and social involvement in middle school age children" PHD, Educational Psychology ( 0525 ) . volume 63-CM . Hoistra- university

- Subrah, manyam et al ( 2000 ) The impact of home computer use on children's activities and development future of children . vol. 10(2) pp 123-144.

- Turow, Joseph (2002 )Family boundaries, commercialism, and the Internet: A framework for research. In: Children in the digital age: Influences of electronic media on development. Calvert, Sandra L.; Jordan\&Amy B. (eds) Westport, CT. Praeger Publishers/Greenwood Publishing Group, Inc. pp. 215-230.

- Wansen yan; etal( 2013) The Relationship between Recent Stressful Life Events, Personality Traits, Perceived Family Functioning and Internet Addiction among College Students. Stress \& Health. Wiley Online library, https://doi.org/10.1002/smi.2490

- Weitzman Geribaun ( 2001 ) family and individual functioning and computer / internet addiction. Dissertation abstract international : section B : the science and engineering . vol . 61 ( 9-B ) pp 5012

- XinXin Shi, Juan wang; Hong Zou ( 2017) Family functioning and Internet addiction among Chinese adolescents; Computers in Human Behavior archive, Volume 76 Issue C, ACM Digital Library ,pp. 201-210, Elsevier Science Publishers B. V. Amsterdam, The Netherlands, The Netherlands 